\title{
VALIDACIÓN CLÍNICA DE UN MODELO EXPERIMENTAL DE PREDICCIÓN DEL MODO DE PARTO TRAS INDUCCIÓN
}

Presentada por Sonia de Miguel Manso para optar al grado de Doctor/a por la Universidad de Valladolid

\author{
Dirigida por: \\ Dr. José Schneider Fontán \\ Dr. Julio Alberto Gobernado Tejedor \\ Dra. Cristina Álvarez Colomo
}




\section{Universidad deValladolid}

\section{AUTORIZACIÓN DEL DIRECTOR/A DE TESIS}

(Art. 7.2 de la Normativa para la presentación y defensa de la Tesis Doctoral en la UVa)

D. José Schneider Fontán, con D.N.I. 13.780.864T, Catedrático y Doctor en Medicina y Cirugía, y Profesor titular de Obstetricia y Ginecología de la Facultad de Medicina de Valladolid, con e-mail: jose.schneider@urjc.es

\section{CO-DIRECTORES:}

D. Julio Alberto Gobernado Tejedor, con D.N.I. 12.375.796W, Profesor externo a la UVA (se adjunta documento de profesor externo), Doctor en Medicina y Cirugía, Licenciado Especialista en el Hospital Clínico Universitario de Valladolid, con e-mail: jagobernado@saludcastillayleon.es

Da Cristina Álvarez Colomo, con D.N.I. 12.374.455H, Doctora en Medicina y Cirugía, y Profesora asociada de Obstetricia y Ginecología de la Facultad de Medicina de Valladolid, con e-mail: 12374455h@saludcastillayleon.es

Como Directores de la Tesis Doctoral titulada VALIDACIÓN CLÍNICA DE UN MODELO EXPERIMENTAL DE PREDICCIÓN DEL MODO DE PARTO TRAS INDUCCIÓN, realizada por Da Sonia de Miguel Manso, con D.N.I. 44.913.374D, alumna del Programa de Doctorado en Ciencias de la Salud impartido por el Departamento de Pediatría e Inmunología, Obstetricia y Ginecología, Nutrición y Bromatología, Psiquiatría e Historia de la Ciencia autorizan su presentación, considerando que el trabajo reúne los requisitos de originalidad necesarios para poder ser presentado como Tesis Doctoral y que la autora ha demostrado un adecuado manejo del método científico como para poder optar al grado de Doctor por la Universidad de Valladolid. 


\section{Universidad deValladolid}

D. José Schneider Fontan (Director de la tesis doctoral)1:

X Declaran que cumple los requisitos para poder ejercer la dirección de la tesis doctoral que establecen el RD 99/2011 (modificado por el RD 195/2016) y el Acuerdo del Comité de Dirección de la Escuela de Doctorado de la Universidad de Valladolid del 17 de febrero de 2014, es decir, que posee "al menos un período de actividad investigadora reconocido de acuerdo con las previsiones del RD 1086/1989 de 28 de agosto" 2.

Valladolid, 9 de Julio de 2020.

El Director de la Tesis,

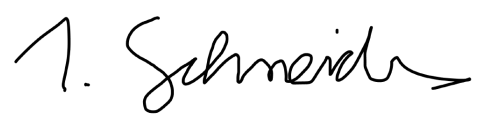

Codirectores de la Tesis,
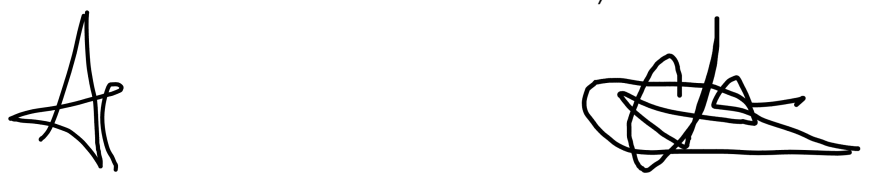

Fdo:

SR/SRA. PRESIDENTE/A DE LA COMISIÓN DE DOCTORADO

\footnotetext{
${ }^{1}$ Esta declaración deben realizarla todos los codirectores de la tesis, en el caso de que haya más de un director.

2 En el caso de que la figura contractual no sea evaluable por tramos o se trate de un profesor de una universidad extranjera, deberá haber aportado a la Comisión académica del Programa de doctorado un CV u otro documento acreditativo de poseer méritos equivalentes a un tramo de actividad investigadora.
} 


\section{Universidad deValladolid}

R.D. 99/2011, de 28 de enero

PROGRAMA DE DOCTORADO EN CIENCIAS DE LA SALUD

DOCTORANDO: SONIA DE MIGUEL MANSO DNI: 44913374D

\section{PROFESORES EXTERNOS A LA UNIVERSIDAD DE VALLADOLID}

(Datos necesarios para grabar en el programa y para el LDAP)

D.N.I / Pasaporte: 12375796W

Nacionalidad: Española

Apellidos, nombre: GOBERNADO TEJEDOR, Julio Alberto

Fecha de nacimiento: 28/06/1969

e-mail: jgobernadot@gmail.com.....

Teléfono: 670097213

Universidad / Institución a la que pertenece: Hospital Clínico Universitario de Valladolid.

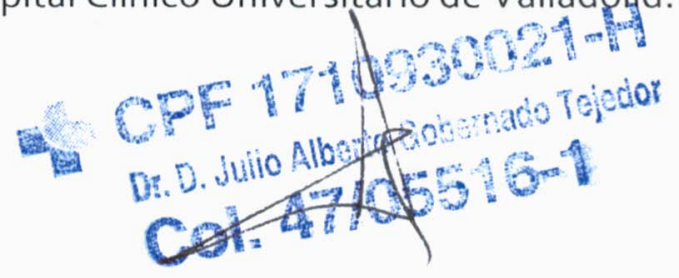


Dedicada a mi gran familia, para que se sientan orgullosos de su esposa y madre, aunque a veces haya antepuesto este trabajo a su compañía.

A mis padres, por ser un ejemplo a seguir, haberme inculcado unos valores admirables y estar apoyándome continuamente.

A mis compañeros Julio y Cristina, por su paciencia, generosidad y valiosísima ayuda. Sois grandes personas y mejores profesionales. 


\section{AGRADECIMIENTOS}

Al Dr. José Schneider, que asumió la dirección del trabajo casi sin conocerme, esperó con paciencia y respondió con rapidez. Durante este tiempo nos hemos conocido, lo cual ha sido una suerte y un gran honor.

Al Dr. Julio Gobernado y su privilegiada mente. Sabe como redireccionar la situación cuando algo no encaja. Nunca tiene una negativa como respuesta y eso es admirable.

A la Dra. Cristina Álvarez, por invitarme a continuar su original trabajo, demostrando confianza y cariño hacia mí. Trabajadora incansable, sabemos lo que es remar juntas.

Al decano de la Facultad de Medicina, Dr. José M. Fidel Fernández, porque constantemente me ha transmitido su apoyo y siempre que lo he necesitado me ha tendido la mano.

A los componentes del Tribunal, por prestar su valioso tiempo a la defesa de este trabajo. Sé que sus agendas están sobrecargadas y una tarea más supone un esfuerzo severo.

A todos mis compañeros, tanto ginecólogos como matronas, por hacer posible una asistencia clínica de calidad y en especial, a las gestantes que aceptaron amablemente formar parte del estudio. 


\section{ABREVIATURAS}

${ }^{\circ}$ grados

$\mu g:$ microgramos

ACOG: Colegio Americano de Obstetras y Ginecólogos

ACP: Ángulo cervical posterior

AINES: Anti-inflamatorios no esteroideos

aOR: Odds Ratio ajustada

AUC: área bajo la curva ROC

BOE: Boletin Oficial del Estado

CA: circunferencia abdominal

$\mathrm{Cl}$ : Consentimiento Informado

CIR: Restricción del crecimiento intrauterino

cm: centímetros

Cols.: Colaboradores

CRL: longitud cráneo-caudal

DBP: Diámetro biparietal

DCP: Distancia céfalo-perineal

DG: Diabetes Gestacional

DS: desviación estándar

E: Especificidad

EHE: Estados hipertensivos del embarazo

EG: Edad gestacional

FCF: Frecuencia cardiaca fetal

FP: falso positivo

FPP: fecha probable de parto

GCP: gestación cronológicamente prolongada

gr: gramos

HCU: Hospital Clínico Universitario

HRD: hoja de recogida de datos

IC: Intervalo de confianza 
IMC: Índice de masas corporal

IP: Inducción del parto

kg: kilogramos

L: litros

LA: líquido amniótico

LC: Longitud cervical

LF: longitud del fémur

LHR+: Positive likelihood ratio o cociente de probabilidades positivo

LHR-: Negative likelihood ratio o cociente de probabilidades negativo

Ipm: Latidos por minuto

$\mathrm{m}$ : metros

$\mathrm{m}^{2}$ : metros al cuadrado

mg: miligramos

MHz: megahercio

min: minutos

MIR: médico interno residente

$\mathrm{mL}$ : mililitros

mm: milímetros

$\mathrm{mU}$ : miliunidades

$\mathrm{n}$ : tamaño muestral

NICE: National Institute for Health and Care Excellence

OCE: Orificio cervical externo

OCI: Orificio cervical interno

OMS: Organización Mundial de la Salud

OR: Odds Ratio

P: Percentil

PE: Preeclampsia

PFE: Peso fetal estimado por ecografía

PG: prostaglandinas

PV: Parto vaginal

RCTG: Registro cardiotocográfico 
$\mathrm{RN}$ : recién nacido

ROC: Receiver Operating Characteristic o Característica Operativa del Receptor

RPM: Rotura prematura de membranas

RR: Riesgo relativo

S: Sensibilidad

S.A.: Sociedad Anónima

S.A.R.L.: "Sociedad Limitada" en idioma francés

SEGO: Sociedad Española de Ginecología y Obstetricia

S.L.: Sociedad Limitada

SPSS: Statistical Package for the Social Sciences

UCl: Unidad de Cuidados Intensivos

US: ultrasonidos

VPN: Valor predictivo negativo

VPP: Valor predictivo positivo

vs: versus 


\section{ÍNDICE}

1. INTRODUCCIÓN

1.1. INDICACIONES DEL PARTO INDUCIDO

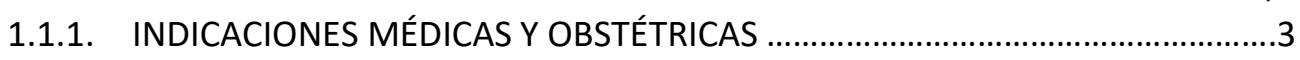

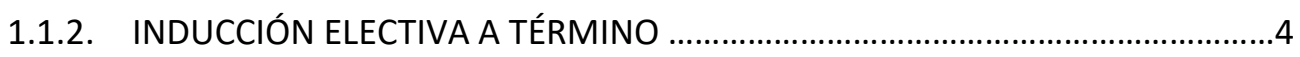

1.1.3. MANEJO ACTIVO POR RIESGO (AMOR-IPAT) ……………..........................4,5

1.2. REPERCUSIONES DE LA INDUCCIÓN DEL PARTO

1.2.1. EFECTO E LA TASA DE PARTO POR CESÁREA …….....................................5,6

1.2.2. EFECTO EN LA MORBILIDAD NEONATAL .....................................................6

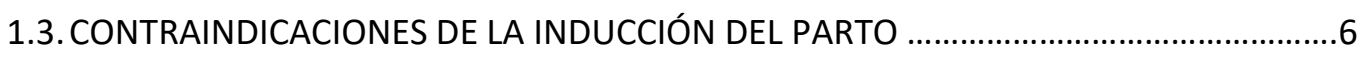

1.4. SITUACIONES CLÍNICAS ESPECÍFICAS

1.4.1. PREVENCIÓN DEL EMBARAZO CRONOLÓGICAMENTE PROLONGADO .........7

1.4.2. ROTURA PREMATURA DE MEMBRANAS A TÉRMINO ....................................7

1.4.3. GESTACIÓN CON CESÁREA ANTERIOR .........................................................

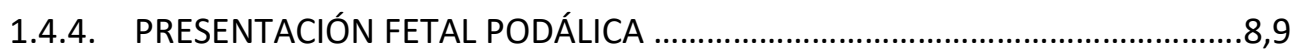

1.4.5. RESTRICCIÓN DEL CRECIMIENTO INTRAUTERINO FETAL ..............................

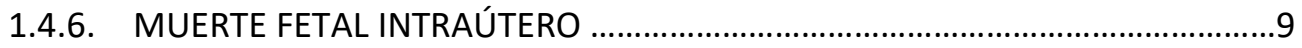

1.4.7. SOSPECHA DE MACROSOMÍA FETAL .........................................................10

1.4.8. HISTORIA DE PARTO PRECIPITADO PREVIO ...................................................10

1.4.9. INDUCCIÓN ELECTIVA EN PACIENTE OBESA ................................................10

1.5. EVALUACIÓN PREVIA A UNA INDUCCIÓN DEL PARTO ..............................................11

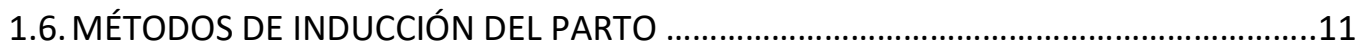

1.6.1. MADURACIÓN CERVICAL O PREINDUCCIÓN ..............................................11

1.6.1.1. MÉTODOS NO FARMACOLÓGICOS ....................................................12-15

1.6.1.2. MÉTODOS FARMACOLÓGICOS .......................................................15-18

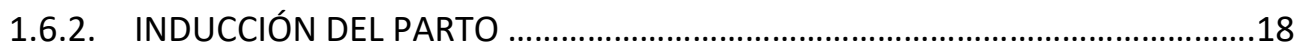

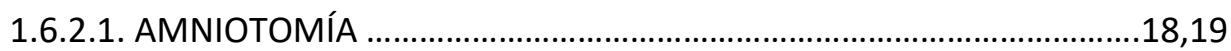

1.6.2.2. OXITOCINA ….................................................................................19-22

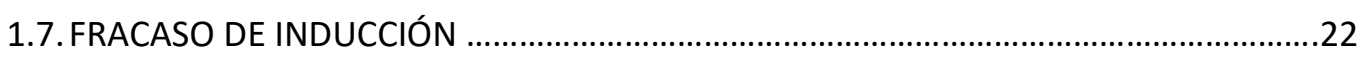

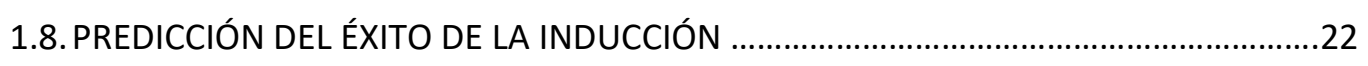

1.8.1. FACTORES PRONÓSTICOS DEL ÉXITO DE LA INDUCCIÓN

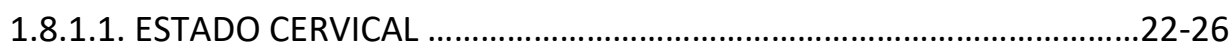

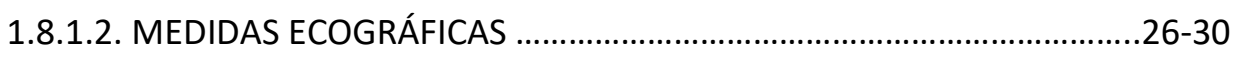

1.8.1.3. MARCADORES BIOQUÍMICOS ..............................................................30,31

1.8.1.4. CARACTERÍSTICAS DE LA POBLACIÓN ..............................................31-33

1.8.1.5. SISTEMAS DE PUNTUACIÓN CON MEDIDAS ECOGRÁFICAS .............33-35

1.8.1.6. EVALUACIÓN ECOGRÁFICA PREINDUCCIÓN PARA VALORAR EL

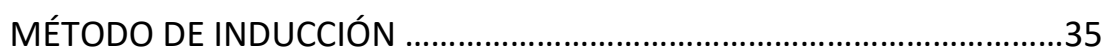

1.8.2. MODELOS PREDICTIVOS DEL ÉXITO DE LA INDUCCIÓN ................................35

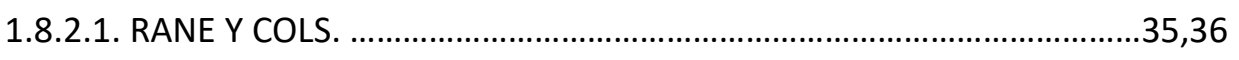

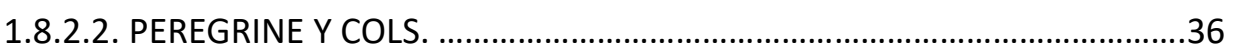

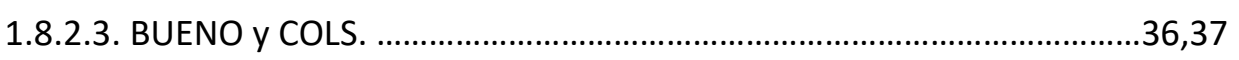

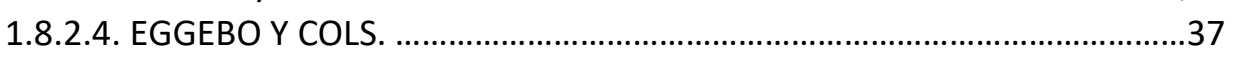

1.8.2.5. VERHOEVEN Y COLS. VALIDACIÓN DE LOS MODELOS DE RANE Y

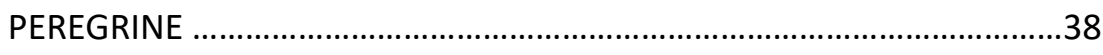

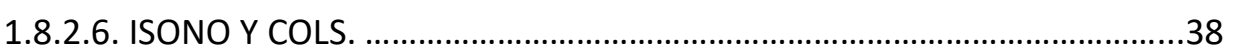




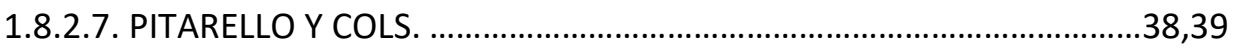

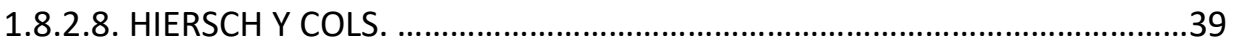

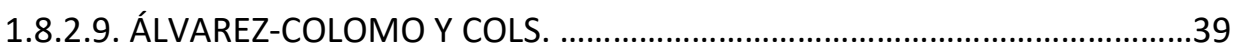

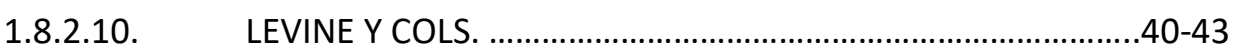

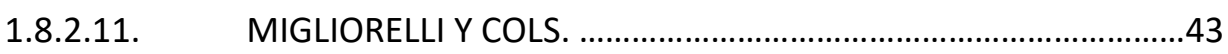

1.8.2.12. REVISIÓN SISTEMÁTICA DE MODELOS DE PREDICCIÓN DEL ÉXITO DE LA INDUCCIÓN .........................................................................4

1.8.2.13. ALAVIFARD Y COLS. VALIDACIÓN EXTERNA DEL MODELO DE

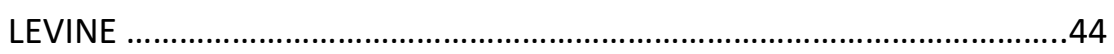

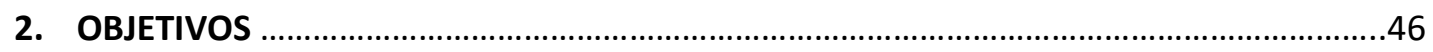

3. MATERIAL Y MÉTODO

3.1. EVALUACIÓN PREVIA A UNA INDUCCIÓN DEL PARTO EN NUESTRO CENTRO ..........48

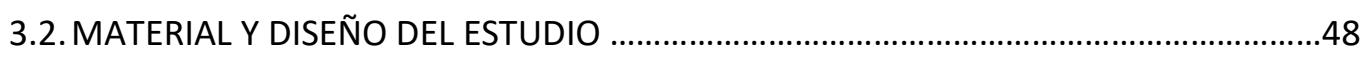

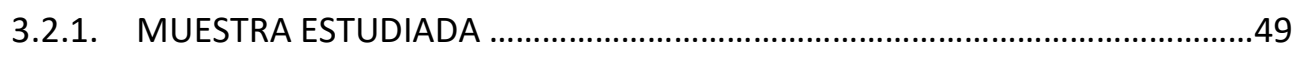

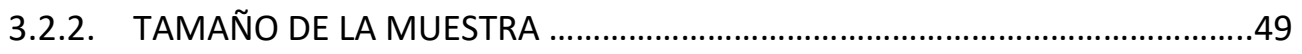

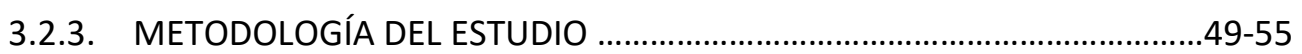

3.2.4. PROTOCOLO DE INDUCCIÓN ...................................................................55-57

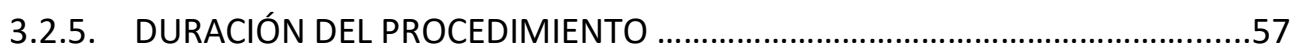

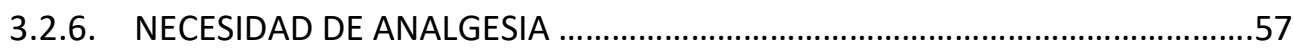

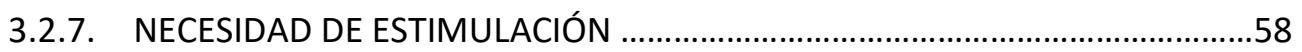

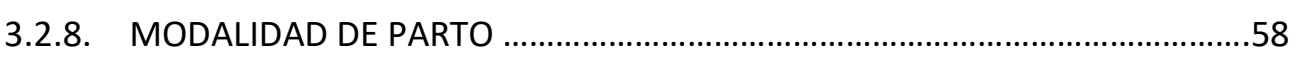

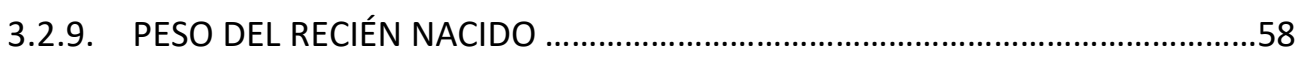

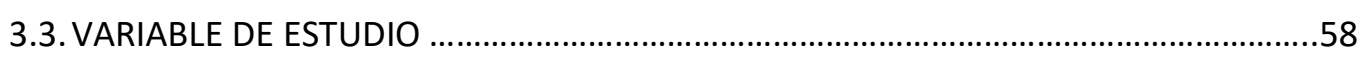

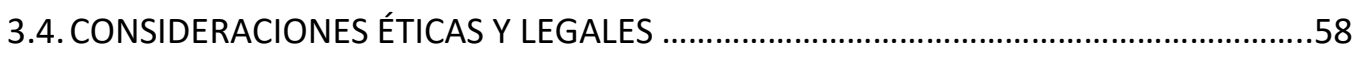

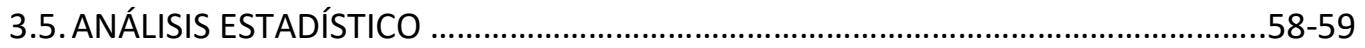

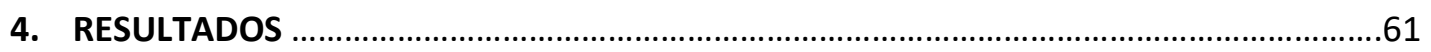

4.1. ESTUDIO COMPARATIVO ENTRE LOS DOS GRUPOS DE ESTUDIO .......................61,62

4.2. VARIABLES Y RELACIÓN CON EL MODO DE PARTO ............................................62-64

4.3. PREDICCIÓN DEL RESULTADO DE LA INDUCCIÓN APLICANDO EL MODELO PILOTO

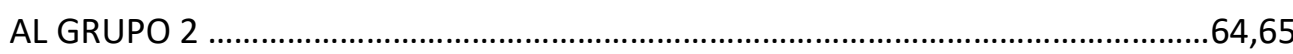

4.4. ANÁLISIS INDIVIDUAL DE LOS PARAMETROS ECOGRAFICOS QUE COMPONEN EL

MODELO PREDICTIVO PILOTO EN AMBOS GRUPOS ..........................................65,66

5. DISCUSIÓN

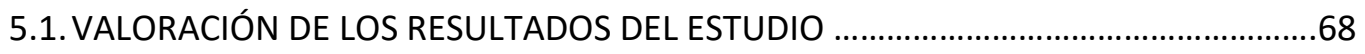

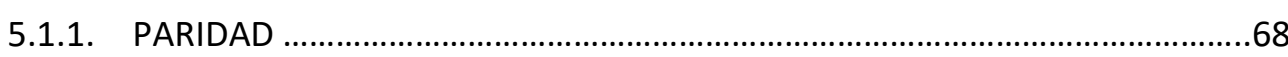

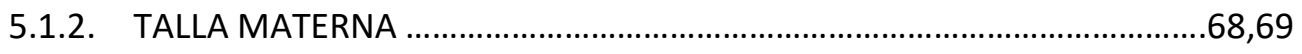

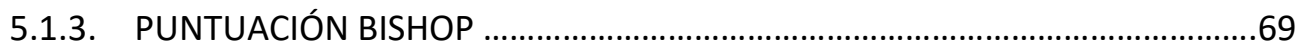

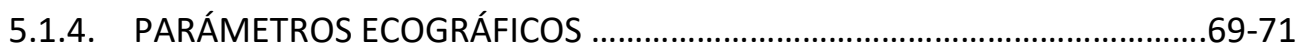

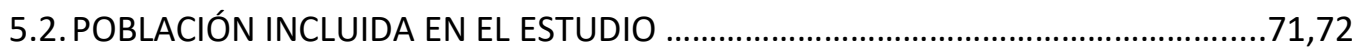

5.3. INDICACIONES DE LA INDUCCIÓN DEL PARTO ……............................................ 72,73

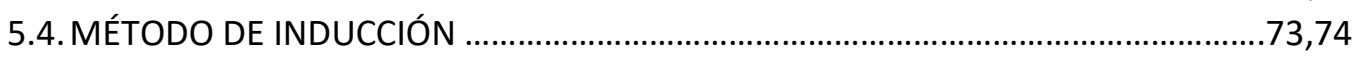

5.5. DEFINICIONES DE ÉXITO Y FRACASO DE LA INDUCCIÓN DEL PARTO ...................74-76 
6. CONCLUSIONES

7. BIBLIOGRAFÍA

$.80-87$

8. ANEXOS $.88-106$

8.1. CHECKLIST ACOG

8.2. CONSENTIMIENTO INFORMADO

8.3. HOJA DE RECOGIDA DE DATOS

8.4. BASE DE DATOS ACCESS

8.5. COMISIÓN DE INVESTIGACIÓN

8.6. ARTÍCULO PUBLICADO EN REVISTA ARCHIVES 
INTRODUCCIÓN 


\section{INTRODUCCIÓN}

La inducción del parto (IP) se refiere al inicio del trabajo de parto mediante procedimientos farmacológicos o mecánicos antes del comienzo espontáneo del mismo.

Es uno de los procedimientos obstétricos más frecuentes realizados en el mundo ${ }^{1}$.

La frecuencia global de IP se ha más que duplicado entre 1990 y 2012, elevándose de un 9,5\% a un $23,3 \%{ }^{2}$. En 2016, el $24.5 \%$ de los partos en USA fueron inducidos ${ }^{3}$, en países menos desarrollados como Sri Lanka, las IP alcanzaron el 35.5\% en 2007-2008 ${ }^{4}$, y en las gestaciones a término precoces (37-38 semanas) el número de inducciones se han cuadruplicado, ascendiendo de un 2 a un $8 \%$ durante el mismo período de tiempo ${ }^{5}$. En España no existe un registro de las IP pero los datos de series publicadas estiman una frecuencia de $20-25 \%$. En el Hospital Clínico Universitario (HCU) de Valladolid, la frecuencia de inducción del parto se ha mantenido estable en los años previos a 2010 (22-25\%), ascendiendo en los siguientes años, hasta alcanzar cifras del $33 \%$ y $36 \%$ (Tabla 1 ).

Tabla 1. Frecuencia de la inducción del parto en el HCU de Valladolid.

\begin{tabular}{|l|l|l|l|}
\hline AÑO & $\begin{array}{l}\text { \% DE INDUCCIÓN DEL } \\
\text { PARTO }\end{array}$ & AÑO & $\begin{array}{l}\text { \% DE INDUCCIÓN DEL } \\
\text { PARTO }\end{array}$ \\
\hline 2010 & 29.60 & 2015 & 30.55 \\
\hline 2011 & 26.60 & 2016 & 28.71 \\
\hline 2012 & 27.80 & 2017 & 28.69 \\
\hline 2013 & 22.42 & 2018 & 33.16 \\
\hline 2014 & 27.02 & 2019 & 36.56 \\
\hline
\end{tabular}

En 2007, el Hospital General Yagüe de Burgos publicó, que en el período de tiempo comprendido entre 2001 y 2004, con un total de 6.423 partos, el $15 \%$ de ellos tuvieron un inicio inducido, con una tasa global de cesárea del $20.6 \%{ }^{6}$.

Mientras tanto, en diciembre de 2008, el proyecto EURO-PERISTAT publicó el primer Informe Europeo de Salud Perinatal, que presenta los indicadores de salud y atención perinatal derivados de datos estadísticos de rutina en 25 estados miembros de la UE y Noruega ${ }^{7}$. Así, las frecuencias varían entre el $9 \%$ de Estonia y Lituania, y el $32 \%$ de Irlanda del Norte o Malta.

A este aumento de la IP en parte contribuyen las indicaciones médicas y obstétricas, pero la mayor proporción es debida a las IP electivas ${ }^{8}$, como las incluidas en una actitud más relajada hacia la inducción, la conveniencia de programar el parto por parte de la paciente y/o el facultativo y porque actualmente disponemos de mejores agentes para la maduración cervical 9. Además, el retraso en la edad de concebir que se ha ido extendiendo entre los países desarrollados ha propiciado el aumento de comorbilidades y complicaciones asociadas al embarazo que determinan en muchas circunstancias la indicación de la IP.

No obstante, la IP no es un procedimiento exento de riesgos (mayor morbilidad materna por hemorragia, infección, mayor tasa de cesárea en comparación con el inicio espontáneo ${ }^{8}$ ) y supone un mayor gasto hospitalario, por el aumento de la estancia media, el uso de fármacos necesarios para la maduración cervical y analgesia materna, los controles materno-fetales requeridos y la atención de diversos profesionales durante un período de tiempo mayor que si se iniciara el parto de forma espontánea.

Además, debido a la duración del proceso, la IP introduce una incertidumbre y una ansiedad en la propia gestante y su entorno, que cuando no consigue el fin último que es lograr un parto 
vaginal (PV) con un recién nacido ( $R N$ ) sano, ocasiona un sentimiento desagradable de haber "perdido el tiempo".

La indicación de una IP se debe a la creencia de que finalizar una gestación conllevará un mejor resultado que si se dejara evolucionar naturalmente.

Históricamente se han estudiado distintas formas de iniciar el trabajo de parto, aunque no siempre con éxito, hasta llegar a la era actual en la cual disponemos de métodos que intentan reproducir el proceso natural, de forma segura tanto para la madre como para el feto y con probabilidades de conducir a la fase activa del parto.

Tal y como se ha mencionado más arriba, la IP es un procedimiento que conlleva implicaciones médicas maternas y/o fetales y también afecta a la estructura asistencial, dado que genera una sobrecarga de trabajo tanto en las salas de dilatación, como en las plantas de hospitalización. También es responsable de una mayor estancia hospitalaria, ya que una IP puede alargarse hasta 3 días, en comparación con un parto de inicio espontáneo, que suele ocurrir generalmente dentro de las primeras 24 horas. A ello, posteriormente se añade el tiempo de ingreso durante el puerperio, que variará según si se trata de un parto vía vaginal o de una cesárea.

La tasa de cesáreas de un hospital se ve significativamente influida por el porcentaje de IP que se indican, lo cual conduce a un aumento de los costes económicos. Además, se trata de un proceso menos eficiente y más doloroso que un inicio de parto espontáneo, necesitando un mayor intervencionismo, tanto de técnicas analgésicas/anestésicas como de partos instrumentales y cesáreas. La guía NICE publicó en 2008 que, en los partos inducidos de Reino Unido, menos de $2 / 3$ de las mujeres tenían un parto sin intervención, hasta un $15 \%$ finalizó con parto instrumentado y un $22 \%$ mediante cesárea intraparto ${ }^{10}$.

\subsection{INDICACIONES DEL PARTO INDUCIDO}

\subsubsection{INDICACIONES MÉDICAS Y OBSTÉTRICAS}

Según el Colegio Americano de Obstetras y Ginecólogos (ACOG), englobarían aquellas situaciones en las que los potenciales riesgos maternos o fetales de dejar evolucionar la gestación, superan al de finalizarla ${ }^{11}$. Cuando se desea acabar un embarazo, sólo podemos hacer una cesárea o inducirlo, por lo cual es preferible una IP dados los mayores riesgos maternos de la cesárea sin que ello conlleve un beneficio neonatal, siempre y cuando no exista una contraindicación para el parto vaginal ${ }^{1}$. Se ha propuesto que la IP mejora los resultados perinatales en mujeres con ciertas complicaciones del embarazo ${ }^{12}$, pero realmente solo existe evidencia científica para un número limitado de indicaciones, entre las cuales se encuentran ${ }^{11,13}$ :

- Embarazo postérmino.

- Rotura prematura de membranas (RPM) a término y pretérmino

- Estados Hipertensivos del Embarazo (EHE): preeclampsia (PE), eclampsia y síndrome HELLP.

- Diabetes Mellitus materna.

- Restricción del crecimiento fetal (CIR).

- Embarazo gemelar.

- Corioamnionitis.

- Desprendimiento prematuro de placenta.

- Muerte fetal intraútero.

- Oligoamnios.

- Coléstasis intrahepática del embarazo.

- Isoinmunización con afectación fetal. 


\subsubsection{INDUCCIÓN ELECTIVA A TÉRMINO}

Es la indicada sin una razón clínica y supone una de las causas más importantes del aumento en las tasas actuales de IP. Este incremento es difícil de explicar, pero posiblemente intervengan factores de tres tipos:

- Relacionados con la gestante: miedo a las posibles complicaciones que pudieran derivarse de una actitud expectante, ansiedad y disconfort materno en el curso normal del embarazo, antecedente de un parto previo distócico o precipitado, sospecha de macrosomía fetal, distancia lejana del domicilio al hospital o incluso conveniencia de fechas ${ }^{14}$.

- Relacionados con el personal que atiende el parto: actitud laxa ante indicaciones poco claras, gestión de camas del hospital, conveniencia de fechas, etc.

- Relacionados con la mejora actual de los distintos medios inductores de la maduración cervical previa al parto.

Las principales desventajas de esta indicación serían: el posible aumento en la tasa de cesáreas, la morbilidad neonatal generada al inducir gestaciones a término tempranas (3738 semanas) ${ }^{15}$ y el incremento de los costes. Sin embargo, reúne unas potenciales ventajas, como la reducción en la tasa de muerte fetal a término (muy baja realmente), de macrosomía fetal y de líquido amniótico meconial (aunque no de aspiración meconial) ${ }^{16}$.

Actualmente existe consenso acerca de que la IP no se indique antes de las 39 semanas. Sin embargo, no hay datos suficientes que lo verifiquen y se necesitan tanto ensayos clínicos randomizados que evalúen este tipo de indicaciones como estudios de análisis coste-eficacia.

No hay consenso sobre la superioridad de la inducción electiva frente al manejo expectante en el embarazo a término (39-40+6 semanas), cuando los riesgos de morbimortalidad neonatal son bajos.

La IP en esta población está controvertida y los pocos estudios que existen aportan evidencia de muy bajo nivel.

Un ensayo randomizado sobre 600 mujeres $\geq 35$ años, comparó la inducción de parto a lo largo de la semana 39 con el manejo expectante y ambos grupos tuvieron similares tasas de cesáreas, de efectos adversos maternos y de resultados perinatales. Sin embargo, no tuvo suficiente potencia estadística para valorar diferencias en la mortalidad anteparto y otros resultados perinatales adversos severos infrecuentes ${ }^{17}$.

La Sociedad de Medicina Materno-Fetal publicó en $2018{ }^{18}$ un ensayo randomizado multicéntrico (ARRIVE, $n=6106$ ), comparando en mujeres nulíparas de bajo riesgo la inducción electiva a las 39 semanas frente al manejo expectante. No encontraron diferencias significativas en sus variables primarias (mortalidad perinatal y severa morbilidad neonatal), pero sí en la reducción de la tasa de cesáreas y trastornos hipertensivos del embarazo en el grupo de nulíparas inducidas. Proponen que sería necesario inducir 28 nulíparas de bajo riesgo en la semana 39 para evitar una cesárea.

\subsubsection{MANEJO ACTIVO POR RIESGO (AMOR-IPAT)}

En 2008 Nicholson y cols. ${ }^{12}$ realizaron un ensayo clínico randomizado con el objetivo de disminuir la tasa de cesáreas, mejorando los resultados neonatales, mediante inducción preventiva que asegure a cada paciente según sus riesgos, la máxima oportunidad de un parto vaginal. 
Se emplea para aumentar la probabilidad de parto vaginal antes de que éste comience de forma espontánea cuando la posibilidad de un parto vaginal fuera menor, por ejemplo, en caso de un feto que ha crecido más que la capacidad pélvica de su madre o cuando ya la placenta es insuficiente para soportar el trabajo del parto.

Supone una estrategia para intentar disminuir los riesgos en el embarazo en vías de prolongación, según los riesgos específicos de cada gestación, evitando sobrepasar la semana 41 en determinadas circunstancias.

Categorizan los factores de riesgo (FR) de cesárea en dos grupos: Insuficiencia úteroplacentaria y Desproporción pélvico-cefálica.

Convierten las OR de cesárea para cada FR específico en un número de días. Estos días se restan, para cada una de esas categorías, de la 41 semana, estimando el límite superior óptimo del día de parto (LS-ODP) para cada categoría de riesgo. De los 2 LS-ODP por cada una de estas dos categorías, para cada mujer, se elige el más bajo, nunca siendo inferior a 38 semanas.

Nicholson y colaboradores concluyen, que tanto en nulíparas ${ }^{19}$ como en multíparas ${ }^{20}$, una inducción preventiva se asocia de manera significativa a mejores resultados al nacimiento, incluyendo menores tasas de cesárea.

\subsection{REPERCUSIONES DE LA INDUCCIÓN DEL PARTO}

\subsubsection{EFECTO EN LA TASA DE PARTO POR CESÁREA}

Muchas cohortes retrospectivas de mujeres nulíparas, reportaban que cuando eran sometidas a inducción médica o electiva del parto, se duplicaba el riesgo de cesárea comparado con el grupo de nulíparas con inicio de parto espontáneo ${ }^{21,}{ }^{22}$. Lo que realmente sucede en estos estudios, es que usando como grupo control a las pacientes que inician el parto de forma espontánea, la tasa de cesárea les favorece, porque están excluyendo al resto de nulíparas manejadas expectantemente y que finalmente tendrán una cesárea programada más que un parto espontáneo.

Cuando las tasas de cesárea para inducción electiva a término tanto en nulíparas como en multíparas se comparan con las tasas para nulíparas y multíparas de la misma edad gestacional manejadas de forma expectante, no hay evidencia de que la inducción electiva incremente la tasa de cesárea, incluso cuando se realiza en cérvix desfavorables.

Por lo tanto, contrariamente a la creencia tradicional de que la IP a término aumentaba la tasa de cesárea, tres revisiones sistemáticas de estudios randomizados encuentran que la tasa de cesárea no aumenta e incluso puede verse disminuida, tanto en casos de cérvix favorables o no:

- Mishamina y cols. (2014) eligieron 157 ensayos controlados randomizados con una población de 31.085 mujeres, obteniendo un riesgo de cesárea un $12 \%$ más bajo con IP vs manejo expectante, en gestaciones a término y postérmino (RR 0.88 , IC $95 \%$ 0.84-0.93) ${ }^{23}$.

- Middleton y cols. (2018) eligieron 30 ensayos con datos de 12.479 mujeres, en las que tras una inducción a término o a término tardío hubo un menor número de cesáreas de forma significativa comparado con el manejo expectante de la gestación (RR 0.92, IC 95\% 0.85-0.99, $n=11.738$ ) ${ }^{24}$.

- Saccone y cols. (2015) analizaron 5 ensayos controlados randomizados de gestaciones únicas entre 39 semanas $0 / 7$ días y 40 semanas $0 / 7$ días, incluyendo 844 pacientes. Las mujeres que recibieron una IP tuvieron una incidencia similar de 
cesárea comparado con las mujeres que siguieron manejo expectante $(9.7 \%$ vs 7.5\%; RR 1.25, IC 95\% 0.75-2.08) ${ }^{25}$.

\subsubsection{EFECTO EN LA MORBILIDAD NEONATAL}

El efecto sobre la morbilidad neonatal, especialmente entre las semanas 37 y 39 , es la responsable de parte de las controversias que envuelven a la inducción electiva a término.

Los problemas respiratorios pueden ser consecuencia del parto prematuro de un feto con la edad gestacional mal datada (infrecuente actualmente, dado que existen protocolos específicos de datación ecográfica de la gestación, con longitud cráneo-caudal (CRL) en primer trimestre o diámetro biparietal (DBP) en segundo trimestre) o la taquipnea transitoria relacionada con una cesárea tras una inducción fallida.

La inducción electiva en partos de embarazos bien datados de $\geq 39$ semanas frente al manejo expectante, no se asocia con mayor riesgo de taquipnea transitoria del RN, sepsis neonatal, convulsiones, hipoglucemia, ictericia o Apgar menor de 7 a los $5 \min ^{26}$.

Por el contrario, los $\mathrm{RN}$ a término precoces $(37-38+6)$ tienen mayor morbilidad neonatal y utilizan más frecuentemente los servicios sanitarios durante el primer año de vida en comparación con los nacidos a las 39-40 semanas ${ }^{27,28}$.

\subsection{CONTRAINDICACIONES DE LA INDUCCIÓN DEL PARTO}

Son circunstancias en las cuales los riesgos maternos y/o fetales asociados al PV, y por tanto a la IP, superan a los riesgos asociados con el parto por cesárea:

- Cesárea anterior corporal (no segmentaria transversa)

- Embarazo tras rotura uterina previa

- Embarazo tras cirugía uterina previa con entrada a cavidad endometrial

- Infección activa por Herpes genital

- Placenta previa o vasa previa

- Prolapso de cordón umbilical o procidencia persistente del cordón

- Situación transversa del feto

- Cáncer invasor del cérvix uterino

- Categoría III del trazado de frecuencia cardiaca fetal (FCF) durante la monitorización o trazado anormal, definido por ACOG (2009) ${ }^{29}$. Requiere una rápida evaluación y comprende las siguientes situaciones:

- Variabilidad ausente de la FCF basal con algunos de los siguientes eventos (la variabilidad normal supone un aumento de $15 \mathrm{lpm}$ sobre la FCF durante al menos 15 segundos, pero inferior a $2 \mathrm{~min}$ ):

- Deceleraciones tardías recurrentes (Disminución de la FCF de al menos $15 \mathrm{lpm}, 30$ segundos tras el acmé de la contracción con lenta recuperación de la FCF basal)

- Deceleraciones variables recurrentes (Disminución de la FCF de al menos $15 \mathrm{lpm}$ coincidiendo con la contracción o antes de 30 segundos del acmé de la misma, con recuperación más o menos rápida de la FCF)

- Bradicardia (disminución de la FCF inferior a $110 \mathrm{lpm}$, durante al menos $2 \mathrm{~min}$ ).

- Bradicardia fetal 


\subsection{SITUACIONES CLÍNICAS ESPECÍFICAS}

\subsubsection{PREVENCIÓN DEL EMBARAZO CRONOLÓGICAMENTE PROLONGADO}

La IP a la semana 41 se asocia con una disminución ligera pero significativa de la mortalidad perinatal, por lo que puede ofrecerse esta opción a la mujer que alcanza esta semana, en el intervalo entre las 41 y 42 semanas ${ }^{30,31}$.

La revisión Cochrane de $2018{ }^{24}$ expone un metaanálisis de 30 estudios randomizados que comparan la inducción a término o a término tardío con el manejo expectante ( $n=12.479)$, concluyendo que promueven la política de inducción de rutina a partir de la 41 semana 0 días, dado que se relaciona con los siguientes resultados:

- Reducción del $67 \%$ en la mortalidad perinatal (RR 0.33, IC 95\% 0.14-0.78, $\mathrm{n}=9.960$ ). El número necesario de tratamientos para un resultado beneficioso adicional con una IP a las 41 semanas para prevenir una muerte perinatal fue de 426.

- Reducción del 67\% en la mortalidad intrauterina (RR 0.33, IC 95\% 0.11-0.96, $\mathrm{n}=9.960$ ).

- Reducción de la tasa de cesáreas (RR 0.92, IC 95\% 0.85-0.99, $\mathrm{n}=11.738$ ).

- Menos RN con Apgar a los 5 min < 7 (RR 0.70, IC 95\% 0.50-0.98, n=9.047).

- No diferencias significativas entre grupos en: parto operatorio, trauma perineal, hemorragia postparto, estancia materna hospitalaria, ingreso en $\mathrm{UCl}$ neonatal y trauma neonatal.

Un registro sueco de partos entre 1982-1991 (n=914.702) demostró tasas significativamente mayores de muerte intraútero a las 41 y 42 semanas frente a las 40 semanas, tanto para primíparas $(0.62,1.26$ y $2.27 \%$ ) como para multíparas $(0.73,1$ y $1.51 \%$ ). Estas tasas se calcularon no sólo en función de las pacientes que parían, sino también de las que no parían a cada edad gestacional ${ }^{32}$.

Varios estudios han estimado el número de inducciones que necesitan ser realizadas en la semana 41 para prevenir una muerte intrauterina, cifrándose en $527^{33}$ y $410^{24}$.

\subsubsection{ROTURA PREMATURA DE MEMBRANAS A TÉRMINO}

Existe gran disparidad entre los estudios que abordan este tema, sobre si es preferible el manejo activo mediante IP o el manejo expectante, con o sin profilaxis antibiótica.

Sin embargo, tanto los resultados maternos como fetales, sobre todo con relación a las complicaciones infecciosas (endometritis, corioamnionitis, sepsis neonatal, ...) parecen sugerir que el manejo activo de la RPM a término con inducción dentro de las primeras 24 horas tras la rotura de la bolsa presenta mejores resultados que la conducta expectante durante más de 24 horas.

Esto es refrendado por la mayoría de las sociedades científicas y ha sido evaluado en la Revisión Cochrane $2017^{34}$, que incluye 23 estudios controlados randomizados sobre 8615 gestantes a término. Concluye que el parto en las primeras 24 horas tras la rotura de la bolsa (ya sea espontáneo o inducido con oxitocina/PG), reduce el riesgo de infección materna y neonatal, la probabilidad de ingreso en $\mathrm{UCl}$ neonatal y la estancia hospitalaria tanto de madres como de recién nacidos. Además, no encuentran diferencias en las tasas de cesáreas, complicaciones serias maternas o mortalidad neonatal. 


\subsubsection{GESTACIÓN CON CESÁREA ANTERIOR}

El 60-80\% de las mujeres con cesárea anterior que intentan un PV, finalmente lo consigue. Para que esto sea posible es fundamental un adecuado balance entre los riesgos y las opciones de éxito. Ciertas condiciones hacen menos probable el PV, como la edad materna avanzada, un alto IMC, un alto peso fetal estimado por ecografía (PFE) y que la causa de la cesárea anterior sea un fallo en la progresión del parto ${ }^{35}$.

Cualquier intento de PV tras cesárea anterior debería ser llevado a cabo en centros con apropiados medios y cuidados, a causa del riesgo de rotura uterina y de otras complicaciones imprevisibles, siendo prioritario poder realizar una cesárea de emergencia.

Es indispensable valorar el número de cesáreas previo y el tipo de incisión uterina, puesto que sólo es posible inducir el parto cuando existe solo una cesárea anterior y la incisión uterina ha sido segmentaria transversa (riesgo de rotura tras cesárea segmentaria transversa $\left.0.32-0.47 \%{ }^{36}\right)$.

Existe evidencia de que la inducción a término reduce la mortalidad perinatal y las tasas de cesárea cuando se compara con el manejo expectante. Sin embargo, no está claro si la inducción en mujeres con cesárea previa confiere los mismos beneficios.

Una cohorte retrospectiva de mujeres con una cesárea anterior como único parto $(n=46.176){ }^{36}$ describe los resultados de la inducción del parto a las 39-41 semanas y los compara con la cesárea electiva y el manejo expectante. Obtienen menor tasa de cesárea con la inducción, sin efecto significativo sobre la mortalidad perinatal ni la rotura uterina, pero con mayor riesgo de ingreso en unidad neonatal.

Si una paciente con cesárea anterior desea más gestaciones, una inducción a término puede maximizar su posibilidad de PV. Mientras que una paciente con dos cesáreas finalizará su siguiente gestación también mediante cesárea, con el aumento de morbilidad materna asociado sin beneficio neonatal.

Con estas premisas, es posible la IP con los métodos mecánicos y farmacológicos habituales, a excepción de Misoprotol (PG E1) que está contraindicado en pacientes con cicatriz uterina previa. Tanto el uso de oxitocina como de PG se asocian a un mayor riesgo de rotura uterina.

El riesgo absoluto de rotura uterina tras inducción es bajo, pero el riesgo relativo, especialmente con el uso de PG, es mayor ${ }^{37}$.

\subsubsection{PRESENTACIÓN FETAL PODÁLICA}

En presentaciones podálicas, el PV puede ser seguro si se cumplen unas buenas condiciones, como son una adecuada selección de las pacientes y la experiencia del obstetra. Bajo estas premisas, puede considerarse una IP.

Basado en la opinión de expertos ${ }^{38}$, se han propuesto unos criterios para minimizar el riesgo de las mujeres que optan a un PV en presentación podálica. Son los siguientes:

- No poseer contraindicación para PV.

- No tener el antecedente de cesárea.

- Inicio espontáneo del parto.

- Gestación única, mayor o igual de 36 semanas, con PFE entre 2.000 y 4.000 gr.

- Ausencia de cualquier anomalía fetal que pueda causar una distocia. 
- Disponer de suficiente experiencia profesional en este tipo de parto y de recursos necesarios para practicar una cesárea de emergencia (anestesia adecuada, pediatra, quirófano y personal necesario...).

- Presentación nalgas puras (extremidades inferiores flexionadas sobre el tronco fetal).

- No hiperextensión del cuello/cabeza fetal (ángulo de la columna cervical $<90^{\circ}$ ).

La mayoría de los expertos no recomiendan la IP en presentación podálica, pero 2 estudios observacionales retrospectivos ${ }^{39,40}$, muestran como la IP en presentación podálica es segura, al no asociar un aumento de riesgo de morbimortalidad materna ni neonatal, en comparación con el parto de nalgas de inicio espontáneo. Aunque sí observan que la tasa de PV es inferior cuando el parto en podálica es inducido y no de inicio espontáneo (64.4\% vs $80 \%{ }^{40}$.

\subsubsection{RESTRICCIÓN DEL CRECIMIENTO INTRAUTERINO FETAL}

No supone una contraindicación absoluta para la IP, pero debe valorarse cada caso de forma individual, según la clasificación del CIR y en función del grado de oxigenación fetal determinado por el estudio Doppler feto-materno.

Se define CIR como un PFE inferior al Percentil (P) 3 o cualquier PFE inferior al P10 con alguna alteración del estudio Doppler fetal o materno o con un RCTG patológico (variabilidad fetal $<5 \mathrm{Ipm}$ y/o patrón desacelerativo) ${ }^{41}$.

El estudio Doppler fetal valora el índice de pulsatilidad de la arteria umbilical, de la arteria cerebral media (ACM) y del ductus venoso, el índice cerebro-placentario (ICP) y la morfología de la onda de la vena umbilical (flujo continuo o pulsátil).

En cambio, el estudio Doppler materno explora el índice de pulsatilidad medio de las arterias uterinas (AUt).

Según la clasificación CIR del Hospital Clinic de Barcelona ${ }^{41}$, sólo es posible finalizar la gestación mediante IP en el CIR tipo I (menor de P3 con Doppler normal o cualquier P menor de 10 con ICP < P5 en 2 ocasiones separadas $>12$ horas o índice de pulsatilidad de ACM $<$ P5 en 2 ocasiones separadas $>12$ horas o índice de pulsatilidad medio de AUt > P95).

El resto de los tipos CIR (II, III y IV) deben finalizar la gestación mediante cesárea electiva.

\subsubsection{MUERTE FETAL INTRAÚTERO}

En estos casos la vía vaginal debe ser de elección para finalizar la gestación, tanto para los fetos en presentación cefálica como en podálica, dado que no existe ningún beneficio fetal asociado a una cesárea, con la que además contribuiríamos a aumentar los riesgos maternos, comprometiendo el futuro reproductivo de la paciente.

La situación transversa en gestaciones avanzadas debe intentarse convertir en longitudinal tras evaluar los riesgos de una versión externa. Sólo debe considerarse la cesárea ante indicaciones maternas. El método de inducción farmacológico de elección son las PG, presentando para esta indicación una eficacia superior el misoprostol (PG E1) frente a la Dinoprostona (PG E2) ${ }^{42}$.

\subsubsection{SOSPECHA DE MACROSOMÍA FETAL}

Un metaanálisis de 4 ensayos randomizados aleatorizados ${ }^{43}$ que incluyeron 1190 mujeres no diabéticas con sospecha de macrosomía fetal a término, concluye que no hubo diferencias entre el grupo de mujeres inducidas por encima de las 38 semanas y el grupo 
de mujeres con manejo expectante respecto a: parto por cesárea, parto vaginal espontáneo y operatorio, distocia de hombros, hemorragia intracraneal, parálisis del plexo braquial, Apgar a los $5 \mathrm{~min}<7, \mathrm{pH}$ de cordón umbilical $<7$. El grupo de inducción presentó como resultados significativos frente al manejo expectante: menor tiempo hasta el parto (media 7.55 días), menor tasa de peso $\geq 4.000$ gr (RR 0.5 ) y $\geq 4.500$ gr y menor incidencia de fracturas fetales (RR 0.17). Por ello, parece razonable la inducción por encima de las 38 semanas cuando existe sospecha de macrosomía fetal en paciente no diabética.

La revisión Cochrane de $2016{ }^{44}$ comparando la inducción del parto vs el manejo expectante en los fetos a término con sospecha de macrosomía, no encuentra diferencias entre ambos grupos en cuanto a la tasa de cesáreas y partos instrumentados, a lesión del plexo braquial ni a datos de asfixia neonatal, como Apgar a los $5 \mathrm{~min}<7$ o pH bajo de arteria umbilical de cordón. Donde sí observan diferencias significativas es en la reducción de distocia de hombros y fracturas en el grupo de inducción. Para prevenir una distocia de hombros sería necesario inducir precozmente a 60 pacientes con sospecha de macrosomía.

Por lo tanto, debido a la problemática del diagnóstico de macrosomía fetal, dado que las estimaciones de peso fetal son inexactas y que muchas mujeres serían innecesariamente inducidas, no está recomendada la inducción del parto en este grupo de mujeres (Nivel Evidencia la, Revisión sistemática de ensayos clínicos aleatorizados, con homogeneidad ${ }^{45}$ ).

\subsubsection{HISTORIA DE PARTO PRECIPITADO PREVIO}

Es posible que una mujer con el antecedente de un PV precipitado solicite una IP electiva, para intentar que el parto se desarrolle en el medio hospitalario bajo los cuidados adecuados. No existe evidencia que defienda esta indicación de inducción de forma rutinaria, aunque hay que individualizar cada caso, escuchando a la paciente, sopesando las ventajas y los potenciales riesgos ${ }^{1}$.

\subsubsection{INDUCCIÓN ELECTIVA EN PACIENTE OBESA}

La obesidad en el embarazo se relaciona con un aumento de severas complicaciones perinatales como DG, PE, cesárea, hemorragia postparto, macrosomía, muerte intraútero y muerte neonatal. El riesgo de desarrollar estos resultados adversos también se relaciona con la EG.

Aunque actualmente, la obesidad no es una indicación por si misma de IP, estas mujeres sin otras indicaciones obstétricas podrían inducirse de forma electiva para teóricamente intentar evitar el riesgo de complicaciones perinatales.

Existe escasa literatura a este respecto, por lo que Lee y cols. (2016) ${ }^{46}$ estudian una cohorte retrospectiva de 2007 ( $n=74.725,40.8 \%$ nulíparas, 59.2\% multíparas con un parto vaginal previo) para determinar el impacto de la inducción electiva entre las 37-40 semanas de mujeres con IMC pregestacional $\geq 30 \mathrm{~kg} / \mathrm{m}^{2}$ (gestaciones únicas, presentación cefálica, sin anomalías fetales y sin complicaciones médicas crónicas). Se compara con mujeres obesas en manejo expectante a cada EG, esto incluye tener un parto espontáneo, una inducción electiva o una inducción médica a posterior EG. Concluyen que la inducción electiva en obesas no se asocia con un riesgo aumentado de resultados adversos perinatales. Incluso obtiene menor riesgo de cesárea en nulíparas entre 37 y 39 semanas, y en multíparas entre 37 y 40 semanas con disminución del riesgo de macrosomía entre 37 y 39 semanas para ambas, nulíparas y multíparas.

Solamente la cohorte retrospectiva de Wolfe y cols. (2014) ${ }^{47}$ que incluyeron 470 pacientes con IMC $\geq 30 \mathrm{~kg} / \mathrm{m}^{2}$ al parto, entre 38 y $38+6$ semanas con cérvix desfavorable (Bishop < 
5), ha descrito que la inducción electiva de pacientes obesas nulíparas entre 39 y 41 semanas se asoció con altas tasas de cesárea frente al manejo expectante, sin diferencias en otras morbilidades maternas y neonatales.

En conclusión, la inducción electiva de mujeres obesas frente al manejo expectante no se asocia con un aumento de los riesgos perinatales y en algunos casos puede reducir el riesgo de macrosomía y cesárea. Particularmente, la inducción electiva a las 39 semanas disminuye el riesgo de cesárea en ambas nulíparas y multíparas, por lo que podría ser una EG razonable para finalizar la gestación en pacientes obesas, puesto que asocian mayores riesgos con la cesárea. Sin embargo, se necesitan más estudios y también análisis de costeefectividad.

\subsection{EVALUACIÓN PREVIA A UNA INDUCCIÓN DEL PARTO}

La evaluación previa a iniciar una IP es fundamental, debe valorar el estado de salud materno y fetal, que la indicación de la inducción es apropiada y confirmar la ausencia de contraindicaciones tanto para el PV y por tanto para la inducción, como para fármacos involucrados en el proceso de la maduración cervical.

La ACOG ha publicado un "checklist" seguro para la evaluación previa a la inducción ${ }^{48}$ (Anexo 1).

\subsection{MÉTODOS DE INDUCCIÓN DEL PARTO}

Puede existir una disparidad de términos al referirnos a la inducción, dado que debemos diferenciar dos períodos muy distintos del proceso del parto. El primero sería la maduración cervical o preinducción, un proceso fisiológico que a través de cambios funcionales y bioquímicos del tejido conectivo cervical consigue modificar sus características, haciendo que se acorte, reblandezca y se posicione anteriormente en la vagina. Tras este proceso, con una puntuación del Bishop igual o superior a 7 puede diferenciarse ya la inducción.

La valoración objetiva de los distintos métodos de inducción del parto es compleja, ya que existen diversos factores que la dificultan ${ }^{1}$ :

- No existe una frontera clara entre maduración o preinducción y la inducción.

- Falta de conocimiento acerca de la fisiología del inicio y mantenimiento del parto.

- Amplia variabilidad biológica en el progreso del trabajo de parto normal.

- Falta de estudios que comparen varios métodos.

- Poca información acerca de la satisfacción de la paciente.

\subsubsection{MADURACIÓN CERVICAL O PREINDUCCIÓN}

Cuando el parto es inducido, el estado cervical impacta en la duración de la inducción y la probabilidad de parto vaginal, por lo que, si el cérvix es desfavorable, debe emplearse algún método de maduración para acortar la inducción y maximizar la posibilidad de parto vaginal.

Aunque el estado cervical puede hacer prever la probabilidad de finalización por cesárea, no puede predecir si evitar la inducción y manejar a la paciente de forma expectante resultaría en una alta posibilidad de parto vaginal ${ }^{49}$.

La mayoría de los autores consideran como cérvix desfavorable una puntuación del score de Bishop ${ }^{50}$, que describe las condiciones cervicales y la altura de la presentación fetal, menor a 6. Otros autores usan puntos de corte inferiores, $\leq 3 \circ 4^{11} \circ<5^{51}$. La tasa de 
éxito de la inducción con un cérvix favorable es similar a la del parto de inicio espontáneo 52.

Es muy importante explicar a la paciente que la maduración cervical es imprescindible para conseguir las condiciones de inicio del parto, por lo que el tiempo que dure este proceso es independiente de las horas que posteriormente dure el parto.

\subsubsection{MÉTODOS NO FARMACOLÓGICOS}

- DESPEGAMIENTO DE MEMBRANAS AMNIÓTICAS O MANIOBRA DE HAMILTON

- BALÓN

- TALLOS DE LAMINARIA Y DILATADORES HIGROSCÓPICOS

- ESTIMULACIÓN MAMARIA

\subsubsection{MÉTODOS FARMACOLÓGICOS}

- PROSTAGLANDINAS: DINOPROSTONA Y MISOPROSTOL

- MIFEPRISTONA

- hIALURONIDASA

- eStRógenOS

- FÁRMACOS DONANTES DE ÓXIDO NITROSO

\subsubsection{MÉTODOS NO FARMACOLÓGICOS}

\section{- DESPEGAMIENTO DE MEMBRANAS AMNIÓTICAS O MANIOBRA DE HAMILTON}

El despegamiento de las membranas amnióticas mejora las condiciones cervicales e incluso puede desencadenar el inicio del parto por su probable base fisiológica, que es el aumento de la producción local de PG, ya que la decidua es la fuente más rica en PG dentro del útero ${ }^{1}$. Se realiza en pacientes ambulatorias, habitualmente en los controles programados a término durante la monitorización no estresante, en los casos en que la propia paciente lo solicite o cuando lo recomiende el facultativo, para intentar el comienzo de un parto espontáneo.

También puede ofrecerse, justo en el momento de la toma de decisión de una inducción del parto, para posibilitar el inicio espontáneo del parto antes de la inducción.

Su realización sistemática a partir de la semana 40 (una vez o de forma repetida) parece disminuir las gestaciones postérmino, por lo que tiene un papel muy importante en la prevención integral del embarazo prolongado ${ }^{10}$.

Precisa de una mínima dilatación cervical para conseguir introducir el dedo del explorador a través del orificio cervical interno y entonces rotarlo circunferencialmente por el segmento inferior uterino para despegar las membranas fetales de la decidua, con la consiguiente liberación de PG.

Si no existe dilatación cervical, se sustituye este despegamiento de las membranas por un masaje alrededor del cuello uterino, en los fondos de saco vaginales, consiguiendo un efecto similar.

La eficacia de esta maniobra se demostró en un metaanálisis de $2005{ }^{53}$ de 22 ensayos controlados, en los que 20 compararon el despegamiento de las membranas frente a ningún tratamiento, 3 frente a la administración de PG y 1 en 
comparación con oxitocina antes de un protocolo de inducción formal a término. Se obtuvieron los siguientes resultados:

- Aumento de la probabilidad de parto antes de 48 horas (RR 0.77; IC 95\% 0.70-0.84).

- Aumento de la probabilidad de parto antes de una semana (RR 0.71; IC 95\% 0.65-0.78).

- Comparado con ningún tratamiento:

- Disminución del riesgo de sobrepasar la semana 41 (RR 0.59 IC 95\%: 0.46-0.74) con menor necesidad de inducción (RR 0.72; IC 95\% 0.521.00).

- Tasas similares de fiebre materna, infección materna/neonatal y tasa de cesáreas.

- Aumento significativo del sangrado no complicado (34\%) (RR 6.58; IC 95\% 3.98-10.87).

- El $68 \%$ de las mujeres consideró la maniobra dolorosa. Sin embargo, el $88 \%$ de las pacientes refirieron que volverían a elegir este procedimiento en un próximo embarazo.

- Finalmente se calculó que, para evitar una inducción formal del parto deberíamos realizar esta maniobra a 8 mujeres.

No debería recomendarse esta maniobra de forma rutinaria, dado que no se ha relacionado con una mejora en los resultados maternos y neonatales. Sin embrago, comparado con ninguna intervención, acorta el tiempo hasta el comienzo del parto espontáneo y reduce la necesidad de inducción, por lo que podría ofrecerse a las pacientes de $\geq 39$ semanas que deseen que comience su trabajo de parto espontáneo ${ }^{54}$.

- MECÁNICOS: BALÓN ÚNICO Y DOBLE, Y TALLOS DE LAMINARIA/DILATADORES HIGROSCÓPICOS

\section{- MECANISMO DE ACCIÓN}

Teóricamente trabajan por presión física directa sobre el orificio cervical interno y produciendo la liberación de PG desde la decidua, membranas y/o cérvix. Además, promueven cambios bioquímicos y biofísicos que conducen a la maduración cervical y al aumento de la contractilidad miometrial ${ }^{49}$.

- CONTRAINDICACIONES

No existen absolutas, pero sería una contraindicación relativa la inserción baja de la placenta, puesto que la colocación de los dispositivos podría desprender la placenta próxima.

Por otra parte, el doble balón de $\operatorname{Cook}^{\circledR}\left(\operatorname{Cook}^{\circledR}\right.$ Cervical Ripening Ballon $\left.{ }^{55}\right)$ en sus instrucciones de manejo, indica que está contraindicado en la rotura prematura de membranas y que, si se produce la amniorrexis espontánea con el balón inserto, debe retirarse lo antes posible.

\section{- EFECTOS SECUNDARIOS}

No causan efectos secundarios sistémicos y producen menores tasas de taquisistolia ( $\geq 6$ contracciones en 10 min durante $30 \mathrm{~min}$ ) en comparación con prostaglandinas ${ }^{56}$.

Un metaanálisis de 71 estudios randomizados ( $n=9.722$ ) no encontró evidencia para aumento de la morbilidad infecciosa materna ni neonatal en el grupo expuesto a catéter de balón comparado con el uso de PG ${ }^{57}$. Estos ensayos excluyeron mujeres con rotura de membranas. 


\section{- ESTIMULACIÓN DEL PEZÓN}

La estimulación del pezón mamario produce oxitocina y por eso se ha relacionado con la maduración cervical.

En una revisión sistemática de 6 estudios controlados ( $n=719$, puntuación Bishop 5-7) que evaluaron el efecto de la estimulación mamaria en la maduración cervical y la inducción del parto, se describieron los siguientes resultados frente a la no estimulación de los pezones ${ }^{58}$ :

○ Mayor número de partos < 72 horas $(93.6 \%$ vs $62.7 \%$, RR 5.79 , IC $95 \%$ 3.41-9.81).

○ Reducción de la hemorragia postparto ( $0.7 \%$ vs $6 \%$, RR 0.16 , IC $95 \%$ 0.030.87).

- No diferencias en la tasa de cesáreas o líquido meconial.

- No hubo ningún caso de hiperestimulación uterina.

Cuando se comparó estimulación mamaria frente a oxitocina, se observó que ${ }^{58}$ :

- No existían diferencias en la tasa de cesáreas o de mujeres sin trabajo de parto tras 72 horas.

\section{- SUPLEMENTOS DE HIERBAS}

No hay evidencia científica para determinar los efectos de suplementos de hierbas como agentes de inducción por lo que no pueden ser ofrecidos como medios de maduración cervical ni de inducción del parto.

\section{- ACUPUNTURA}

Se ha hipotetizado que la estimulación neuronal de la acupuntura puede aumentar la contractilidad uterina y también aliviar el dolor del parto y madurar el cérvix.

Una revisión sistemática que evaluó los efectos de la acupuntura en mujeres sometidas a inducción del parto no encontró resultados significativos debido a limitaciones metodológicas y tasas de abandono ${ }^{59}$.

Por lo tanto, no puede recomendarse el uso de acupuntura como método de inducción o maduración cervical.

\section{- homeopatía}

Se ha sugerido que un tipo de homeopatía con hierbas del género Caulophyllum es útil para iniciar el trabajo de parto, cuando las contracciones con cortas y/o irregulares o cuando se frena la dinámica uterina. Una revisión sistemática realizada para comparar la homeopatía en tercer trimestre como método de maduración e inducción frente a placebo/ningún tratamiento u otros métodos ( 2 estudios, 133 mujeres) concluye que, la evidencia disponible es pobre e insuficiente por lo que no se recomienda su uso ${ }^{60}$.

El Ministerio de Sanidad en 2011 publicó un documento sobre terapias naturales en el embarazo, desaconsejando su uso, al no poder demostrar sus beneficios ni su inocuidad y seguridad ${ }^{61}$.

\section{- RELACIONES SEXUALES}

Las relaciones sexuales has sido propuestas como método de maduración cervical dado que el semen contiene PG y el orgasmo es facilitado por la liberación endógena de oxitocina. 
Una revisión sistemática encontró 1 estudio de 28 mujeres, en el que el grupo de tratamiento tenía relaciones sexuales durante 3 noches consecutivas y el grupo control abstinencia sexual. No encontró diferencias significativas en la puntuación de Bishop ni en las mujeres que parieron a los 3 días de la intervención ${ }^{62}$.

Por esto, no se recomiendan las relaciones sexuales como método de inducción.

\subsubsection{MÉTODOS FARMACOLÓGICOS \\ - PROSTAGLANDINAS \\ - MECANISMO DE ACCIÓN}

Los derivados sintéticos de la PG E son los que se usan para la inducción del parto por sus efectos biológicos sobre el cérvix uterino, como el remodelado del colágeno extracelular, el incremento del contenido acuosos y los cambios en la matriz extracelular. Consiguen así ablandar, borrar y dilatar el cuello, contribuyendo a su maduración. Además, pueden aumentar la contractilidad del miometrio.

\section{- CONTRAINDICACIONES}

- Embarazos a término con cesárea anterior o antecedente de cirugía mayor uterina (miomectomía con gran compromiso miometrial o entrada a cavidad, reparación de anomalías uterinas congénitas...) ${ }^{63}$.

- La dinámica uterina regular establecida es una contraindicación relativa, dado que la suma de un agente uterotónico externo provocaría una actividad uterina excesiva. Se debería evitar la administración de PG si la paciente ya tiene $\geq 2$ contracciones dolorosas cada $10 \mathrm{~min}$. $Y$ esto adquiere mayor importancia si ya se ha recibido una dosis de $P G$, puesto que tienen un efecto uterotónico acumulativo.

- Debemos tener especial atención antes de la administración de PG si existen factores de riesgo específicos como la gran multiparidad, el estado fetal, el grado de disconfort/dolor de la paciente y el número total de dosis de PG administradas.

\section{- ADMINISTRACIÓN Y CONTROLES}

Antes de la administración debe realizarse una monitorización fetal no estresante de al menos 30 min de duración, para valorar la FCF y la actividad uterina ${ }^{11}$.

El control tras la administración de PG se realiza con monitorización fetal no estresante a la hora y posteriormente cada 3-4 horas, pero el número y frecuencia de controles dependerá de cada agente específico, de la respuesta uterina, de la repercusión fetal...

Si no se consigue el inicio del parto, se repetirá la dosis de PG (el número de dosis y el tiempo de repetición depende de cada agente específico) o se iniciará la administración de oxitocina con o sin amniotomía.

\section{- EFECTOS SECUNDARIOS}

Son debidos a que las PG E afectan a diversos órganos y tejidos. Incluyen escalofríos y/o fiebre, náuseas, vómitos, diarrea y taquisistolia con o sin anomalías en la FCF (hasta en un 30\%). Dependen de la dosis, vía de administración y galénica del producto.

Si ocurre taquisistolia con cambios adversos en la FCF, debe retirarse la medicación, lo que será posible con el dispositivo intravaginal de PG E2. Con el gel intracervical de PG E2 esto no es posible, ni tampoco ayuda el lavado cérvicovaginal. Respecto a la PG E1 vaginal, se puede retirar y precisa lavado vaginal. Si persiste repercusión en la FCF tras la retirada de la PG, puede administrarse un tocolítico (Ritodrina, agente simpático mimético Beta2 o 
Atosibán, antagonista competitivo del receptor de oxitocina) así como otras medidas de resucitación fetal intrauterina ${ }^{64}$.

- EFICACIA

Múltiples metaanálisis de ensayos randomizados demuestran su eficacia al reducir el riesgo de no conseguir el parto vaginal en 12-24 horas, sin embargo no se ha podido demostrar de forma consistente una clara reducción de la tasa global de cesáreas ${ }^{63,65,66}$.

El tipo de PG, vía de administración, frecuencia y dosis, no ha sido determinado a pesar muchos estudios. Algunos metaanálisis concluyen que:

- La administración local en vagina y endocérvix asocia menos frecuencia de efectos adversos en comparación con la vía oral, manteniendo una respuesta clínica aceptable ${ }^{67}$.

- La PG E2 intravaginal consigue más PV en 24 horas que la PG E2 intracervical, pero ambas asocian similares tasas de taquisistolia y cesárea ${ }^{68}$.

- La PG E1 intravaginal consiguió la mayor probabilidad de PV ${ }^{66}$.

○ PG E1 (MISOPROSTOL)

Es un análogo sintético de la PG E1, que puede administrarse por vía oral, sublingual y vaginal. Hasta hace poco sólo estaba comercializado en España en comprimidos de $200 \mu \mathrm{g}$ (Cytotec ${ }^{\circledR} 200 \mu \mathrm{g}$, Laboratorios Bial, S.A. Vizcaya, España) con la única indicación de prevención de lesiones gastrointestinales en pacientes con uso crónico de AINES y tratamiento de úlcera duodenal.

Desde 1980 se ha usado el misoprostol de forma "no autorizada" o aduciendo un "uso compasivo" ("Off-label" en inglés) como método de maduración cervical e inducción del parto.

En 2008 la Agencia Española de Medicamentos y Productos Sanitarios autorizó el uso de misoprostol $25 \mu \mathrm{g}$ (Misofar ${ }^{\circledR} 25 \mu \mathrm{g}$, Pfizer S.L. Madrid, España) en comprimidos vaginales para la inducción del parto y el misoprostol vaginal de $200 \mu \mathrm{g}$ (Misofar ${ }^{\circledast} 200 \mu \mathrm{g}$, Pfizer S.L. Madrid, España) para la maduración cervical en intervenciones ginecológicas.

Se encuentra en desarrollo un dispositivo vaginal de liberación prolongada de misoprostol $(100-200 \mu \mathrm{g})^{1}$.

A dosis más altas de misoprostol, se consiguen mayores tasas de éxito en la inducción, pero a expensas de mayores tasas de hiperestimulación uterina ${ }^{10}$.

- VAGINAL (PROPESS ${ }^{\circledR}$, Ferring Pharmaceuticals, Alemania)

Es un dispositivo intravaginal que contiene un reservorio de $10 \mathrm{mg}$ de dinoprostona, para mantener una liberación controlada y constante. La liberación media es aproximadamente $0,3 \mathrm{mg}$ por hora durante 24 horas en mujeres con las membranas intactas, mientras la liberación en mujeres con rotura prematura de membranas es algo más alta y más variable.

A través de un tacto vaginal en condiciones de asepsia, en el que pueden utilizarse lubricantes acuosos, se coloca en el fondo de saco vaginal posterior, con la intención de abrazar el cérvix. La cinta que acompaña al dispositivo, para facilitar su extracción, puede dejarse fuera de la vagina, o introducir la mayor parte de ella en la vagina dejando el extremo fuera para tirar de él cuando sea necesario. Se retira cuando ha comenzado la fase activa del parto o tras 12-24 horas. No se recomienda una segunda dosis. Puede dejarse el dispositivo in situ si el parto progresa adecuadamente. 
Una ventaja de Propess $^{\circledR}$ es que puede retirarse en casos de alteración de la FCF o taquisistolia, aunque esta posibilidad no se ha acompañado de mejores resultados clínicos que con otros métodos de maduración cervical.

Este dispositivo de liberación prolongada se ha posicionado al frente de otras presentaciones vaginales, por ser más cómodo y poder ser extraído con total seguridad.

- CERVICAL (PREPIDIL ${ }^{\circledR}$, actualmente no está comercializado en España) Contiene $0.5 \mathrm{mg}$ de dinoprostona en $2.5 \mathrm{~mL}$ de gel para administración endocervical.

No aporta más eficacia que la administración vaginal y supone mayor invasividad e incomodidad. No existen diferencias en mujeres con cérvix favorable entre PG E2 intracervical y vaginal en los resultados maternos y neonatales ${ }^{65}$.

\section{- MIFEPRISTONA (Mifeprostona Linepharma ${ }^{\circledR}$ comprimidos 200 mg, Amring,}

\section{S.A.R.L. Paris, Francia)}

Conocida también como RU-486, es un antiprogestágeno. Su actual indicación es la finalización del embarazo durante el primer y segundo trimestre, en combinación con PG.

No existe una información suficiente para apoyar su uso en la inducción del parto 69. Además, se han encontrado graves efectos secundarios neonatales de la función renal por hipoxia cuando se produjo el parto entre las 16 y 28 semanas $^{70}$.

\section{- HIALURONIDASA}

Se ha propuesto su uso como inductor de la maduración cervical, mediante inyección intracervical, dado que el nivel de ácido hialurónico aumenta mucho tras el inicio del parto. El cérvix es fibroso y está compuesto de ácido hialurónico, proteoglicanos y colágeno. El aumento de ácido hialurónico aumenta la concentración acuosa y esto forma parte del proceso madurativo cervical.

Una revisión sistemática encontró un ensayo controlado $(n=168)$ comparando la inyección intracervical de hialuronidasa con placebo para la inducción del parto en tercer trimestre, encontrando los siguientes resultados ${ }^{71}$ :

- Mejoría de las condiciones cervicales tras 24 horas (RR 0.62, IC 95\% 0.520.74).

- Disminución en la tasa de cesáreas ( $18 \%$ vs $49 \%$, RR 0.37 , IC $95 \%$ 0.22$0.61)$.

- Sin efectos secundarios maternos ni neonatales.

Sin embargo, el carácter invasivo del procedimiento lo hace poco recomendable para la inducción del parto.

\section{- eStRóGenOS}

Se ha descrito que el aumento en sangre del cociente Estrógenos/Progesterona puede activar la producción de PG locales, por lo que existen estudios sobre los estrógenos y la maduración cervical.

La evidencia es limitada y sugiere que los estrógenos tienen resultados maternos y fetales similares al placebo. No existen datos fiables para compararlos con PG E2 vaginal u oxitocina ${ }^{4}$. 


\section{- FÁRMACOS DONANTES DE ÓXIDO NITROSO}

El óxido nitroso es un mediador de la maduración cervical sin producción de contracciones uterinas ni efectos adversos materno-fetales. Se han estudiado varios donantes de óxido nitroso, como nitroglicerina y mononitrato de isosorbida, como inductores del parto en comparación con otros fármacos.

Se desaconseja su uso por no demostrar superioridad frente a otros fármacos inductores y por su mayor tasa de efectos secundarios.

\section{- CORTICOIDES}

No se puede establecer una evidencia suficiente para uso en la inducción del parto, aunque se ha postulado su papel en el desencadenamiento del parto.

\subsubsection{INDUCCIÓN DEL PARTO}

Cuando se ha alcanzado una puntuación Bishop $\geq 6$ se prosigue la inducción con amniotomía y/o perfusión de oxitocina.

La oxitocina es menos eficaz en mujeres con cérvix desfavorable, de ahí la necesidad de una maduración cervical previa.

Cuando se realiza la maduración cervical con Dinoprostona o Misoprostol, el parto se inicia espontáneamente en el $50 \%$ de los casos, evitando así la necesidad de oxitocina ${ }^{65}$.

Si tras la maduración cervical no se consigue el inicio del parto, entonces es necesaria la oxitocina y la amniotomía en cuanto sea posible. En función de la PG empleada, la oxitocina puede ser iniciada:

- 6-12 horas tras la dosis final de Dinoprostona gel intracervical.

- 30 minutos tras retirar el dispositivo intravaginal de Dinoprostona.

- 4 horas tras la dosis final de Misoprostol vaginal.

\subsubsection{AMNIOTOMÍA}

La amniotomía es la rotura deliberada artificial de las membranas y sólo en posible si las membranas son accesibles físicamente. Cuando el cuello es desfavorable no se recomienda, por su invasividad y los posibles riesgos potenciales de infección. Antes de proceder a la amniotomía hay que asegurar que la presentación fetal está bien apoyada sobre el cérvix y que no se tactan partes fetales ni cordón umbilical entre la membrana y la cabeza fetal, para reducir el riesgo de prolapso de cordón umbilical.

En cambio, si el cérvix es favorable, la amniotomía parece ser eficaz, aunque se asocia con mayor necesidad de oxitocina en comparación con PG E2 vaginal ${ }^{10}$.

En una revisión sistemática de 17 estudios randomizados $(n=2.566)$ sobre la combinación de amniotomía y oxitocina, se encontraron los siguientes resultados ${ }^{72}$ :

- La combinación fue más efectiva que la amniotomía sola en lograr el parto en 24 horas ( 1 estudio, $n=100$, RR 0.03, IC 95\% 0.001-0.49)

- La combinación frente a PG E2 en cérvix desfavorable, no obtuvo diferencias respecto al parto en menos de $24 \mathrm{~h}$ y a la tasa de cesáreas.

- La combinación frente a PG vaginales en cérvix favorable produjo más hemorragia postparto (RR 5.5, IC 95\% 1.26-24.07) y mayor insatisfacción (RR 53, IC 95\% 3.32846.51).

Por todo esto, no se debe utilizar la amniotomía sola o combinada con oxitocina como método principal de inducción, a menos que existan razones clínicas específicas para 
no emplear PG, ya que además disponemos de métodos mecánicos como el catéter de balón que podría ser útil en estas circunstancias.

Otra cuestión distinta es realizar una amniotomía temprana o no en mujeres que están en proceso de inducción. No existen diferencias en la tasa de cesáreas entre realizar amniotomía temprana o avanzada la dilatación, pero la amniotomía temprana en nulíparas sí acorta el tiempo de la inducción y consigue más partos en las primeras 24 horas $^{73}$.

Un estudio randomizado que comparaba la amniotomía temprana (definida como dilatación cervical $\leq 4 \mathrm{~cm}$ ) frente al manejo habitual en nulíparas con inducción del parto, concluyó que la amniotomía temprana acortaba el tiempo hasta el parto $>2$ horas y aumentaba la proporción de partos en las primeras 24 horas (68\% vs 56\%, RR 0.72 , IC $95 \%$ 0.59-0.89) ${ }^{73}$. En el grupo de manejo habitual, la amniotomía se realizó según criterio del médico responsable y la dilatación media en el momento de la rotura de membranas fue de $7.4 \mathrm{~cm}$.

\subsubsection{OXITOCINA (SYNTOCINON ${ }^{\circledR}$ )}

Es el principio activo que más conocemos por su utilización durante décadas. Antes de la década de los 50, la inducción del parto era practicada solamente con amniotomía. Debemos la disponibilidad de la oxitocina a Du Vigneaud, que la aisló en 1953, recibiendo por ello el Premio Nobel de 1955.

Puede utilizarse sola, en combinación con amniotomía o tras la maduración cervical con métodos farmacológicos y no farmacológicos. Es muy importante distinguir su uso como inductor del parto, del uso más frecuente actualmente, que es la estimulación y mantenimiento de la dinámica uterina durante el parto.

\section{A. FARMACOCINÉTICA}

La administración exógena de oxitocina produce contracciones uterinas desde la semana 20 de gestación. La respuesta va aumentando hasta la semana 34, desde la cual aumenta mucho más la respuesta, debido al comienzo de las contracciones espontáneas. Estos incrementos de la sensibilidad miometrial se deben al aumento de los receptores miometriales de oxitocina. El progreso del parto espontáneo no se relaciona con el aumento de la concentración de oxitocina. Las contracciones uterinas tampoco se asocian a cambios en la concentración plasmática de oxitocina y la hipocontractilidad no parece ser el resultado de un déficit de oxitocina. Sin embargo, variaciones en los genes de los receptores de oxitocina si parecen asociarse con la cantidad de oxitocina requerida durante la inducción y la duración del parto ${ }^{54}$.

La oxitocina es un péptido de 9 aminoácidos con una vida media corta (3-6 min). Por ello, son necesarios $40 \mathrm{~min}$ para que cualquier dosis de oxitocina alcance una concentración constante y consiga una respuesta uterina máxima.

\section{B. ADMINISTRACIÓN}

No es posible la vía oral ya que sería degradada en formas más pequeñas e inactivadas por las enzimas digestivas. Se puede emplear vía nasal e intravenosa. Por vía intravenosa, no tiene acción en el sistema nervioso central, dado que no atraviesa la barrera hematoencefálica.

Se administra intravenosamente a través de bombas de infusión continua. Cada hospital debería implementar un protocolo de perfusión de oxitocina para minimizar los posibles errores y complicaciones de administración. 
Un régimen común es crear una solución de 60 unidades de oxitocina en $1000 \mathrm{~mL}$ de un suero cristaloide ( $60 \mathrm{mU} / \mathrm{min}$ ), que permiten un ritmo de infusión en $\mathrm{mL} /$ hora para alcanzar la dosis deseada en $\mathrm{mU} / \mathrm{min}$.

\section{DOSIS DE INICIO Y MANTENIMIENTO}

Existen protocolos de baja y alta dosis (Tabla $4{ }^{74}$ ) pero ningún protocolo ha tenido la evaluación científica necesaria para demostrar su superioridad, eficacia y seguridad frente a otro. Los protocolos difieren en la dosis de comienzo (0.5-6 $\mathrm{mU} / \mathrm{min}$ ), en el período de tiempo entre incrementos (10-60 $\mathrm{min}$ ) y en la dosis máxima (16-64 $\mathrm{mU} / \mathrm{min}$ ), pero las tasas de éxito para los distintos protocolos y las complicaciones materno-perinatales son similares ${ }^{11}$.

Tabla 4. Protocolos de infusión de oxitocina, tomado de Wing DA en "Induction of labor with oxytocin" 74 .

\begin{tabular}{|l|c|c|c|}
\hline \multicolumn{1}{|c|}{ Régimen } & $\begin{array}{c}\text { Dosis inicio, } \\
\mathbf{m U / m i n}\end{array}$ & Aumento, mU/min & $\begin{array}{c}\text { Intervalo de } \\
\text { aumento, } \\
\text { minutos }\end{array}$ \\
\hline Baja dosis dosis & $0.5-1$ & 1 & $30-40$ \\
\hline $\begin{array}{l}\text { Baja } \\
\text { alternativa }\end{array}$ & $1-2$ & $1-2$ & $15-30$ \\
\hline Alta dosis & 6 & $\begin{array}{c}6 \\
\text { Si hiperestimulación } \\
\text { reducir el aumento a 3. } \\
\text { Si hiperestimulación } \\
\text { recurrente reducir el } \\
\text { aumento a 1. }\end{array}$ & $15-40$ \\
\hline $\begin{array}{l}\text { Alta dosis } \\
\text { alternativa }\end{array}$ & 4 & 15 \\
\hline
\end{tabular}

\section{EVALUACIÓN DE LA FCF Y DINÁMICA UTERINA}

Cuando se administra oxitocina, es imprescindible la monitorización continua de la FCF y la actividad uterina, para ajustar las dosis en función de la dinámica uterina (inadecuada o excesiva) y de la respuesta fetal a las contracciones (si aparecen desaceleraciones de la FCF, la dosis se puede reducir o suspender).

\section{E. EFECTOS ADVERSOS}

\section{- TAQUISISTOLIA}

- Se define según ACOG como > 5 contracciones en 10 min, durante al menos 30 min. Debe evaluarse si asocia cambios o no en la FCF. Estos cambios engloban: desaceleraciones persistentes, taquicardia o variabilidad a corto-plazo disminuida.

- El riesgo de taquistolia con oxitocina es muy variable entre estudios. Con los preparados de PG el riesgo es de hasta un 5\%, generalmente bien tolerado y no asociado a resultados adversos. Ocurre más frecuentemente con protocolos de altas dosis o cuando se asocia a PG.

- Las contracciones causan una interrupción intermitente del intercambio de sangre materno-fetal, pero una actividad excesiva uterina puede sobrepasar el nivel crítico para cada feto y resultar en una hipoxia fetal.

Raramente la taquisistolia produce una rotura uterina, y esto es más común en multíparas que en primíparas. 
- Si se producen cambios en la FCF, debe discontinuarse la infusión de oxitocina e iniciar medidas de resucitación intrauterina ${ }^{64}$ como: colocar a la madre en decúbito lateral izquierdo, administrar oxígeno en mascarilla nasal (10 L/min), corrección farmacológica de la hipotensión materna, amnioinfusión (introducción de solución salina a la cavidad uterina) y aumentar el fluido intravenoso ( $>500 \mathrm{~mL}$ de fluido cristaloide como Ringer Lactato). Si no se produjera respuesta, puede administrarse un tocolítico, como Ritodrina (agonista Beta2 mimético) en infusión continúa comenzando a 0,15 mg/min subiendo hasta que ceda la actividad uterina hasta $0,35 \mathrm{mg} / \mathrm{min}$, o en bolos repetidos (hasta 3 ) de $1 \mathrm{mg}$ separados al menos $10 \mathrm{~min}$ o como Atosibán (antagonista competitivo de oxitocina) $6.75 \mathrm{mg}$ en bolo de $1 \mathrm{~min}$.

- Si no se altera la FCF, se puede reevaluar la tasa de infusión de oxitocina, disminuyendo la dosis o discontinuando la perfusión. En este caso, cuando se reinicie la infusión, se recomienda a dosis bajas.

\section{- HIPONATREMIA}

Como la oxitocina tiene una estructura similar a la vasopresina puede unirse al receptor renal y producir una excesiva retención acuosa. Puede ocurrir hasta en el $5 \%$ de las parturientas, sobre todo cuando protocolos de altas dosis son administrados con más de $3 \mathrm{~L}$ de soluciones hipotónicas y en prolongados períodos de tiempo ( $\geq 7$ horas) ${ }^{75}$.

Una excesiva retención de líquido produciría hiponatremia, que de forma aguda y severa es causante de: cefalea, anorexia, náuseas, vómitos, dolor abdominal, letargia, inconsciencia, convulsiones tipo gran mal y lesión neurológica potencialmente irreversible.

El tratamiento consiste en suspender la infusión de oxitocina y soluciones hipotónicas, restringir la ingesta de agua y administrar suero salino hipertónico.

\section{- HIPOTENSIÓN}

La hipotensión y taquicardia pueden ser causados por una inyección rápida de oxitocina, tal y como se emplea en la prevención de hemorragia postparto administrando de bolos de $>5$ unidades. Con el uso habitual de la oxitocina en la inducción del parto, no se producen hipotensiones maternas. En casos extremos de hipotensión y taquicardia, se han descrito arritmias e infarto de miocardio.

- HIPERBILIRRUBINEMIA NEONATAL

No existe una clara relación directa con la oxitocina, podría deberse más bien a factores relacionados con la inducción, por ejemplo, una gestación pretérmino complicada.

\section{F. COMPLICACIONES}

\section{- TAQUISITOLIA}

Ver lo referido en el apartado de efectos adversos.

\section{- ROTURA UTERINA}

El riesgo de rotura uterina está aumentado durante la IP, pero el riesgo absoluto es bajo y la mayoría de los casos ocurren en mujeres con cicatriz uterina.

Un gran estudio prospectivo evaluó el riesgo de rotura uterina según el parto fuera de inicio espontáneo o inducido en mujeres con una o más cesáreas anteriores ( $n=17.898$ mujeres que intentan un PV tras cesárea y $n=15.801$ mujeres con cesárea repetida electiva). Mujeres que se indujeron sólo con oxitocina tuvieron un riesgo tres veces más alto de rotura uterina que las que iniciaron de forma espontánea el parto (OR 3.01, IC 95\% 1.66-5.46), aunque las diferencias absolutas de rotura uterina fueron pequeñas ${ }^{76}$. 


\section{- EMBOLISMO DE LÍQUIDO AMNIÓTICO}

Una gran cohorte poblacional retrospectiva de 3 millones de partos concluyó que la inducción del parto se asociaba con un aumento del riesgo de embolismo de LA (aOR 1.8, IC 95\% 1.2-2.7) ${ }^{77}$.

Sin embargo, el riesgo absoluto fue pequeño: 10.3 por 100.000 nacimientos tras inducción médica vs 5.2 por 100.000 nacimientos sin inducción médica. Sin embargo, dado que las pacientes se indujeron por razones médicas, la no inducción del parto podría potencialmente resultar en mayor morbilidad/mortalidad maternofetal que la propia inducción. Estos hallazgos deberían ser confirmados por otros autores antes de considerar introducir cambios en el manejo de la inducción.

\subsection{FRACASO DE INDUCCIÓN}

El resultado más frecuente de una inducción es el PV, aunque en menor porcentaje que las mujeres que inician el parto espontáneamente. La estimación global de fracaso de inducción para un cérvix desfavorable es del $15 \%{ }^{78} \mathrm{~m}$ (análisis de PG E2 en gel como método de maduración cervical e inducción en 59 estudios prospectivos, $n=3.313$ ). Un factor de mal pronóstico para PV es una puntuación baja del índice de Bishop, antes o después de la maduración cervical.

No hay un estándar universal para definir un fracaso de inducción, pero parece fundamental disponer de un tiempo suficiente para que se produzca la maduración cervical y el inicio de la fase activa del parto $(4 \mathrm{~cm})$. Respetando a las mujeres que progresan lentamente porque aún siguen en la fase latente del parto, se reduce el número de cesáreas indicadas por fracaso de inducción ${ }^{1}$.

El Colegio Americano de Obstetras y Ginecólogos en un Workshop junto con otras asociaciones, propone definir el fracaso de inducción como la incapacidad de producir contracciones regulares y cambios cervicales tras la administración de oxitocina durante las 12 horas posteriores a la rotura de membranas ${ }^{79}$. El objetivo es proveer criterios basados en la evidencia para disminuir el número de cesáreas por fracaso de inducción en la fase latente, extendiendo la fase latente $\geq 24$ horas y administrando oxitocina durante 12-18 horas tras la rotura de membranas. El tiempo de maduración cervical no está incluido cuando se calcula la duración de la inducción o se diagnostica un fracaso de inducción

\subsection{PREDICCIÓN DEL ÉXITO DE LA INDUCCIÓN}

La probabilidad del éxito de la inducción varía notablemente, influida por muchos factores, como las características epidemiológicas y clínicas de la paciente, la indicación de la inducción, la EG, el estado feto-placentario (PFE, insuficiencia placentaria), el manejo de la inducción, el estado cervical, así como de la elección del objetivo a alcanzar.

Se han estudiado multitud de factores que pueden influir en el resultado de la IP y también se ha intentado integrarlos en modelos predictivos del éxito o fracaso de la IP, con la finalidad de pronosticar el verdadero resultado de la IP.

\subsubsection{FACTORES PRONÓSTICOS DEL ÉXITO DE LA INDUCCIÓN}

\subsubsection{ESTADO CERVICAL}

Las características del cuello uterino son muy importantes para predecir el progreso y el éxito de la inducción del parto. Por eso, esas características se han descrito y cuantificado en varios sistemas de puntuación. Además, con estas puntuaciones 
podemos ofrecer maduración cervical ante puntaciones bajas para intentar mejorar el éxito de la inducción.

A día de hoy, la puntuación de Bishop ${ }^{50}$ parece ser la mejor herramienta para la evaluación del estado cervical. Revisiones sistemáticas concluyen que es igual o más efectivo para predecir el éxito de la inducción que la fibronectina fetal ${ }^{80}$ o la medida ecográfica de la longitud cervical ${ }^{81}$, y que la dilatación es el elemento más importante del score Bishop ${ }^{82,83}$.

A continuación, se repasa la historia de distintos sistemas de puntuación del estado cervical.

\section{A. PUNTUACIÓN DE CALKINS}

En 1930, Calkins y cols. ${ }^{84}$ identificaron factores que podrían predecir la duración de la inducción, publicando entonces la primera descripción del estado cervical con un sistema de puntuación, a través de una exploración rectal. Este sistema considera: la intensidad de las contracciones, el grosor de la pared cervical y la longitud del canal cervical, puntuándolos de 1 a 5 . Posteriormente propuso otros factores cervicales como borramiento cervical (presente o ausente), encajamiento de la presentación fetal, si se situaba en la espina ciática o pasada la espina, y consistencia cervical (puntuación 2, blando como los labios y 3 , duro como el ala nasal).

\section{B. PUNTUACIÓN DE COCKS}

En 1955, Cocks y cols. ${ }^{85}$ describieron 5 tipos de cérvix. Los tipos 1 y 2 se consideraron maduros, valorando la consistencia, borramiento y dilatación. Los tipos 3 y 4 se consideraron inmaduros. Un cérvix anómalo se catalogó como tipo 5. Concluyeron que, pacientes con cérvix inmaduros tenían con mayor frecuencia un parto con fórceps o cesárea y que pacientes con cérvix tipo 5 , un parto mediante cesárea.

\section{PUNTUACIÓN DE FIELDS}

En 1963, Fields y cols. ${ }^{86}$ presentaron un score similar al que al año siguiente presentaría Bishop. Además de los factores cervicales consideraron: EG, PFE, actitud de la paciente hacia la inducción, presencia de contracciones y aumento en la cantidad de flujo vaginal (Tabla 5). Una puntuación $\geq 16$ se consideraba favorable, excepto en nulíparas y presentación podálica, en cuyo caso precisarían una puntuación $\geq 18$. Describieron que puntuaciones $\leq 10$ se relacionaban con una tasa de complicaciones aumentada por 2 , con aumento de la duración del parto y de la tasa de parto operatorio. 
Tabla 5. Sistema de puntuación de Fields y cols. ${ }^{86}$.

\begin{tabular}{|c|c|c|c|}
\hline & \multicolumn{3}{|c|}{ SCORE } \\
\hline FACTOR & 0 & 1 & 2 \\
\hline $\begin{array}{l}\text { Tiempo de la inducción } \\
\text { respecto a FPP }\end{array}$ & $\begin{array}{c}\text { Incierto o }>3 \\
\text { antes }\end{array}$ & $\begin{array}{l}\text { 1-3 semanas } \\
\text { antes }\end{array}$ & $\begin{array}{l}<1 \text { semana } \\
\text { antes }\end{array}$ \\
\hline $\begin{array}{l}\text { Actitud respecto a la } \\
\text { inducción }\end{array}$ & $\begin{array}{l}\text { Opuesta, } \\
\text { temerosa }\end{array}$ & $\begin{array}{l}\text { Dudosa, } \\
\text { aceptable }\end{array}$ & Entusiasta \\
\hline PFE (g) & $<2.500$ & Incierto & $>2.500$ \\
\hline Tono uterino a palpación & Flácido & Algo de tono & Firme \\
\hline Consistencia cervical & Firme & Algo blando & Blando \\
\hline Borramiento (\%) & $<80$ & 80 & $>80$ \\
\hline Posición del eje cervical & Posterior & $\begin{array}{c}45 \text { grados } \\
\text { respecto al eje } \\
\text { vaginal } \\
\end{array}$ & Hacia la vulva \\
\hline $\begin{array}{l}\text { Estación de ra } \\
\text { presentación } \\
\text { (respecto espina } \\
\text { (cm) }\end{array}$ & $\leq-2$ & De -1 a 0 & $\geq+1$ \\
\hline Dilatación (cm) & $0-1$ & $2-3$ & $>3$ \\
\hline Flujo vaginal reciente & Sin cambios & Aumentado & $\begin{array}{l}\text { Teñido de } \\
\text { sangre }\end{array}$ \\
\hline
\end{tabular}

\section{PUNTUACIÓN DE BISHOP}

En 1964, Bishop ${ }^{50}$ describe un "score pélvico", actualmente conocido como la puntuación Bishop, usando ya la exploración vaginal del cérvix, y no rectal. Se basa en factores cervicales que previamente habían mostrado correlación con el éxito de la inducción del parto: dilatación, borramiento, consistencia, posición, y además la estación de la presentación fetal (Tabla 3). Bishop subrayó que su sistema de puntuación solo era apropiado para pacientes multíparas, con gestaciones no complicadas, a término y con fetos en presentación cefálica.

Tabla 3. Sistema de puntuación de Bishop ${ }^{50}$.

\begin{tabular}{|l|c|c|c|c|}
\hline \multicolumn{5}{|c|}{ TEST DE BISHOP } \\
\hline Factor & $\mathbf{0}$ & $\mathbf{1}$ & $\mathbf{2}$ & $\mathbf{3}$ \\
\hline Dilatación & 0 & $1-2 \mathrm{~cm}$ & $3-4 \mathrm{~cm}$ & $>5 \mathrm{~cm}$ \\
\hline Borramiento & $0-30 \%$ & $40-50 \%$ & $60-70 \%$ & $80-100 \%$ \\
\hline Consistencia & Dura & Media & Blanda & \\
\hline Posición & Posterior & Media & Anterior & \\
\hline $\begin{array}{l}\text { Estación pélvica de } \\
\text { la presentación }\end{array}$ & $-3 \mathrm{~cm}$ & $-2 \mathrm{~cm}$ & $-100 \mathrm{~cm}$ & $+10+2 \mathrm{~cm}$ \\
\hline
\end{tabular}

La mayoría de la evidencia apoya que puntuaciones altas del score Bishop ( $\geq 8)$ predicen una alta probabilidad de PV, similar a si el parto hubiera comenzado de forma espontánea ${ }^{87}$ pero una puntuación baja $(\leq 6)$, aunque asocie una mayor tasa de cesárea y menor probabilidad de PV, no es un buen predictor de probabilidad de cesárea ${ }^{88}$.

Los distintos métodos para la maduración cervical mejoran la probabilidad de PV en mujeres con puntuación baja del sistema Bishop, pero los puntos de corte óptimos para determinar si una puntuación Bishop es alta o baja no están bien definidos. Esta falta de acuerdo sobre los puntos de corte, dado que la consistencia cervical es una valoración subjetiva y que influyen otros factores distintos de la 
maduración cervical, afectan a la probabilidad de cesárea tras una inducción. Además, históricamente se ha comparado la probabilidad de cesárea tras inducción con las mujeres que iniciaban de forma espontánea el parto, pero la verdadera comparación clínica sería entre las mujeres que se inducen y las que persisten con manejo expectante.

\section{E. MODIFICACIONES DE LA PUNTUACIÓN BISHOP}

En un intento de aumentar la predicción de éxito de la inducción y disminuir la morbilidad asociada, se han propuesto algunas modificaciones de la puntuación original de Bishop. Pero ésta persiste, siendo hoy en día la más comúnmente empleada y para cualquier tipo de paciente, no solo para las que Bishop aconsejó (multíparas, a término, gestaciones no complicaciones y presentaciones cefálicas).

\section{I) BURNETT}

Su puntuación da a cada categoría Bishop un máximo de 2, para una puntuación total de $10^{89}$ (Tabla 6). Tuvo también algunas consideraciones como requisitos previos a una inducción: parto a término, presentación cefálica y no tener antecedente de cirugía mayor uterina. Con esta modificación, predecía que puntuaciones 9-10 conseguían el parto en $<4$ horas, puntuaciones 6-8 parían dentro de las 6 horas y que el resultado era imprevisible para puntuaciones $<6$.

Tabla 6. Puntuación modificada de Bishop según Burnett ${ }^{89}$.

\begin{tabular}{|l|c|c|c|}
\hline Factor & \multicolumn{3}{|c|}{ Puntuación } \\
\hline & $\mathbf{0}$ & $\mathbf{1}$ & $\mathbf{2}$ \\
\hline Dilatación del cérvix & $<1 \mathrm{~cm}$ & $1-2 \mathrm{~cm}$ & $>2 \mathrm{~cm}$ \\
\hline Longitud cervical & $>2 \mathrm{~cm}$ & $1-2 \mathrm{~cm}$ & $<1 \mathrm{~cm}$ \\
\hline Posición del cérvix & Posterior & Media & Anterior \\
\hline $\begin{array}{l}\text { Consistencia del } \\
\text { cérvix }\end{array}$ & Firme & Blando & $\begin{array}{c}\text { Bando y } \\
\text { estirable }\end{array}$ \\
\hline Estación de la cabeza & $\geq-2 \mathrm{~cm}$ & $-1 \mathrm{~cm}$ & $\geq 0$ \\
\hline
\end{tabular}

\section{II) FRIEDMAN Y COLABORADORES}

Estos autores encuentran que los factores de la puntuación Bishop influyen en distinta proporción en la duración de la fase latente del parto, tras relacionar de forma inversa la duración de la fase latente con la puntuación cervical preinducción ${ }^{90}$. Por lo que proponen que se gradúe el peso de los factores ${ }^{91}$, así la dilatación supondría 2 veces el peso de consistencia, estación y borramiento, y 4 veces el peso de posición.

\section{III) CALDER}

Esta puntuación ${ }^{92}$, empleada frecuentemente en Reino Unido, utiliza la longitud cervical en $\mathrm{cm}$ y no el borramiento cervical en porcentaje y hace la medida de la estación de la presentación en $\mathrm{cm}$ y no dividiendo a la pelvis en tercios, como hizo originariamente Bishop. En esta modificación, la posición media del cérvix se asemeja a la posición anterior.

\section{IV) LANGE Y COLABORADORES}

En 1982, Lange y cols. ${ }^{93}$, evalúan 1.189 pacientes que iban a inducirse por razones médicas o por RPM. Confirman que la puntuación Bishop con la longitud cervical y la estación de la presentación en $\mathrm{cm}$, se correlaciona 
bien con el éxito de la inducción. Tras un análisis de regresión logística, determinan que la dilatación es el factor más determinante de la puntuación Bishop y que se debía multiplicar por 2 la puntuación obtenida en este punto (Tabla 7).

Tabla 7. Puntuación pélvica propuesta por Lange y cols. ${ }^{93}$.

\begin{tabular}{|l|c|c|c|c|c|}
\hline \multicolumn{7}{|c|}{ Puntuación } \\
\hline Factor & $\mathbf{0}$ & $\mathbf{1}$ & $\mathbf{2}$ & $\mathbf{3}$ & $\begin{array}{c}\text { Multiplicar } \\
\text { por }\end{array}$ \\
\hline Dilatación (cm) & 0 & $1-2$ & $3-4$ & $>4$ & X 2 \\
\hline Longitud (cm) & 3 & 2 & 1 & 0 & X 1 \\
\hline Estación (cm) & -3 & -2 & -100 & $+10+2$ & X 1 \\
\hline
\end{tabular}

\section{V) BISHOP SIMPLIFICADO}

En 2011, Laughon y cols., en una cohorte de más de 5.400 nulíparas con inducción a término, comprueban que sólo 3 de los 5 factores Bishop (dilatación, estación y borramiento) se asocian de forma significativa con el parto vaginal ${ }^{94}$. Este score Bishop, simplificado con 3 componentes, predice PV con similares o mejores resultados que el score Bishop original (VPP $87.7 \%$ vs $87 \%$, VPN $31.3 \%$ versus $29.8 \%$, LHR+ 2.34 vs 2.19 y correcta tasa de clasificación $51 \%$ vs $47.3 \%)$.

\section{VI) BISHOP SIMPLIFICADO INCLUYENDO PARIDAD}

En 2016, Ivars y cols. proponen utilizar una puntuación Bishop simplificada incluyendo la paridad ${ }^{95}$. Realizan un estudio retrospectivo sobre 326 mujeres inducidas, mediante análisis uni/multivariante de la relación entre el éxito de la inducción (PV) y los componentes de la puntuación Bishop y la paridad. Retirando la posición y la consistencia del score Bishop y añadiendo la paridad, mejora de forma significativa la predicción del éxito de la inducción (AUC: 0.68, p=0.001).

\subsubsection{MEDIDAS ECOGRÁFICAS}

El papel de la ecografía para seleccionar mujeres que probablemente finalicen con éxito una inducción del parto es incierto.

Múltiples estudios valoran estos factores ecográficos, comparándolos fundamentalmente con la puntuación Bishop, actualmente única herramienta utilizada de forma universal como valoración previa a una inducción.

Varios autores ${ }^{51,96}$ y revisiones sistemáticas ${ }^{80,97}$ no dan superioridad a la evaluación de medidas ecográficas frente al Bishop, en la predicción del éxito de la inducción.

Sin embargo, otros estudios sí demuestran superioridad de predicción del éxito de la inducción con medidas ecográficas frente al score Bishop ${ }^{82,98,99}$.

La principal limitación al extraer todas estas conclusiones es que las poblaciones de los estudios no son comparables, pues unos incluyen solo nulíparas, otros excluyen RPM o cesárea anterior, no existe consenso sobre los puntos de corte de las distintas variables, no hay uniformidad en el manejo de la inducción, y la definición del éxito de la inducción también varía de unos a otros.

A pesar de la precisión ecográfica de la medida de la longitud cervical, el desarrollo de medidas ecográficas para otras características cervicales, como consistencia o 
dilatación no ha sido evaluado. Estas medidas morfológicas obtenidas por ecografía son limitadas para predecir el fracaso de inducción, y para este fin podrían necesitarse otros marcadores biológicos, como fibronectina fetal ${ }^{51}$.

El resto de los factores de la puntuación Bishop intentan valorarse ecográficamente con la medida de la LC (borramiento), ACP (posición) y DCP (posición y encajamiento de la cabeza en relación con la estación pélvica).

\section{A. LONGITUD CERVICAL}

La medida ecográfica de la LC para la prevención del parto prematuro está más que validada actualmente ${ }^{100}$. No ocurre lo mismo cuando se estudia en relación con la predicción del éxito de la inducción.

En una revisión sistemática de 31 estudios prospectivos ${ }^{81}$, que incluyeron 5.029 mujeres, la medida ecográfica de la LC no resultó significativamente superior al Bishop en la predicción del éxito de la inducción.

Dividieron los estudios por objetivos primarios: parto por cesárea (22 estudios, $\mathrm{n}=3922$ ), PV > 24h (7 estudios, $\mathrm{n}=886$ ) y no alcanzar la fase activa del parto (2 estudios, $\mathrm{n}=211$ ).

Los resultados de predicción de cesárea para distintos puntos de corte de LC fueron:

- $20 \mathrm{~mm}: \mathrm{S}=82 \%, \mathrm{E}=34 \%, \mathrm{LHR}+1.2$ y LHR- 0.53 .

- $30 \mathrm{~mm}: \mathrm{S}=64 \%, \mathrm{E}=74 \%$, LHR+ 2.5 y LHR- 0.49 .

- $40 \mathrm{~mm}: \mathrm{S}=13 \%, \mathrm{E}=95 \%$, LHR+ 2.6 y LHR- 0.92 .

Los resultados de predicción de $\mathrm{PV}>24$ horas según distintos puntos de corte de la LC fueron:

- $25 \mathrm{~mm}: \mathrm{S}=58 \%, \mathrm{E}=80 \%$, LHR+ 2.9 y LHR- 0.53 .

- $32 \mathrm{~mm}: \mathrm{S}=84 \%, \mathrm{E}=60 \%$, LHR+ 2.1 y LHR- 0.27 .

Los autores no calcularon los puntos de corte para la predicción de no alcanzar la fase activa de parto.

Existe gran heterogeneidad entre los estudios, por lo que estos datos son limitados. Sería preciso incluir en estos metaanálisis la evaluación de múltiples factores concurrentes como paridad, EG o método de inducción, entre otros.

En cambio, otros autores sí encuentran que la LC ecográfica es mejor predictor del éxito de la inducción que la puntuación Bishop:

- LC COMO PREDICTOR DE PARTO VAGINAL: El objetivo principal del estudio observacional de Gómez y cols. ${ }^{101}$ sobre 177 mujeres, entre 36-42 semanas con maduración cervical (PG) y oxitocina, fue lograr un PV en $<60$ horas. Tanto la puntuación Bishop, como la paridad y la LC contribuyeron de forma independiente a la probabilidad de PV en $<60$ horas. El AUC fue mayor para LC (0.76) que para Bishop (0.65). Los mejores puntos de corte para predecir el PV en $<60$ horas fueron: $\mathrm{LC}=24 \mathrm{~mm} \mathrm{(S=66 \% ,} \mathrm{E}=77 \%)$ y Bishop=4 ( $S=77 \%, E=56 \%)$.

Concluyeron que la medida ecográfica de la LC fue mejor predictor de PV $<$ 60 horas que la puntuación Bishop.

- LC COMO PREDICTOR DE PARTO VAGINAL Y DEL INTERVALO INDUCCIÓNPARTO: Estos fueron los resultados primarios de Elgohorori y cols. ${ }^{102}$ en un estudio prospectivo de 107 gestaciones únicas a término que iban a inducirse. Las AUC (LC 0.87 y B 0.67) mostraron los puntos de corte 
óptimos para predecir PV, que fueron: $\mathrm{LC} \leq 34 \mathrm{~mm}(\mathrm{~S}=62.1 \%, \mathrm{E}=100 \%)$ y $\mathrm{B}$ $>5(\mathrm{~S}=23 \%, \mathrm{E}=88.2 \%)$.

El punto de corte $\leq 34 \mathrm{~mm}$ para LC obtuvo mayor sensibilidad para la predicción de PV en multíparas que en nulíparas (85.1\% vs $35 \%)$. Y el punto de corte $\mathrm{LC}>35 \mathrm{~mm}$ tuvo mayor sensibilidad para la predicción del intervalo inducción-parto en nulíparas frente a multíparas ( $85.3 \%$ vs $30 \%$ ). Por tanto, la medida ecográfica de la LC fue mejor predictor de PV y de intervalo inducción-parto que la puntuación Bishop.

- LC COMO PREDICTOR DE ÉXITO DE LA MADURACIÓN CERVICAL Y DE PV: Con estos objetivos, Kehila y cols. ${ }^{103}$ realizan un estudio observacional sobre 77 mujeres nulíparas de 41 semanas con puntuación Bishop $\leq 5$. Todas las pacientes recibieron maduración cervical con PG previa a la inducción oxitócica. Tras análisis de regresión logística, demuestran que la LC ecográfica es el único predictor de éxito independiente para ambos objetivos primarios.

Los mejores puntos de corte de LC fueron: $34.6 \mathrm{~mm}$ para predecir el éxito de la maduración cervical y $32.5 \mathrm{~mm}$ para predecir el PV. Se conseguía un PV en el $90 \%$ de las ocasiones si $L C<32.5 \mathrm{~mm}$ y en el $50 \%$ de los casos si LC $>32.5 \mathrm{~mm}$.

Por tanto, comparado con la puntuación Bishop, la medida ecográfica de la LC resultó ser mejor predictor de éxito de la maduración cervical y de PV en nulíparas de 41 semanas con cérvix desfavorable.

\section{B. DILATACIÓN ECOGRÁFICA}

Es la medida transversa del canal endocervical, entendido como la banda hipoecoica que existe entre $\mathrm{OCl}$ y $\mathrm{OCE}$, que podría ser comparada con la dilatación de la puntuación Bishop, que es subjetiva.

Eggebo y cols. en $2009{ }^{83}$, manifiestan que no existe mucha correlación entre la medida ecográfica del canal endocervical y la dilatación cervical mediante tacto vaginal.

Sin embargo, Pitarello y cols. en $2013{ }^{104}$, sí que demuestran que influye de forma significativa en el éxito de la inducción. Realizan un estudio prospectivo sobre 190 mujeres a término que iban a ser inducidas, evaluando la medida ecográfica de la dilatación cervical como predictora de PV global y de PV $<24$ horas. El manejo de la inducción fue: solo misoprostol intravaginal, solo oxitocina intravenosa o combinación de misoprostol y oxitocina.

Tras el análisis univariante, la dilatación ecográfica se asoció de forma significativa al éxito de la inducción:

- Para conseguir PV: con punto de corte $7.4 \pm 2.6$ mm OR: 1.4 (IC 95\% 1.21.6, $\mathrm{p}<0.01)$.

- Para conseguir PV <24 horas: con punto de corte $7.6 \pm 2.6 \mathrm{~mm}$ OR: 1.4 (IC $95 \%$ 1.2-1.7, $p<0.01$ ).

\section{C. ÁNGULO CERVICAL POSTERIOR (ACP)}

Es el ángulo formado por 2 líneas que convergen en el OCl: una pasa por el canal endocervical y otra por la pared uterina posterior.

Una revisión de la literatura ${ }^{104}$, expresa que la relación del ACP con el resultado de la inducción no es concluyente. 
Otros autores sí han encontrado relación con el resultado de la inducción:

- ACP COMO PREDICTOR DEL COMIENZO DEL PARTO < 12 HORAS Y PARTO VAGINAL: Prado y cols. ${ }^{105}$ estudian una cohorte prospectiva de 204 embarazos a término que van a inducirse. Encuentran que la variable ecográfica ACP es válida para la predicción del PV, pero no para el inicio del parto $<12$ horas, con una potencia limitada $(S=66.4 \%, E=59.1 \%$, área bajo la curva ROC 0.63).

- ACP COMO PREDICTOR DE PARTO VAGINAL:

- Eggebo y cols. ${ }^{83}$ realizan un estudio prospectivo de 275 mujeres a término sin cesárea anterior que iban a inducirse, tanto con misoprostol como con oxitocina. Encuentran que un $\mathrm{ACP}<90^{\circ}$ predice el éxito de la inducción, con una OR=2.6 (IC 95\% 1.1-6.1, p=0.003).

- Keepanasseril y cols. ${ }^{98}$ estudian 145 mujeres nulíparas, entre 34-41 semanas, sin cesárea anterior. El manejo fue con misoprostol solo o con combinación de dinoprostona y oxitocina. Tras análisis múltiple de regresión logística, el ACP mostró predicción del éxito de la inducción de forma independiente. En las curvas ROC, el mejor punto de corte fue un $A C P$ de $100^{\circ}$ con $S=65 \%, E=72 \%$ y $A U C=0.741$ ( $\left.p<0.001\right)$.

- ACP COMO PREDICTOR DEL INTERVALO INDUCCIÓN-PARTO, PARTO VAGINAL <24 HORAS Y CESÁREA: Rane y cols. ${ }^{106}$ describen la inducción de 604 mujeres entre 35-42 semanas. Tras el análisis multivariante, para un $A C P \geq 120^{\circ}$ obtienen una $O R=1.57(1.02-2.39, p=0.038)$ y concluyen que la predicción del éxito de la inducción es superior con la evaluación de medidas ecográficas (LC, ACP y posición occipital) que con la puntuación Bishop.

\section{FORMA DEL ACUÑAMIENTO CERVICAL}

Es la forma que presenta el $\mathrm{OCl}$ mediante exploración ecográfica, similar a una $T$, una $\mathrm{V}$ o una $\mathrm{U}$. La presencia de embudización o funneling consiste en la dilatación del $\mathrm{OCl}$, generando un triángulo cuyo vértice está en el canal cervical, y correspondería con el patrón de acuñamiento $\mathrm{V} \circ \mathrm{U}^{51}$, ya que el $\mathrm{T}$ no tendría dilatación del OCl.

Roman y cols. ${ }^{51}$ estudian 106 mujeres con puntuación Bishop $\leq 5$, a las que inducen con gel de PG E2 o con oxitocina/amniotomía. El signo funneling está presente en el $27 \%$ de las pacientes y obtienen un bajo VPP para fracaso de inducción (17.9\%).

Otros autores sí relacionan el acuñamiento cervical con el resultado de la inducción:

- En una revisión sistemática de estudios controlados $(20, n=3101)$ de Hatfield y cols. ${ }^{97}$, la presencia de acuñamiento predijo el éxito de la inducción con un LHR+ 2.64 (IC 95\% 1.79-3.88), LHR- 0.64 (IC 95\% 0.460.88), una $S=43.8 \%$ (IC 95\% 29.2-65.6\%), una $E=82.7 \%$ (IC 95\% 75.4\%$97.7 \%$ ) y un AUC de 0.80 .

○ Sieroswewsky y cols. ${ }^{99}$, comparando los valores predictivos del éxito de la inducción entre puntuación Bishop y medidas ecográficas, encuentran correlación significativa entre el acuñamiento cervical y el resultado de la inducción, concluyendo que la evaluación ecográfica muestra mejor valor predictivo que el score Bishop. 


\section{E. DISTANCIA CÉFALO-PERINEAL}

El examen digital no evalúa de forma precisa la posición y el descenso de la cabeza fetal durante la primera y segunda etapas del parto.

La estación fetal se evalúa mediante el tacto vaginal como la relación entre la cabeza fetal y la espina ciática.

Según la OMS, la distancia de la espina ciática al periné es de $5 \mathrm{~cm}$.

Sin embargo, la espina ciática es difícil de visualizar por ecografía.

Lewin y cols. en 1977 107, sugieren medir la distancia entre la cabeza fetal y la punta del sacro. Y Sherer en $2007^{108}$, relaciona el encajamiento de la cabeza fetal con la medida ecográfica entre sínfisis del pubis y cabeza fetal.

Eggebo y cols. ${ }^{109}$ introducen la DCP, que es una medida más sencilla de realizar, como distancia entre la piel perineal y la cabeza fetal, a través de ecografía transperineal. Proponen que, como el canal del parto es curvado, habrá asociación, pero no relación directa, entre la DCP y la estación de la cabeza fetal.

La medida ecográfica de la DCP no había sido evaluada como predictora del éxito de la inducción, hasta que Eggebo y cols. ${ }^{109}$ encontraron que predecía el resultado del parto en mujeres con RPM a término ( $n=152)$, estableciendo el punto de corte en $45 \mathrm{~mm}$. Con DCP $\geq 45 \mathrm{~mm}$ se predecía el parto instrumental o por cesárea: $\mathrm{S}=83 \%, \mathrm{VPP}=31 \%, \mathrm{VPN}=89 \%$, LHR+ 1-4.

Posteriormente, Eggebo y cols. ${ }^{83}$ concluyen que la combinación de medidas ecográficas (LC, ACP, DCP) y la exploración digital de la dilatación predice el éxito o fracaso de la inducción en un 71\% (IC 95\% 61-80\%, p<0.01), pero de forma independiente la DCP no es útil. Establecieron el punto de corte para DCP en $\leq 40$ $\mathrm{mm}$.

Hafiz ${ }^{110}$, realiza un estudio prospectivo, incluyendo RPM $(n=100)$, y evalúa la capacidad predictiva para PV o cesárea $\leq 24$ horas de: puntuación Bishop, LC y DCP. Los mejores puntos de corte predictivos fueron: $\mathrm{LC} \leq 33 \mathrm{~mm}$ y $\mathrm{DCP} \leq 86 \mathrm{~mm}$. DCP y LC obtuvieron mayor predicción de éxito de la inducción que puntuación Bishop, con las siguientes AUC:

- DCP 78\% (IC 95\% 61-95\%, p=0.04)

- LC 73\% (IC 95\% 61-94\%, $p=0.05$ )

- Bishop 59\% (IC 95\% 34-85\%, p=0.046)

\subsubsection{MARCADORES BIOQUÍMICOS}

\section{A. FIBRONECTINA FETAL}

La fibronectina fetal es una glicoproteína presente en el LA y en el espacio entre la decidua y el corion. Cuando se acerca el inicio del parto, la FNF puede detectarse en el flujo cervical y vaginal (QuikCheck ${ }^{\circledast}$ fFN de Hologic, Kit de Prueba rápida de oro coloidal ${ }^{\circledR}$ de Beijing Hotgen Biotech Co. Ltd, ...).

Inicialmente se describió como factor predictor del parto prematuro y solamente pocos autores han sugerido que puede ser un buen predictor del resultado de la inducción.

Roman y cols. ${ }^{51}$ realizan un estudio prospectivo para comparar medidas ecográficas y FNF frente a puntuación Bishop, en relación al resultado de la inducción, en 106 mujeres con cérvix desfavorable. No encuentran relación 
significativa de la FNF con el fracaso de la inducción, resultado similar a lo publicado por otros autores ${ }^{111,112}$. En cambio, Crane y cols. ${ }^{80}$ tras una revisión sistemática, encuentran que la FNF sí predice el éxito de la inducción, pero de forma no superior a la puntuación Bishop.

Por ello, son necesarios más estudios, incluidos de coste-beneficio, para aclarar si esta prueba $u$ otros marcadores bioquímicos pueden ser potenciales predictores del resultado de la inducción.

\section{B. PROTEÍNA TRANSPORTADORA DEL FACTOR DE CRECIMIENTO SIMILAR A LA INSULINA-1 (IGFBP-1)}

La IGFBP-1 es producida por el sincitiotrofoblasto, citotrofoblasto y la decidua, por lo que su concentración es mucho más alta en el LA que en la secreción cervical.

Su detección cérvico-vaginal se ha utilizado potencialmente para identificar a mujeres en riesgo de parto pretérmino que no parirán en las siguientes 48 horas, ya que ayuda a detectar la rotura de membranas (ACTIM-PROM ${ }^{\circledR}$ de Laboratorios Rubió).

En mujeres que van a ser inducidas, la mediana de concentración de IGFBP-1 en cérvix favorables es cuatro veces mayor que en cérvix desfavorables ${ }^{113}$.

En el análisis secundario de un estudio randomizado de mujeres nulíparas y multíparas en vías de prolongación, IGFBP-1 predijo tanto el comienzo espontáneo del parto como el éxito de la inducción ${ }^{114}$.

Vallikkannu y cols. ${ }^{115}$, realizan un estudio prospectivo sobre 193 nulíparas con membranas íntegras, para evaluar el papel de IGFBP-1 como predictor del éxito de la inducción comparado con puntuación Bishop y LC ecográfica.

La muestra cervical se recogió a través de un espéculo vaginal y a continuación se evaluó la puntuación Bishop y la LC por ecografía vaginal.

IGFBP-1 predijo el PV (aOR=5.5, IC 95\% 2.3-12.9, $\mathrm{p}<0.001)$ y el $\mathrm{PV}<24$ horas (aOR=4.9, IC 95\% 2.1-11.6, $p<0.006)$ tras ajustar por puntuaciones Bishop $(\geq 40 \geq$ 5) y $L C(\leq 29 \mathrm{~mm}$ o $\leq 27 \mathrm{~mm})$. Para obtener PV tuvo una $\mathrm{S}=81 \%, E=59 \%, V P P=82 \%$, VPN=58\%, LHR+ 2.0 y LHR- 0.3 .

Concluyen que, IGFBP-1 es mejor predictor de parto vaginal que puntuación Bishop y LC, y que puede ayudar a tomar decisiones respecto a la inducción de nulíparas.

\subsubsection{CARACTERÍSTICAS DE LA POBLACIÓN}

Varias publicaciones han descrito menores tasas de cesárea en inducciones electivas a término cuando se comparaba con el manejo expectante. Estos datos se han confirmado en diversos tipos de poblaciones y se han controlado por potenciales factores de confusión. Por tanto, la simple decisión de inducir puede ser mejor predictor del resultado de la inducción, que múltiples características de la población. Es más probable que una inducción sea exitosa en las siguientes circunstancias ${ }^{80,94}$ :

- Gestación a término

- Multípara sin relación con la puntuación Bishop

- Mujeres con bolsa rota

- Mujeres con un parto vaginal previo

- Mujeres altas y no obesas

- Recién nacido previo con peso inferior a $4.000 \mathrm{gr}$

- Mujeres sin comorbilidades asociadas con insuficiencia placentaria 
A continuación, se amplía la información de las características poblacionales más relevantes en relación con la predicción de la inducción.

\section{A. PARIDAD}

Es un fuerte predictor del resultado de la inducción, tanto para PV como para intervalo inducción-parto ${ }^{95,96,116}$.

En población nulípara, hay autores que han demostrado que la puntuación Bishop es un buen predictor, tanto en cérvix desfavorables como en favorables.

Por otra parte, el riesgo de cesárea fue menor para cada semana adicional de gestación (de 37 hasta 39 semanas) con inducción electiva frente al manejo expectante, en relación a la paridad y al score Bishop ${ }^{88}$.

Sin embargo, la comparación entre inducción y parto espontáneo no es una alternativa real, como tampoco lo es ser nulípara o multípara.

Por lo tanto, la premisa ideal debería ser cómo y cuándo sería el momento óptimo para inducir a una mujer nulípara.

\section{B. TAMAÑO FETAL Y EDAD GESTACIONAL}

Ambas características pueden ser factor de confusión en los resultados de inducción dado que se interrelacionan. Se complica aún más en relación con la pelvis materna, dado que desconocemos qué tamaño fetal máximo es el adecuado para cada pelvis.

En 2005, un estudio en los Países Bajos ${ }^{117}$, describió el riesgo de cesárea tras inducción de nulíparas, en relación con el peso al nacimiento:

- 3.500 gr: aOR= 1.66 (IC 95\% 1.22-2.47).

- 4.000 gr: $\mathrm{aOR}=2.38$ (IC 95\% 1.45-3.91).

Datos retrospectivos reportan que inducir a menor EG, antes del desarrollo de macrosomía fetal, asocia mejores tasas de parto vaginal.

Tanto para sospecha de macrosomía como no, la inducción a menor EG se asocia a disminución o no diferencia en la tasa de cesárea comparado con el manejo expectante. Esta relación se mantiene para gestación a término (39-40+6), a término tardío $(41-41+6)$ y postérmino $(42-42+6)^{88}$.

\section{INDICE DE MASA CORPORAL}

La obesidad por sí misma se ha asociado al fracaso de la inducción y así lo refrendan varios autores:

- Vrouenraets (117) exponen que un IMC $>30 \mathrm{~kg} / \mathrm{m} 2$ muestra una aOR de 2.87 (IC 95\% 1.84-4.48) para fracaso de inducción.

- Bajpai y cols. ${ }^{82}$ (asociaron de forma significativa un IMC $>30 \mathrm{~kg} / \mathrm{m} 2$ con un alto porcentaje de fracaso de inducción $(37.5 \%$ vs $19,4 \%$ para IMC $<30$ $\mathrm{kg} / \mathrm{m}^{2}, \mathrm{p}=0.032$ ).

\section{ALTURA MATERNA}

Aunque es un factor incluido en el IMC, por sí misma la talla materna, se ha relacionado en varios modelos predictivos con el resultado de la inducción de forma inversa, es decir, a menor altura materna más riesgo de cesárea como resultado de la inducción. 


\section{E. EDAD MATERNA Y COMORBILIDADES}

Se ha demostrado un aumento del riesgo de muerte intrauterina a mayor edad materna.

Las cohortes antiguas encontraban que, en mujeres de más edad, tanto nulíparas como multíparas, aumentaba la duración del parto, pero estudios más recientes encuentran lo contrario, menor duración del parto a mayor edad.

A mayor edad también aumentan las enfermedades crónicas que por frecuencia pueden aparecer y estas mujeres, que retrasan la maternidad, se encuentran con estas patologías afrontando un embarazo.

Sin embargo, no se ha demostrado relación significativa entre los resultados de la inducción y el manejo expectante en las mujeres con diabetes gestacional, diabetes mellitus e hipertensión crónica.

\subsubsection{SISTEMAS DE PUNTUACIÓN CON MEDIDAS ECOGRÁFICAS}

\section{A. ELGOHORORI}

Elgohorori y cols. ${ }^{118}$ publican un estudio con 104 gestaciones a término, en las que realizan 2 valoraciones preinducción, una con la puntuación Bishop y otra con una puntuación Bishop modificada, en la que reemplazan la valoración digital de la longitud cervical por la longitud cervical ecográfica. Encuentran diferencias significativas entre ambas puntuaciones.

La puntuación Bishop modificada por ecografía mostró asociación significativa con el modo de parto y más aún con el intervalo inducción-parto, en comparación con la puntuación Bishop que no mostró asociación significativa.

Las AUC determinaron los óptimos puntos de corte para predecir PV:

- Bishop > 5: $\mathrm{S}=23 \%, \mathrm{E}=88.2 \%$.

- Bishop modificado > 3: $S=62 \%$, $E=82 \%$.

Por tanto, la puntuación Bishop modificada por ecografía es mejor que la puntuación original para predecir el intervalo inducción-parto y el éxito de la inducción.

\section{B. EGGEBO}

Eggebo y cols. ${ }^{83}$, realizan un estudio prospectivo comparativo en 275 gestaciones a término para valorar la tasa global de PV. Previamente a la inducción realizan 2 exploraciones a cada paciente: digitalmente (puntuación Bishop) y ecográficamente (LC, ACP, dilatación y DCP). Tras el análisis univariante, obtienen como predictores de éxito de la inducción, la dilatación cervical como único factor del score Bishop y 3 de las 4 medidas ecográficas realizadas $\left(L C \leq 25 \mathrm{~mm}, A C P>90^{\circ}\right.$ y DCP $\leq 40 \mathrm{~mm}$ ).

Por tanto, proponen una puntuación simplificada de 0 a 4 en base a medidas ecográficas y a la dilatación cervical digital (Tabla 8).

Tabla 8. Puntuación propuesta con combinación de medidas ecográficas y dilatación cervical digital, según Eggebo y cols. ${ }^{83}$.

\begin{tabular}{|l|c|c|}
\hline Factor & \multicolumn{2}{|c|}{ Puntuación } \\
\hline & $\mathbf{0}$ & $\mathbf{1}$ \\
\hline DCP & $>40 \mathrm{~mm}$ & $\leq 40 \mathrm{~mm}$ \\
\hline LC & $>25 \mathrm{~mm}$ & $\leq 25 \mathrm{~mm}$ \\
\hline ACP & $\leq 90^{\circ}$ & $>90^{\circ}$ \\
\hline Dilatación cervical digital & Cerrado & Dilatado \\
\hline
\end{tabular}




\section{SIEROSZEWSKI}

Sieroszewski y cols. ${ }^{99}$ realizan un estudio prospectivo en 101 mujeres para comparar el valor predictivo del resultado de inducción de las medidas ecográficas frente a la puntuación Bishop. Obtienen predicción significativa con los puntos de corte del score Bishop (7.21 versus 5.5, $\mathrm{p}<0.001)$ y respecto a las medidas ecográficas, mostraron correlación significativa independiente, el ACP, la LC (punto de corte $23.5 \mathrm{~mm}$ ) y la forma $V$ del acuñamiento cervical.

Crean una puntuación para medidas ecográficas, graduada de $0-10$, con el punto de corte 4.5 significativo de éxito en el resultado de la IP.

Así concluyen que estas medidas ecográficas tienen un mejor valor predictivo que la puntuación Bishop.

\section{BAJPAI}

Bajpai y cols. ${ }^{82}$ estudian una muestra de 107 mujeres a término, con membranas íntegras y sin cesárea previa, a las que se evalúa mediante examinación vaginal (puntuación modificada de Bishop según Burnett ${ }^{89}$ (Tabla 6) y ecografía transvaginal. Mediante ecografía se puntúan 5 características que intentan compararse con los factores de la puntuación Bishop, que son: longitud cervical, longitud Funnel, anchura Funnel, posición del cérvix y distancia de la presentación al OCE (Tabla 9).

Tabla 6. Puntuación modificada de Bishop (Rango: 0-10) tomada de Burnett en "Preinduction scoring: an objective approach to induction of labor" ${ }^{89}$.

\begin{tabular}{|l|c|c|c|}
\hline Factor & \multicolumn{3}{|c|}{ Puntuación } \\
\hline & $\mathbf{0}$ & $\mathbf{1}$ & $\mathbf{2}$ \\
\hline Dilatación del cérvix & $<1 \mathrm{~cm}$ & $1-2 \mathrm{~cm}$ & $>2 \mathrm{~cm}$ \\
\hline Longitud cervical & $>2 \mathrm{~cm}$ & $1-2 \mathrm{~cm}$ & $<1 \mathrm{~cm}$ \\
\hline Posición del cérvix & Posterior & Media & Anterior \\
\hline Consistencia del cérvix & Firme & Blando & Bando y estirable \\
\hline Estación de la cabeza & $\geq-2 \mathrm{~cm}$ & $-1 \mathrm{~cm}$ & $\geq 0$ \\
\hline
\end{tabular}

Tabla 9. Puntuación cervical mediante ecografía transvaginal (Rango: 0-10), según Bajpai y cols. ${ }^{82}$.

\begin{tabular}{|l|c|c|c|}
\hline Factor ecográfico & \multicolumn{3}{|c|}{ Puntuación } \\
\hline & $\mathbf{0}$ & $\mathbf{1}$ & $\mathbf{2}$ \\
\hline Longitud cervical & $>3 \mathrm{~cm}$ & $2-3 \mathrm{~cm}$ & $<2 \mathrm{~cm}$ \\
\hline Longitud Funnel & Ausente & $\leq 0.5 \mathrm{~cm}$ & $>0.5 \mathrm{~cm}$ \\
\hline Anchura Funnel & Ausente & $\leq 0.5 \mathrm{~cm}$ & $>0.5 \mathrm{~cm}$ \\
\hline Posición del cérvix & Curvado & - & Recto \\
\hline $\begin{array}{l}\text { Distancia de la } \\
\text { presentación al al } \\
\text { orificio cervical } \\
\text { externo }\end{array}$ & $>3 \mathrm{~cm}$ & $2-3 \mathrm{~cm}$ & $<2 \mathrm{~cm}$ \\
\hline
\end{tabular}

Resultaron ser predictores del éxito de la inducción (alcanzar la fase activa de parto $<24$ horas), solamente la dilatación respecto de la puntuación Bishop y respecto de las medidas ecográficas, solo la LC y la distancia de la presentación al OCE. 
Obtuvieron puntos corte de ambas puntuaciones, concluyendo que esta puntuación ecográfica en lugar de la puntuación Bishop es una herramienta útil para predecir el resultado de la inducción. Una puntuación ecográfica $\geq 4$ demostró una mayor capacidad diagnóstica comparada con una puntuación Bishop $\geq 4$.

\subsubsection{EVALUACIÓN ECOGRÁFICA PREINDUCCIÓN PARA VALORAR EL MÉTODO DE INDUCCIÓN}

El grupo de Bartha en $2005{ }^{119}$ randomiza 80 mujeres con una evaluación preinducción según criterio Bishop o ecográfico, al uso de PG intracervical o no. Sugieren los siguientes valores como puntos de corte: puntuación Bishop $<6$ o mediante ecografía, $\mathrm{LC}>30 \mathrm{~mm}$ y acuñamiento del $\mathrm{OCl}<30 \%$ de la longitud total, y en estas pacientes utilizan PG. Obtienen una menor necesidad de maduración cervical con PG en el grupo valorado mediante ecografía, sin diferencias en el resultado de la inducción ni en la morbilidad neonatal. Sus resultados exponen que un $35-40 \%$ de las mujeres maduradas con PG, no se benefician del criterio Bishop usando la puntuación $<6$.

Otros autores han encontrado mejores puntos de corte para la predicción de la inducción, como Pandis y cols. ${ }^{120}$, que empleando AUC, definen los valores de LC 28 $\mathrm{mm}$ y puntuación Bishop 3 para predecir PV $<24$ horas. Sin embargo, la LC parece ser mejor predictor que la puntuación Bishop con $\mathrm{S}=87 \%$ y $\mathrm{E}=71 \%$ comparado con $\mathrm{S}=58 \%$ y $\mathrm{E}=77 \%$, respectivamente.

Como ambos factores están correlacionados, la obtención de conclusiones en los estudios que comparen estos 2 métodos va a depender de los puntos de corte usados.

\subsubsection{MODELOS PREDICTIVOS DEL ÉXITO DE LA INDUCCIÓN}

Surgen tras numerosos estudios que han comparado variables maternas, ecográficas y/o bioquímicas frente a la puntuación Bishop para la predicción del resultado de la IP. No disponemos de evidencia suficiente para anteponer ninguna evaluación preinducción al score Bishop en la evaluación previa a una IP. Y tampoco disponemos de un punto de corte de la puntuación Bishop por debajo del cual no se iniciaría una IP, por el riesgo aumentado de cesárea, y se indicaría directamente una cesárea electiva.

El objetivo general de todas las propuestas de modelos de predicción es mejorar la información que podemos proporcionar a la paciente previa a una IP por cualquier indicación, en relación con el resultado de su inducción, es decir, información relativa a la probabilidad de conseguir un PV o de finalizar mediante cesárea. El fin último sería incluso, no iniciar una inducción del parto en aquellas mujeres con un pronóstico desfavorable para el PV, indicándolas en este caso una cesárea de forma primaria.

\subsubsection{RANE Y COLS. (2005)}

Este grupo crea modelos de regresión logística con variables pre-inducción (LC ecográfica, paridad, EG, edad materna e IMC) en 822 pacientes, entre 35 y 42 semanas 121.

Su análisis indicó que la predicción significativa para la probabilidad de PV en 24 horas era determinada por las variables: LC (OR=0.86. IC 95\% 0.84-0.88, $p<0.0001)$, paridad (OR=3.59, IC 95\% 2.47-5.22, $p<0.0001)$ y EG (OR=1.19, IC 95\% 1.07-1.32, p $\leq 0.0001)$ y no por IMC o edad materna.

El riesgo de cesárea se asoció significativamente con todas las variables a estudio: LC (OR=1.09, IC 95\% 1.06-1.11, $p<0.0001$ ), paridad (OR=0.25, IC 95\% 0.17-0.38, $p<0.0001$ ), IMC (OR=1.85, IC 95\% 1.24-2.74, $p=0.024)$, EG (OR=0.88, IC 95\% 0.78-0.98, $p=0.0215)$ y edad materna (OR=1.04, IC 95\% 1.01-1.07, $\mathrm{p}=0.0192$ ). 
Finalmente, tras regresión logística, exponen unas complicadas fórmulas matemáticas de predicción de PV en 24 horas y para cesárea teniendo en cuenta las anteriores variables predictoras para cada uno de los eventos.

Tabla 9. Fórmulas matemáticas de predicción según Rane y cols. ${ }^{121}$.

\begin{tabular}{|c|c|c|}
\hline PARTO VAGINAL EN 24 HORAS & $\mathbf{S}$ & $\mathbf{E}$ \\
\hline $\begin{array}{l}(-4112-0.156(\mathrm{LC})+1.144(1 \text { si } \mathrm{M} ; 0 \text { si } N)+ \\
0.1768(\mathrm{EG}))\end{array}$ & $86 \%$ & $57 \%$ \\
\hline CESÁREA POR CUALQUIER INDICACIÓN & $\mathbf{S}$ & $\mathbf{E}$ \\
\hline $\begin{array}{l}(1.4404+0.0841 \text { (LC) }-1.3834(1 \text { si } M ; 0 \text { si N) + } \\
0.6125(1 \text { si IMC } \geq 30 ; 0 \text { si IMC }<30)-0.1314(E G)+ \\
0.039 \text { (EM)) }\end{array}$ & $21 \%$ & $96 \%$ \\
\hline $\begin{array}{l}\text { CESÁREA POR FALTA DE PROGRESIÓN DEL } \\
\text { PARTO }\end{array}$ & $\mathbf{S}$ & $\mathbf{E}$ \\
\hline $\begin{array}{l}(1.917+0.1048 \text { (LC) - } 1.3616(1 \text { si } M ; 0 \text { si } N)+ \\
0.7261 \text { (1 si IMC } \geq 30 ; 0 \text { si IMC }<30)-0.1816(E G)+ \\
0.0457 \text { (EM) }\end{array}$ & $10 \%$ & $99 \%$ \\
\hline
\end{tabular}

\subsubsection{PEREGRINE Y COLS. (2006)}

Este grupo evalúa si factores maternos y/o parámetros ecográficos son útiles en la predicción del riesgo de cesárea tras inducción, en 267 gestaciones $\geq 36$ semanas ${ }^{122}$. Tras el análisis de regresión logística determinan los factores que mejor predicen el riesgo de cesárea y son: paridad (OR=20.56, IC 95\% 7.97-53.05, $p<0.001)$, IMC (OR 6.17, IC 95\% 2.10-18.13, $p<0.001$ ), talla materna (OR=6.17, IC 95\% 2.10-18.13, $p<0.001$ ) y LC ecográfica (OR=1.07, IC 95\% 1.04-1.11, $p<0.001$ ).

Después calculan con esos 4 parámetros una puntuación de riesgo individual para cada gestante y un modelo predictivo para predecir de forma razonablemente segura el riesgo de cesárea (Tabla 10), con un AUC de 0.83. Aunque reconocen que no puede definir con qué porcentaje de probabilidad podría recomendar la cesárea de forma electiva a una paciente, para así evitar una inducción fallida.

Tabla 10: Fórmulas matemáticas de la puntuación de riesgo y de la probabilidad de riesgo de cesárea según Peregrine y cols. ${ }^{122}$.

\begin{tabular}{|l|}
\hline PUNTUACIÓN DE RIESGO (PR) \\
\hline PR = 43 (1 si N; 0 si M) + 26 (1 si IMC $\geq 30 ; 0$ si IMC $<30)+$ LC - Talla materna (cm) \\
\hline PROBABILIDAD DE CESÁREA \\
\hline \\
\hline \% CS = 100/ (1 + EXP(-5.7311175 + (PR/14.1))) \\
\hline M: multípara. N: nulípara. LC: longitud cervical en mm. CS: cesárea. \\
\hline
\end{tabular}

\subsubsection{BUENO y COLS. (2007)}

Sobre una muestra de 196 mujeres entre 37-42 semanas, estudian las posibles variables pre-inducción que mejor predicen el éxito de la inducción (PV $<24$ h) ${ }^{116}$. Obtiene que predecían el éxito de la inducción: LC (OR=1.089, IC 95\% 1.039-1.142, $\mathrm{p}<0.001$ ), puntuación Bishop ( $\mathrm{OR}=0.751, \mathrm{IC} 95 \%$ 0.66-0.886, $\mathrm{p}=0.001$ ) y paridad (OR=4.7, IC 95\% 2.001-11.41, $\mathrm{p}<0.001$ ).

Integran estas variables en un organigrama (Figura 1) y encuentran que la mejor predicción resultaba al introducir la paridad en primer lugar.

El éxito de inducción en nulíparas resultó de un 50.8\% y en multíparas de un $83.3 \%$ $(p=0.0001)$. 
Figura 1. Análisis de decisión según la mejor secuencia estadística según Bueno y cols. 116.

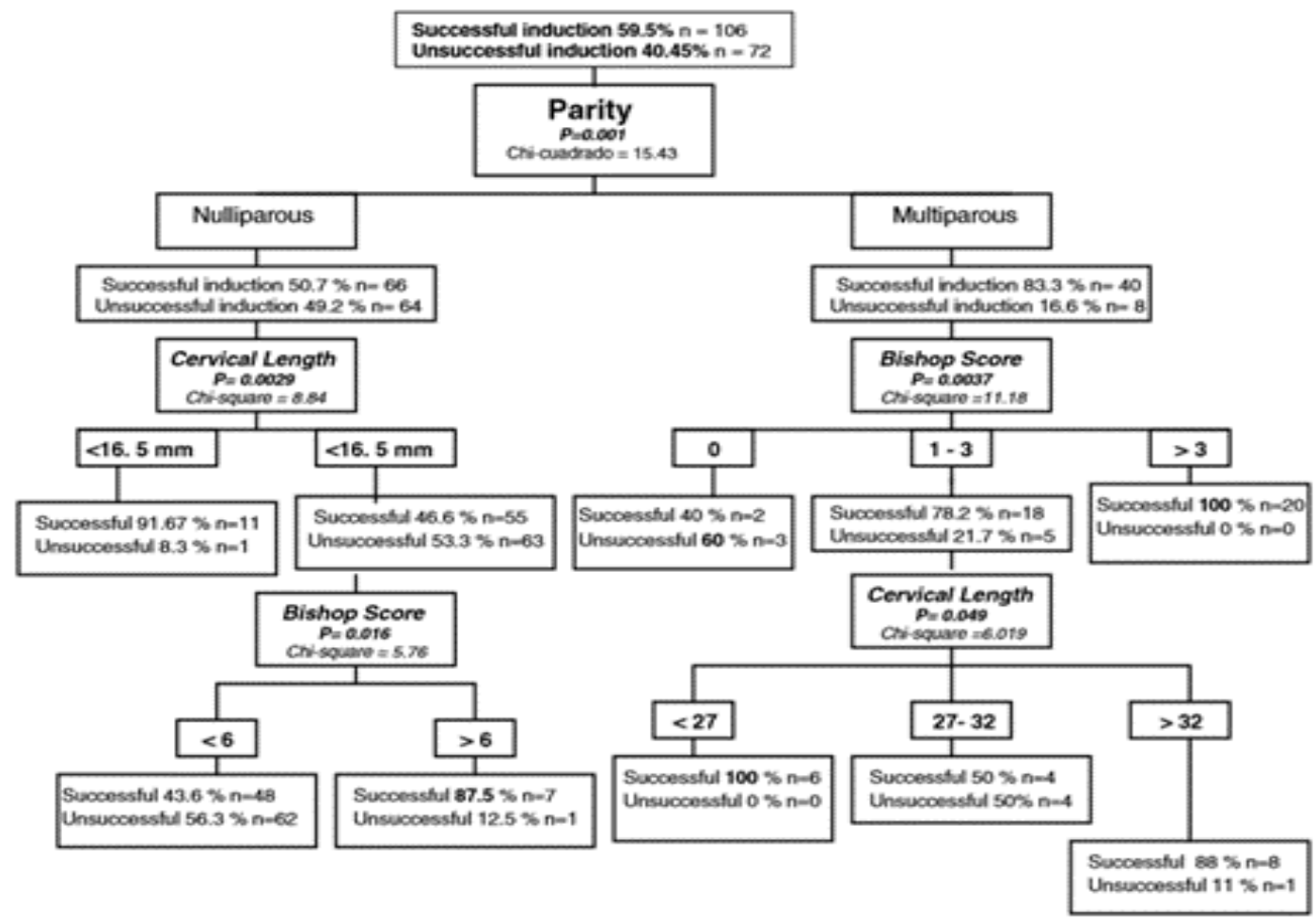

\subsubsection{EGGEBO Y COLS. (2009)}

Realizan un estudio sobre 275 gestaciones > 37 semanas, comparando las características cervicales de la puntuación Bishop frente a sus posibles correlaciones ecográficas (menos la consistencia): LC, ACP, dilatación y DCP como factores predictores de conseguir un PV tras la IP ${ }^{83}$.

Tras el análisis univariante obtienen como predictores de éxito una $\mathrm{LC} \leq 25 \mathrm{~mm}$, un ACP > 90으, una DCP $\leq 40 \mathrm{~mm}$ y la evaluación digital de la dilatación cervical. Tras ajustar por variables maternas en el análisis de regresión logística, los mejores predictores fueron la paridad, la talla materna y el ACP.

Crean un modelo predictivo con DCP, ACP, LC y dilatación digital que obtiene una capacidad del $68 \%$ para discriminar entre éxito o fracaso de la inducción.

Proponen una puntuación simple de 0-4 según esas medidas ecográficas y la dilatación cervical (Tabla 8), con la que obtienen un poder de predicción de PV del 71\%.

Tabla 8. Puntuación propuesta por Eggebo y cols. con combinación de medidas ecográficas y dilatación cervical digital ${ }^{83}$.

\begin{tabular}{|l|c|c|}
\hline Factor & \multicolumn{2}{|c|}{ Puntuación } \\
\hline & $\mathbf{0}$ & $\mathbf{1}$ \\
\hline DCP & $>40 \mathrm{~mm}$ & $\leq 40 \mathrm{~mm}$ \\
\hline LC & $>25 \mathrm{~mm}$ & $\leq 25 \mathrm{~mm}$ \\
\hline ACP & $\leq 90 \circ$ & $>90 \circ$ \\
\hline Dilatación cervical digital & Cerrado & Dilatado \\
\hline
\end{tabular}

Probaron este modelo de puntuación en su población y encontraron que el $40 \%$ de las mujeres con resultado 0 , el $77 \%$ con resultado 1 , el $88 \%$ con resultado 2 , el $94 \%$ con resultado 3 y el $95 \%$ con resultado 4 , conseguían un PV y, por tanto, el éxito de la inducción. 


\subsubsection{VERHOEVEN Y COLS. (2009). VALIDACIÓN DE LOS MODELOS DE RANE Y PEREGRINE}

Realizan un estudio prospectivo en 240 gestaciones a término para validar en su población ${ }^{123}$ los dos modelos predictivos del resultado de cesárea tras IP de Rane ${ }^{121} \mathrm{y}$ Peregrine ${ }^{122}$. No hubo diferencias en las características demográficas ni en la indicación de la inducción entre su población y los estudios de Rane y Peregrine. Las tasas de cesárea fueron: $11 \%$ para Verhoeven, $20 \%$ para Rane y $30 \%$ para Peregrine.

Este estudio describe que la puntuación Bishop tiene un AUC para predecir cesárea de 0.62 pero no encuentra una clara asociación entre la LC y el riesgo de cesárea, con una curva ROC de 0.55 .

Usando el modelo de Peregrine, este grupo obtuvo un AUC de 0.76 y con el modelo de Rane de 0.67. Ambas curvas ROC para los 2 modelos mostraron diferencias significativas $(p<0.001)$.

Concluyen que la capacidad predictiva de estos modelos en su población fue limitada y que ambos sobreestimaban el riesgo de cesárea.

Esta sobreestimación puede ser debida a la paridad y a las distintas tasas de cesárea de cada población.

Además, la capacidad predictiva de la LC en el estudio de Verhoeven y cols. es mejorable. Esto puede explicarse porque en su estudio era medida tanto por un ginecólogo entrenado, como por un residente o por una matrona, y en cambio en otros estudios, la LC es medida siempre por la misma persona.

\subsubsection{ISONO Y COLS. (2011)}

Este grupo evalúa los datos de 1029 gestaciones $\geq 35$ semanas que habían sido inducidas, entre 2002 y $2009{ }^{124}$. Compararon las tasas de cesárea entre subgrupos, divididos por paridad y riesgo, como anomalía fetal o complicación materna.

La tasa de cesárea fue más alta en el grupo de nulíparas frente a multíparas (17.8\% versus $2.0 \%)$.

Así, crean un modelo predictivo de cesárea tras inducción del parto en un grupo de 392 nulíparas de bajo riesgo con rotura prematura de membranas. Los factores: puntuación Bishop, EG, IMC, talla materna y peso al nacimiento fueron analizados mediante regresión logística. Tras una prueba de validación cruzada de dos pasos, se determinó la mejor combinación de parámetros para la predicción del riesgo de cesárea, calculando una fórmula predictiva (Tabla 11).

Tabla 11. Fórmula predictiva de cesárea en nulíparas de bajo riesgo propuesta por Isono y cols. ${ }^{124}$.

\begin{tabular}{|c|}
\hline$\% \mathrm{CS}=($ odds $/ 1+$ odds $) * 100$ \\
\hline Odds $=\mathrm{e}^{\mathrm{x}}$ \\
\hline $\mathrm{X}=8.18+1.23 * \mathrm{PN}(\mathrm{kg})-7.74 * \mathrm{TM}(\mathrm{m})-0.253 * \mathrm{~B}$ \\
\hline CS: cesárea. PN: peso al nacimiento. TM: talla materna. B: Bishop. \\
\hline
\end{tabular}

Este modelo potencialmente aporta una predicción más segura para el resultado de la inducción que la tradicional puntuación Bishop, especialmente cuando hay una talla materna baja (típica de la población japonesa ejemplo de su muestra) y un feto con estimación alta de peso. Contribuyen así a un manejo mejorado de los casos de inducción del parto en mujeres nulíparas.

\subsubsection{PITARELLO Y COLS. (2013)}

Realizan un estudio prospectivo sobre 190 mujeres para intentar predecir el éxito de la inducción mediante variables ecográficas, factores maternos y puntuación Bishop ${ }^{96}$.

Como medidas ecográficas utilizan: LC, dilatación cervical y estación de la cabeza fetal, definiéndola como la distancia entre la parte más baja de la cabeza fetal y el OCE. 
Tanto las variables ecográficas como la puntuación Bishop y la paridad, predijeron de forma significativa el PV global y el PV en 24 horas, que ocurrieron en el $70 \%$ y $62.6 \%$ respectivamente.

Así, construyen una ecuación matemática (Tabla 12) para calcular la probabilidad de cada evento considerando estas variables predictoras, alcanzando AUC de $80.1 \%$ para PV y $79.3 \%$ para PV en 24 horas.

Tabla 12. Ecuaciones matemáticas para estimar la probabilidad de PV y PV en 24 horas según Pitarello y cols. ${ }^{96}$.

\begin{tabular}{|c|c|c|c|c|c|}
\hline Resultado & Estimación de probabilidad & $\mathbf{S}$ & $\mathbf{E}$ & AUC & $p$ \\
\hline Parto vaginal & $\begin{array}{l}(\exp (1.98 \times \mathrm{Pa}+0.26 \times \text { Dilatación - } \\
0.07 \times \text { Estación }+0.30 \times \text { Bishop })) /(1+ \\
(\exp (1.98 \times \mathrm{Pa}+0.26 \times \text { Dilatación }- \\
0.07 \times \text { Estación }+0.30 \times \text { Bishop })))\end{array}$ & $71.3 \%$ & $76.2 \%$ & $80.1 \%$ & $<0.01$ \\
\hline $\begin{array}{l}\text { Parto vaginal en } \\
24 \text { horas }\end{array}$ & $\begin{array}{l}(\exp (1.87 \times \mathrm{Pa}+0.29 \times \text { Dilatación }- \\
0.09 \times \text { Estación }+0.30 \times \text { Bishop })) /(1+ \\
(\exp (1.87 \times \mathrm{Pa}+0.29 \times \text { Dilatación }- \\
0.09 \times \text { Estación }+0.30 \times \text { Bishop })))\end{array}$ & $73.6 \%$ & $71.3 \%$ & $79.3 \%$ & $<0.01$ \\
\hline
\end{tabular}

La autora y colaboradores concluyen que las ecuaciones matemáticas pueden ser clínicamente útiles para predecir las opciones de PV de una gestante previamente a la IP.

\subsubsection{HIERSCH Y COLS. (2017)}

Estudian una cohorte retrospectiva de 986 mujeres que fueron inducidas previa maduración cervical con dispositivo vaginal de liberación lenta de PG E2 ${ }^{125}$. Pretenden identificar factores predictores del éxito de la maduración cervical, definiendo el fracaso como una puntuación Bishop $<7$ a las 24 horas o necesidad de cesárea por falta de progresión del parto con una dilatación $\leq 5 \mathrm{~cm}$.

El éxito de la maduración cervical se relacionó con la nuliparidad (OR=0.42, IC 95\% 0.22-0.81, $\mathrm{p}=0.009)$, la EG (OR=1.29, IC 95\% 1.02-1.61, p<0.03) y la dilatación cervical al ingreso (OR=4.58, IC 95\% 2.57-8.17, $\mathrm{p}<0.001)$.

Los autores crean un modelo de predicción con las características anteriores, obteniendo un AUC significativa de 0.792 y concluyen que los parámetros de paridad, EG y dilatación cervical pueden predecir el éxito de la maduración cervical con PG E2 vaginal.

\subsubsection{9. ÁLVAREZ-COLOMO Y COLS. (2016)}

La autora realiza un estudio prospectivo ${ }^{126}$ sobre 151 mujeres que iban a inducirse por cualquier indicación, incluyendo nulíparas/multíparas, antecedente de cesárea y bolsa íntegra/rota. El propósito es validar la ecografía para la predicción del resultado de la inducción comparado con la puntuación Bishop y diseñar un modelo predictivo del modo de parto (vaginal/cesárea) que incluya variables ecográficas y clínicas.

Las mayores AUC las obtuvieron para DCP (0.734), seguido de puntuación Bishop (0.678) y LC (0.663). Por tanto, los parámetros ecográficos DCP y LC fueron predictores útiles y comparables al score Bishop.

Las variables que se relacionaron con el modo de parto fueron, clínicas: IMC, TM (cm), cesárea previa, parto vaginal previo y puntuación Bishop, y ecográficas: LC y DCP.

Tras un modelo de regresión logística binaria, diseñaron una ecuación matemática (Tabla 13) para la predicción de cesárea como resultado de la inducción, que predijo 
correctamente el $82.8 \%$ de los eventos (Tabla 14), siendo mejor predictor del éxito que del fracaso de inducción, con una tasa de FP del 15\%.

Tabla 13. Fórmula matemática de probabilidad para la predicción del modo de parto (cesárea) propuesta por Álvarez-Colomo y cols. ${ }^{126}$.

\section{PROBABILIDAD PARA LA PREDICCIÓN DEL MODO DE PARTO}

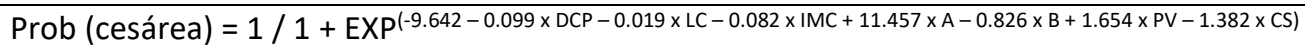

$\mathrm{S}=76.3 \%, \mathrm{E}=85 \%, \mathrm{VPP}=63 \%, \mathrm{VPN}=91.4 \%$

DCP: distancia céfalo-perineal (mm). LC: longitud cervical $(\mathrm{mm})$. A: altura materna $(\mathrm{cm})$.

B: Bishop. PV: parto vaginal previo. CS: cesárea previa.

$\mathrm{B}(<4)$, PV y CS son variables dicotómicas, su presencia se corresponde con 1 /ausencia 0.

Tabla 14. Modelo predictivo propuesto por Álvarez-Colomo y cols. ${ }^{126}$.

\begin{tabular}{|c|c|c|c|}
\hline \multirow{2}{*}{} & \multicolumn{2}{|c|}{ Esperado } & \multirow{2}{*}{ \% Éxito } \\
\cline { 2 - 4 } & Vaginal & Cesárea & \\
\hline Observado & 96 & 9 & 91.4 \\
\hline Vaginal & 17 & 29 & 63 \\
\hline Cesárea & \multicolumn{3}{|c|}{82.8} \\
\hline Total & \multicolumn{3}{|l|}{} \\
\hline
\end{tabular}

Concluyen que su modelo matemático aplicado a mujeres que van a iniciar una inducción les predice un riesgo de cesárea similar al que obtendrían al iniciar de forma espontánea el parto. Pero la predicción de cesárea no les permite evitar el proceso de la inducción dado el alto porcentaje de falsos positivos.

\subsubsection{LEVINE Y COLS. (2018)}

Esta autora americana primero crea un modelo predictivo realizando un análisis secundario (resultado de cesárea tras IP) de un estudio randomizado que comparaba el tiempo hasta el parto entre 4 métodos de IP ( $n=491$, tasa de cesárea $27.7 \%$, gestaciones $\geq 37$ semanas, bolsa íntegra, Bishop $\leq 6$ y dilatación cervical $\leq 2 \mathrm{~cm}$, incluyen tanto nulíparas como multíparas y excluyen pacientes con cesárea anterior) 127. Tuvieron en cuenta 21 variables con una prevalencia de al menos un $5 \%$, que se asociaran con el resultado de cesárea ( $p<0.20$ en análisis bivariante). El análisis multivariante final incluyó solo las variables con una $p<0.05$ y las asociaciones se presentaron con aOR y sus IC al $95 \%$. Después este modelo, en un intento de validación interna, es evaluado usando una cohorte observacional de mujeres que iban a iniciar una IP en la misma institución y durante el mismo período del ensayo randomizado $(n=364$, tasa de cesárea $32.7 \%)$. Así reestiman y redefinen asociaciones entre los FR y la cesárea. Por último, el modelo predictivo validado es sometido a una validación externa y la autora publica un algoritmo para estimar el riesgo de cesárea en mujeres con cérvix desfavorable que van a iniciar una IP ${ }^{128}$.

Para la validación externa se realiza un análisis secundario de varios estudios y se recogen datos de más de 200.000 partos de 19 hospitales en EEUU. Tras aplicar los criterios de inclusión y exclusión del modelo de la cohorte, permanecen 8.466 pacientes para el análisis (tasa de cesárea 26.4\%). Obtienen 5 variables independientes y significativas para predecir el riesgo de cesárea: nuliparidad, $\geq 40$ semanas, IMC, talla 
y Bishop modificado (dilatación, borramiento y estación de la cabeza fetal). No hubo diferencias significativas en la tasa de cesárea entre la cohorte de derivación y el grupo de validación externa $(p=0.53)$.

El modelo predictivo con estas variables obtiene un AUC de 0.73 (IC 95\% 0.72-0.74).

Se creó un normograma basado en el modelo final (Figura 2). Un normograma se crea tras estimar la probabilidad predicha de cesárea usando coeficientes de regresión logística desde el modelo.

Figura 2. Normograma para predecir probabilidad de cesárea, propuesto por Levine y cols. ${ }^{128}$.

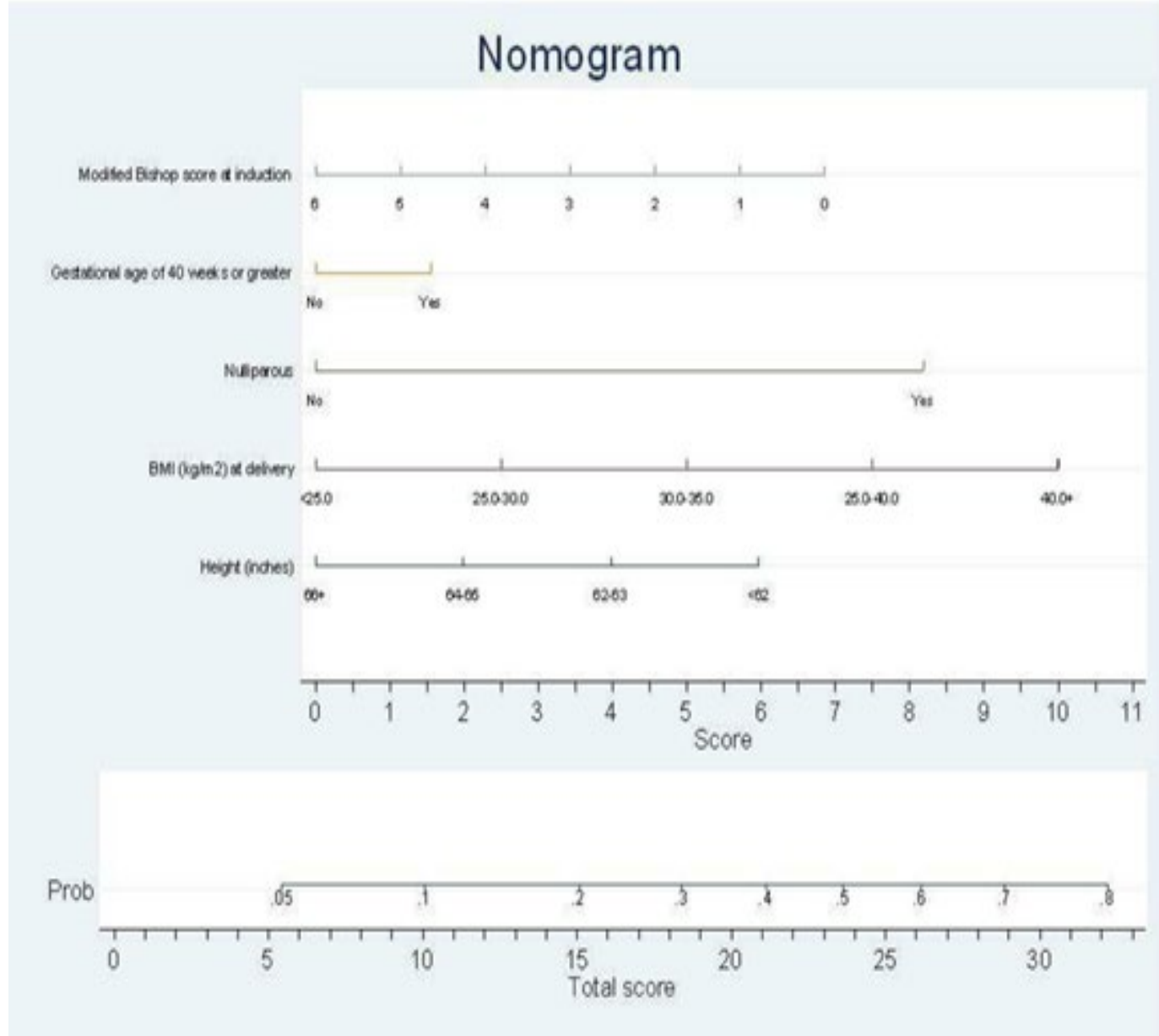

La figura 3 expone la predicción de probabilidad de cesárea basada en la calculadora de Levine (eje-x) comparada con la incidencia actual de cesárea (eje-y). 
Figura 3. Probabilidad de Cesárea tras inducción con cérvix desfavorable propuesta por Levine y cols. ${ }^{128}$.

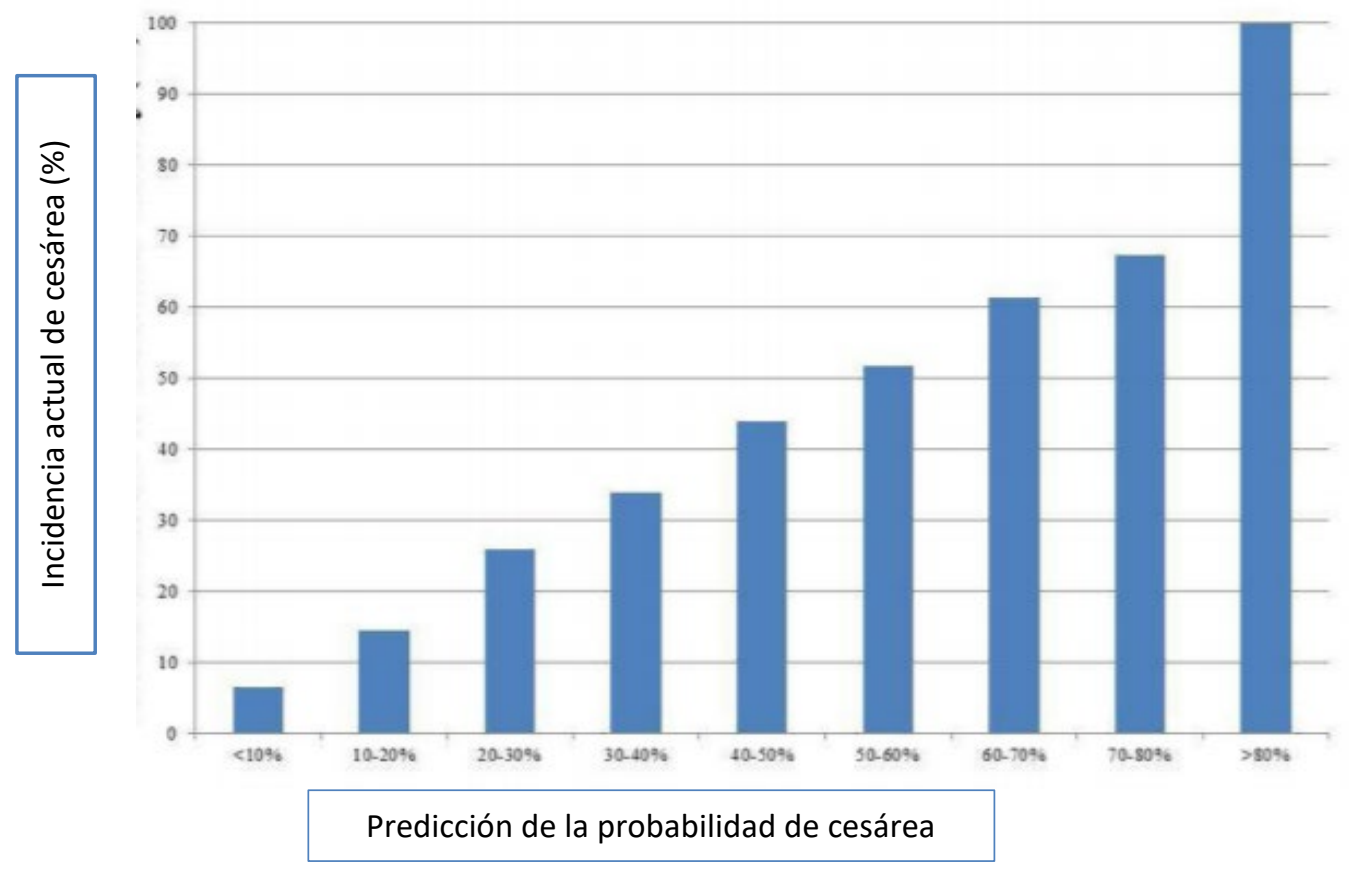

La calculadora pude obtenerse en el siguiente enlace http://www.uphs.upenn.edu/obgyn/labor-induction-calculator/ y a continuación expongo un ejemplo en la Figura 4.

Figura 4. Calculadora de la probabilidad de cesárea según modelo predictivo propuesto por Levine y cols. ${ }^{128}$.

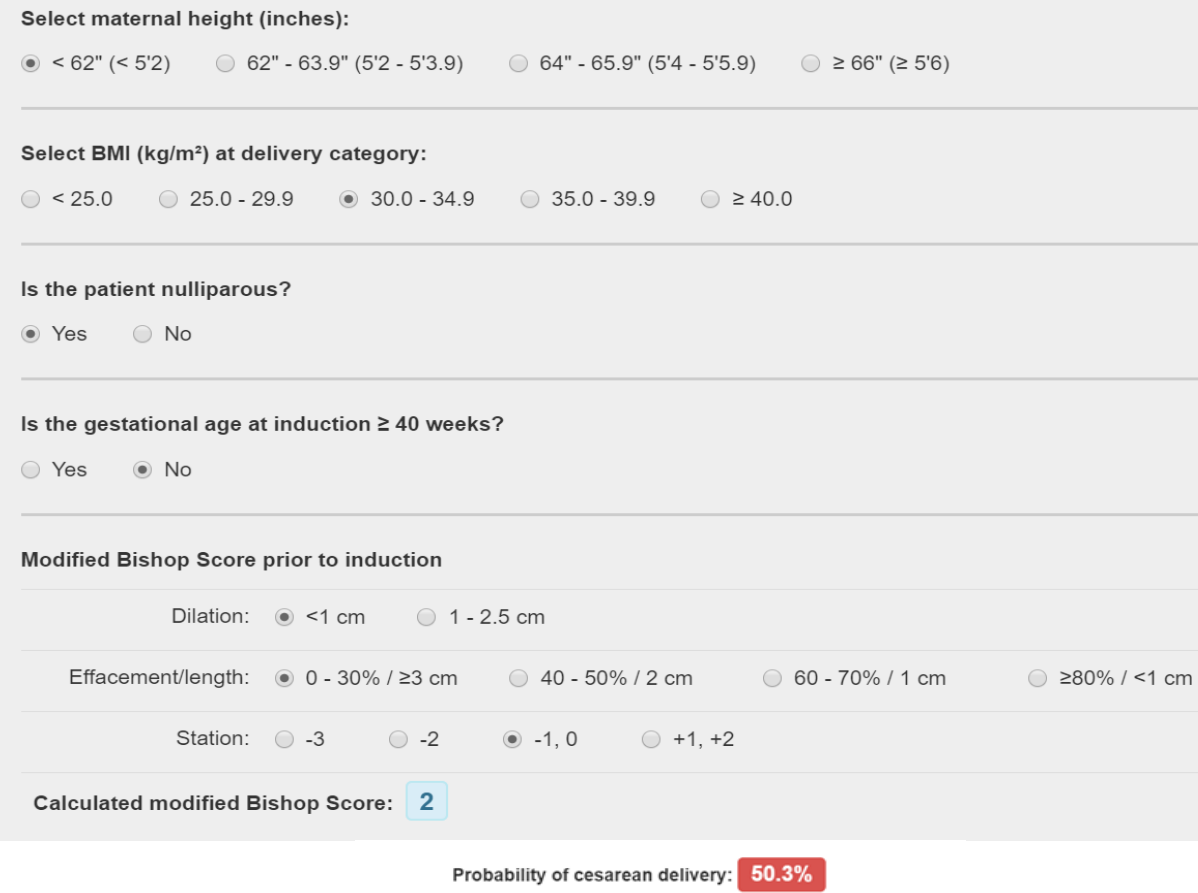

La figura 4, predice una probabilidad de cesárea del 50.3\% para una paciente con talla inferior a $157 \mathrm{~cm}$, IMC entre 30-34.9, nulípara de 39 semanas y con puntuación Bishop 
modificada 2 (dilatación cervical $<\mathrm{b} 1 \mathrm{~cm}$, borramiento cervical 0-30\% y estación de la cabeza fetal a $-1 \mathrm{~cm}$ de la espina ciática).

Es una herramienta nueva que puede ayudar a aconsejar a las pacientes y a informarles de las expectativas de su inducción del parto, ofreciendo una medicina personalizada.

Sin embargo, es importante resaltar que la calculadora aporta un porcentaje de riesgo de cesárea y que no existe un punto de corte por encima del cual podemos indicar una cesárea a la paciente.

\subsubsection{MIGLIORELLI Y COLS. (2018)}

Este grupo diseña un estudio prospectivo en el Hospital Clínic de Barcelona ${ }^{129}$ para desarrollar un modelo predictivo del riesgo de cesárea tras inducción, mediante la combinación de variables clínicas y ecográficas. Tras estimar el tamaño muestral, utilizan el $70 \%$ de la muestra para construir un modelo predictivo y la población restante se empleó para la validación del modelo. La muestra total fue de 477 gestaciones únicas, $\geq 37$ semanas, nulíparas/multíparas, incluyendo pacientes con antecedente de cesárea. El modelo resultante final fue estimado y calibrado por todas las participantes. El principal resultado de la inducción se definió como el parto por cesárea debida a fracaso de inducción o a no progresión del parto.

La tasa de cesárea en la muestra fue $21.4 \%$.

Las variables predictivas incluidas en el modelo final fueron:

- Parto vaginal previo: OR=0.088, IC 95\% 0.04-0.21.

- Altura materna (cm): OR=0.904, IC 95\% 0.87-0.94.

- IMC previo al embarazo: OR=1.084, IC 95\% 1.02-1.15.

- PFE por ecografía (kg): OR=3.965, IC 95\% 2.18-7.22.

- LC ecográfica (mm): OR=1.065, IC 95\% 1.04-1.09.

Crearon una ecuación matemática que estima el riesgo de cesárea para una tasa de FP del 5\% (Tabla 15).

Tabla 15. Ecuación matemática para probabilidad de cesárea tras inducción del parto propuesta por Migliorelli y cols. ${ }^{129}$.

\begin{tabular}{|l|}
\hline Probabilidad del riesgo de cesárea \\
\hline Riesgo $(\%)=\left[1 /\left(1+\mathrm{e}^{-\mathrm{r}}\right)\right] \times 100$ \\
\hline $\mathrm{Y}=7.004-(2.435 \mathrm{si} \mathrm{PV})-(0.1012 \times \mathrm{A})+\left(8.050 \times 10^{-2} \times \mathrm{IMC}\right)+(1.377 \times \mathrm{PFE})+(6.314$ \\
$\left.\times 10^{-2} \times \mathrm{LC}\right)$ \\
\hline $\mathrm{S}=44.1 \%, \mathrm{E}=94.9 \%, \mathrm{VPP}=70.3 \%, \mathrm{VPN}=86.2 \%, \mathrm{LHR}+8.7$ y LHR- 0.59. \\
\hline $\mathrm{PV}:$ parto vaginal previo. A: altura materna en $\mathrm{cm}$. IMC: IMC previo al embarazo $\mathrm{kg} / \mathrm{m}^{2}$. \\
PFE: peso fetal estimado por ecografía en $\mathrm{kg}$. LC: longitud cervical ecográfica en $\mathrm{mm}$. \\
\hline
\end{tabular}

El modelo definitivo mostró un AUC de 0.826 (IC 95\% 0.78-0.87), mientras que para la puntuación Bishop el AUC fue de 0.619 (IC 95\% 0.56-0.68), $p<0.001$.

Este modelo, que combina variables ecográficas y clínicas, obtuvo una capacidad predictiva superior a la puntuación Bishop y podría permitir un consejo individualizado en relación con el riesgo de cesárea de una mujer candidata a inducción del parto. Emplear este modelo podría decantar la balanza hacia el manejo expectante de la gestación cuando la indicación de la inducción no pesa más que el riesgo de cesárea calculado preinducción. 


\subsubsection{REVISIÓN SISTEMÁTICA DE MODELOS DE PREDICCIÓN DEL ÉXITO DE LA INDUCCIÓN (2019)}

Meier y cols. revisan y comparan modelos clínicos que utilizan factores clínicos y demográficos accesibles (no ecográficos ni bioquímicos), que han sido propuestos $\mathrm{y} / \mathrm{o}$ validados para predecir el éxito de la inducción, en un intento de realizar recomendaciones válidas para la práctica clínica ${ }^{130}$.

Se identificaron 16 estudios y finalmente se incluyeron 14 modelos predictivos, entre 1966 y 2018. Sólo pudo realizarse un análisis descriptivo en vista de la heterogeneidad clínica y metodológica entre los estudios. De estos modelos, 6 fueron validados de forma interna y 3 de forma externa.

En la mayoría, el rendimiento del modelo fue medido con el AUC, que varió entre 0.68 y 0.79 en general, para los modelos de validación interna fue 0.67-0.77 y para los validados externamente fue $0.61-0.73^{127,140}$.

En base a esta revisión y a las limitaciones de los modelos incluidos, no se puede recomendar ningún modelo basado en factores clínicos y obstétricos para determinar el éxito de la inducción del parto.

En esta revisión no se tuvieron en cuenta modelos predictivos que incluyeran parámetros ecográficos y/o bioquímicos, que combinados con los clínicos y demográficos podrían teóricamente aumentar la capacidad de predicción.

Deben investigarse las actitudes de las mujeres y de los profesionales sanitarios que las cuidan, además de las implicaciones clínicas y de recursos antes del uso de modelos de predicción del éxito de la inducción

\subsubsection{ALAVIFARD Y COLS. VALIDACIÓN EXTERNA DEL MODELO DE LEVINE}

Este grupo realiza una validación externa del modelo predictivo de Levine y cols. ${ }^{128}$ en su población de Toronto (Canadá) ${ }^{131}$, sobre 256 mujeres que cumplieron los criterios de inclusión del modelo de Levine. La tasa de cesárea fue del $29.3 \%$ y la capacidad predictiva del modelo fue modesta, con un AUC de 0.61 (IC 95\% 0.53-0.68). Aducen posibles razones de esta reducción en la predicción, como la inclusión de demasiadas variables predictoras (21) en el modelo de Levine y diferencias poblacionales, concluyendo que un modelo predictivo no puede usarse como una herramienta preinducción aislada. 
OBJETIVOS 


\section{OBJETIVOS}

Hoy en día, ningún modelo predictivo puede utilizarse como herramienta aislada en la valoración de una paciente previamente a una IP.

Con la intención de profundizar en la seguridad de los modelos predictivos, este trabajo se propone validar de forma interna el modelo predictivo piloto de Álvarez-Colomo y cols. ${ }^{126}$.

Para la validación del modelo predictivo de Álvarez-Colomo y cols. ${ }^{126}$, planteamos la siguiente hipótesis:

- $H_{0}$ (Hipótesis nula): Expresaría que no se encuentran diferencias en el modelo predictivo piloto tras ser aplicado por varios observadores, es decir, esta hipótesis validaría el modelo, que sería reproducible independientemente del operador que lo aplicara.

- $\mathrm{H}_{1}$ (Hipótesis alternativa): Es la que reportaría diferencias en el modelo cuando lo desarrollan varios operadores y, por tanto, no validaría el modelo predictivo.

Según la hipótesis planteada, nos proponemos alcanzar los siguientes objetivos:

- Objetivo principal:

Validación del modelo predictivo piloto de Álvarez-Colomo en condiciones de práctica clínica habitual

- Objetivos secundarios:

En el caso de que no se validara el modelo predictivo piloto, estudio de las posibles causas de dicho fracaso 
MATERIAL Y MÉTODOS 


\section{MATERIAL Y MÉTODOS}

\subsection{EVALUACIÓN PREVIA A UNA INDUCCIÓN DEL PARTO EN NUESTRO CENTRO}

La evaluación previa a una IP en nuestro Centro incluye una serie de parámetros:

- Estimación de la EG según la FPP obtenida con la datación del embarazo en la ecografía de la semana 12 o si ésta no se realizó, con un DBP descrito por ecografía, idealmente antes de la semana 20 de gestación.

- Antecedentes obstétricos previos: aborto, parto eutócico, parto instrumentado, cesárea y en este caso, fecha de la misma (no se recomendará IP si la cesárea anterior se realizó en un tiempo inferior a 18 meses, en este caso la paciente tiene la autonomía de decidir si desea intentar un PV de inicio espontáneo). Sólo iniciaremos una IP en pacientes con cesárea anterior cuando se cumplen las siguientes premisas:

- Sólo un antecedente de cesárea segmentaria transversa previa

- Distancia de la inducción con la anterior cesárea de más de 18 meses

- PFE no superior a $4000 \mathrm{gr}$

- No contraindicación para PV

- Indicación de la inducción, causa médica o no médica-electiva, indicando el diagnóstico clínico o las circunstancias oportunas.

- Información verbal y por escrito si así lo solicita la paciente, de la indicación de la inducción y del procedimiento de esta, respuesta a preguntas que se puedan plantear y obtención verbal del consentimiento para la inducción.

- Valoración de las pruebas de laboratorio pertinentes, como analítica en sangre de tercer trimestre con hemoglobina, hematocrito, plaquetas y coagulación, y resultado del Estreptoco Agalactiae Grupo B en muestra vaginal y rectal. Se precisarán pruebas de laboratorio si la patología médica de la paciente así lo requiere.

- Revisar problemas especiales que puedan existir: condiciones médicas, alergias a medicamentos y necesidades especiales como compresión mecánica de extremidades inferiores, control de glucemia horaria intraparto, prevención de la hemorragia postparto si existen factores de riesgo previos a la inducción (anemia, multiparidad, cicatriz uterina previa, gemelar, polihidramnios, tratamiento con heparina, alteraciones de la hemostasia como hemofilia o plaquetopenia) entre otras.

- Determinar la presentación fetal: maniobras de Leopold y tacto vaginal con o sin ecografía.

- Examinación cervical mediante tacto vaginal con el test de Bishop ${ }^{50}$, para valorar si se precisa maduración cervical, con agentes mecánicos o farmacológicos. En caso de puntuación de $B \geq 7$ se procederá a la inducción mediante amniotomía e infusión oxitócica (Tabla 3).

- Evaluar el estado de las membranas amnióticas (bolsa íntegra o rota).

- Evaluación del patrón de FCF por monitorización fetal no estresante durante al menos 20-30 min, para asegurar que el feto tolerará el inicio de la inducción. Un trazado normal ${ }^{29}$ es el que presenta una FCF basal entre 110 y $160 \mathrm{lpm}$, con una variabilidad (amplitud de la fluctuación respecto de la FCF basal) de 6-25 lpm con aceleraciones transitorias (aumento de la FCF en $15 \mathrm{lpm}$, al menos 15 segundos y menos de $2 \mathrm{~min}$ ) y sin desaceleraciones.

\subsection{MATERIAL Y DISEÑO DEL ESTUDIO}

El presente trabajo es un estudio observacional prospectivo realizado en el Hospital Clínico Universitario de Valladolid, en el período de tiempo comprendido entre el 1 de septiembre de 2010 y el 31 de Julio de 2012. La población de estudio está compuesta por las gestantes que iban a iniciar una inducción médica del parto durante ese periodo. 


\subsubsection{MUESTRA ESTUDIADA}

La selección de las gestantes se realizó mediante la técnica de muestreo por oportunidad, por cada uno de los cuatro observadores del estudio, indistintamente, según estuvieran asignados esa jornada ordinaria de mañana al área de paritorio. Se escogían las pacientes que iban a iniciar una IP y cumplieran los criterios de inclusión establecidos (Tabla 15).

Como criterios de exclusión de inicio se consideraron el no cumplir alguno de los criterios de inclusión y/o que la mujer no comprendiera el lenguaje castellano tanto oral, como escrito.

Tabla 15. Criterios de inclusión de estudio.

\begin{tabular}{|c|}
\hline Edad $\geq 18$ años \\
\hline Inducción médica del parto por cualquier indicación, médica u obstétrica \\
\hline $\begin{array}{l}\text { Comprobación del bienestar fetal con monitorización fetal no estresante con resultado } \\
\text { de patrón reactivo }\end{array}$ \\
\hline Ausencia de contraindicación para el parto vaginal \\
\hline $\begin{array}{l}\text { Ausencia de contraindicación para el empleo de los fármacos utilizados en la inducción } \\
\text { del parto }\end{array}$ \\
\hline $\begin{array}{l}\text { Información verbal y obtención del consentimiento informado por escrito para la } \\
\text { inducción médica del parto }\end{array}$ \\
\hline $\begin{array}{l}\text { Información verbal y obtención del consentimiento informado por escrito para la } \\
\text { participación en el estudio (Anexo } 2 \text { ). }\end{array}$ \\
\hline
\end{tabular}

\subsubsection{TAMAÑO DE LA MUESTRA}

Dado que el estudio piloto de Álvarez-Colomo y cols. se realizó sobre 151 pacientes, este estudio amplió el tamaño muestral con la intención de mejorar la potencia estadística y aportar mayor número de población a la que aplicar su modelo predictivo. Se estimó que para apreciar potenciales diferencias estadísticamente significativas sería necesario un tamaño muestral de 250 pacientes, aunque finalmente se incluyeron en el estudio 231 gestantes, porque 19 pacientes no consintieron formar parte del mismo.

\subsubsection{METODOLOGÍA DEL ESTUDIO}

Tras comprobar los criterios de inclusión, informar a la paciente y obtener la firma en el consentimiento informado del estudio, se inició la recogida de datos y se incluyeron en el documento diseñado con este fin (HRD-Anexo 3):

- Variables antropométricas: peso, talla e IMC.

- Edad

- Antecedentes obstétricos

Incluye la existencia de partos previos, el número de ellos, si fueron de inicio espontáneo o inducidos y si inducidos, la indicación de la IP. Respecto de la manera de finalizar el parto, si fue eutócico, instrumentado o cesárea y la indicación de esta.

Para la clasificación de las mujeres según sus antecedentes obstétricos se emplearon los criterios de Robson, que estratifican las gestantes en 10 grupos, mutuamente excluyentes y de gran relevancia clínica para valorar y comparar las tasas de cesáreas ${ }^{132}$, tanto dentro del mismo centro asistencial como entre distintos centros. De hecho, no es útil comparar de manera general la tasa de cesáreas de cada hospital. Lo verdaderamente relevante es referenciar el porcentaje de cesáreas a cada población específica, estratificada según los criterios de Robson, basados en 4 parámetros: categoría de la gestación, antecedentes obstétricos, EG en el momento del parto y forma de inicio del mismo. 
- Edad Gestacional

Se define como días según el primer día del último período menstrual corregido por la ecografía del primer trimestre (CRL), cuando la amenorrea no coincida con la EG. Se realiza el análisis estadístico con la EG en días, aunque en la HRD se rellene la EG como semanas y días de gestación.

- Indicación de la IP

Se incluyó cualquier indicación de IP, tanto obstétrica (RPM, GCP...) como por causa médica (EHE, DG ...)

- Parámetros ecográficos

La exploración ecográfica fue realizada de forma indistinta por uno de los cuatro profesionales que estaban autorizados para ello en el estudio. Estos cuatro investigadores tenían amplia experiencia ecográfica tanto en ecografía obstétrica como en ecografía vaginal para la valoración del cérvix.

Tras la recogida de los datos anteriores, se realizó una ecografía obstétrica básica abdominal, con sonda cónvex de $3.5 \mathrm{MHz}$ en un ecógrafo Toshiba Nemio (Toshiba Matsusita, Tokio, Japón). Se registró la posición de la presentación fetal y se obtuvieron las medidas de DBP, CA y LF según los criterios previamente establecidos ${ }^{133}$. El cálculo del PFE se obtuvo gracias al software del propio ecógrafo según las fórmulas propuestas por Hadlock ${ }^{134}$.

La DCP se realizó según la técnica propuesta por Eggebo y cols. ${ }^{109}$, con la gestante en posición de litotomía y con la vejiga vacía. Se apoya la sonda cónvex 3.5-6.5 $\mathrm{MHz}$ multifrecuencia, colocada de forma transversal, sobre la vulva y piel perineal, a nivel de las tuberosidades isquiáticas. Se presiona de forma firme, pero sin crear incomodidad a la paciente, obteniendo tres medidas entre el límite óseo externo de la cabeza fetal y la piel perineal. La DCP es la media aritmética de esas 3 medidas. Para evitar el contacto de la sonda con los fluidos vulvares, se envuelve la sonda en la funda que se utiliza para proteger la sonda endovaginal, colocando gel conductor de US entre la sonda y la funda, evitando que queden burbujas que impedirían la conducción correcta de los US (Figura 5).

Figura 5. Medida de la distancia céfalo-perineal.

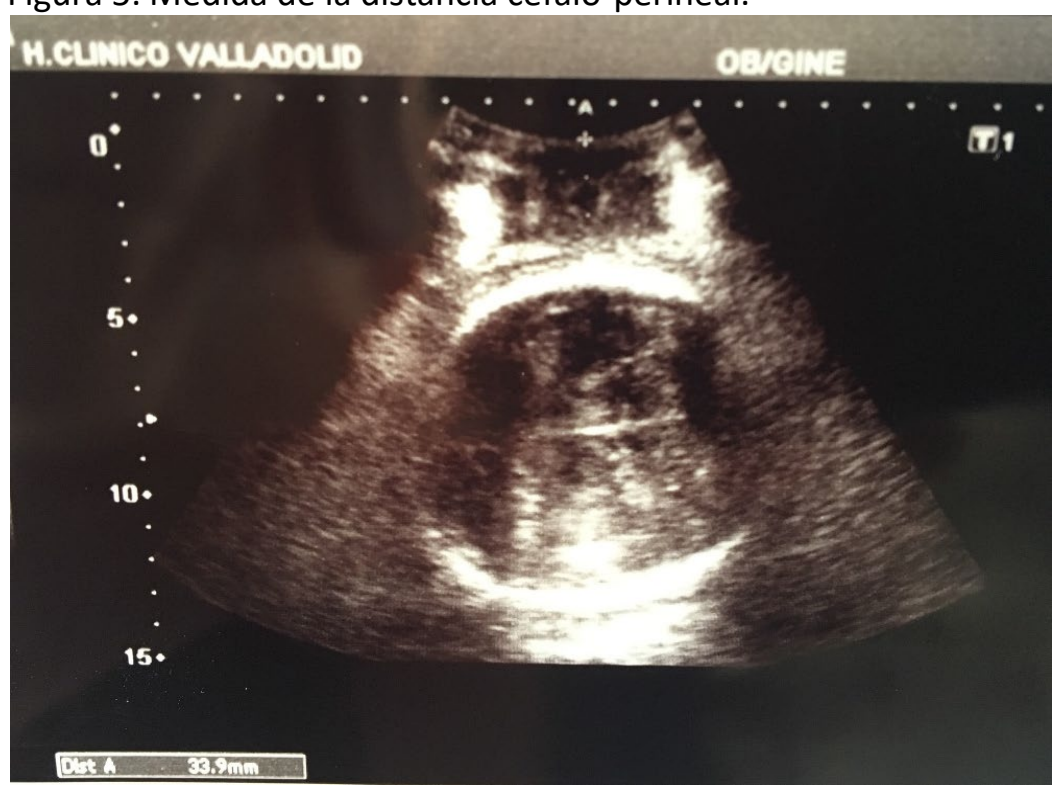

La medida de la LC se realiza según la técnica ampliamente difundida para la predicción del parto prematuro con este parámetro ${ }^{100}$. La paciente se encuentra 
en posición de litotomía con vejiga vacía y se emplea la sonda endocavitaria de 7.5 $\mathrm{MHz}$, protegida con funda y colocando gel conductor. Se introduce la sonda en la vagina apoyándose contra el cuello, pero sin presionarlo, hasta que se obtiene la imagen del cérvix uterino, en un corte sagital. Antes de proceder a la medición cervical, debe ampliarse la imagen hasta ocupar por lo menos los 2/3 de la pantalla, sin que el $\mathrm{OCl}$ y el OCE dejen de ser visualizados. Al mismo tiempo, hay que comprobar que el estroma cervical por encima y por debajo del canal cervical tenga la misma apariencia y grosor.

La medida se realiza entre el $\mathrm{OCl}$ y el OCE, repitiendo esta operación 3 veces y escogiendo la más corta de las tres medidas (Figura 6).

Figura 6. Medida de la longitud cervical

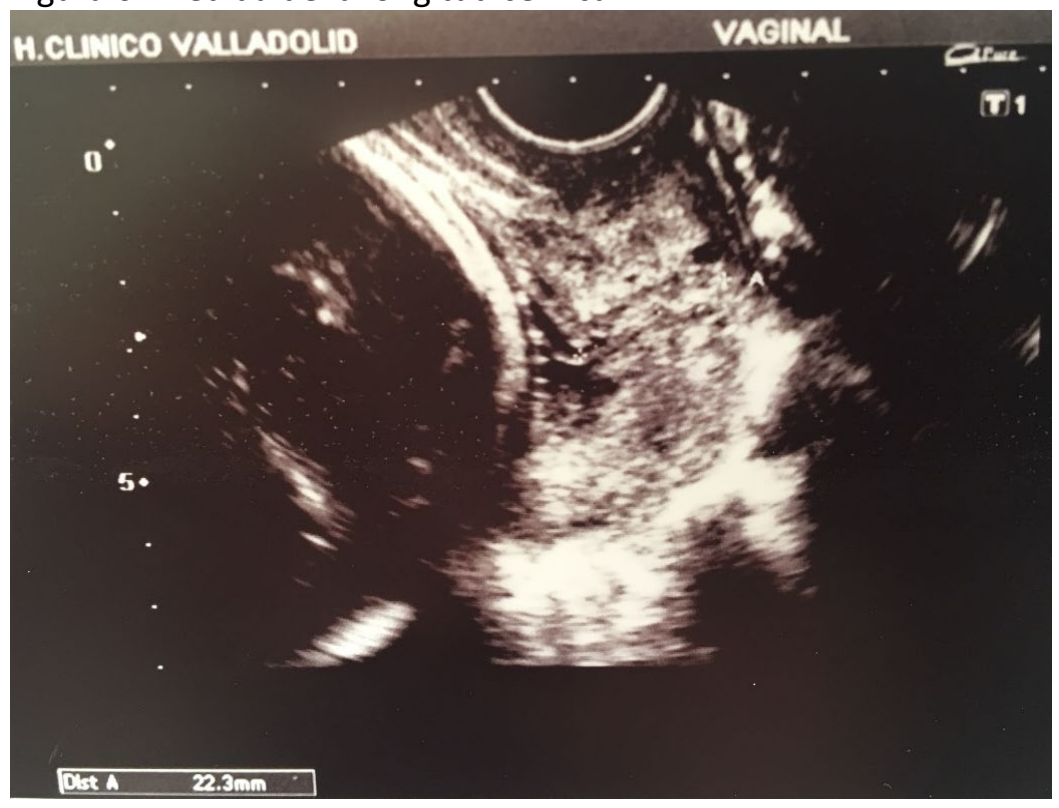

El ACP se mide según la metodología propuesta por Rane y cols. ${ }^{106}$. Es el ángulo, calculado por el software del ecógrafo, formado por la unión de 2 líneas, una que coincidiría con la LC y otra que pasaría por la pared posterior uterina (Figura 7). Para obtenerlo, partimos de la misma imagen sagital óptima para calcular la LC, esta vez centrándonos en el $\mathrm{OCl}$.

Si el canal cervical es demasiado curvo, se buscaría una línea que uniera el OCl con el OCE, que es la línea que usaríamos como LC (Figura 8).

Figura 7. Medida del ángulo cervical posterior, según Rane y cols. ${ }^{106}$.
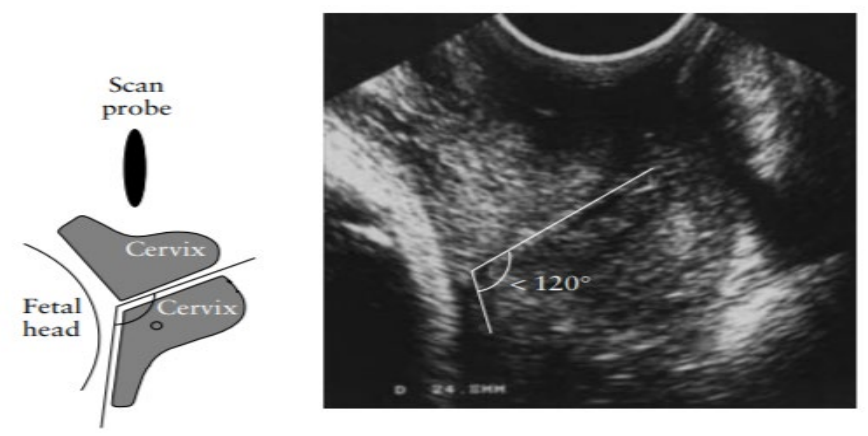
Figura 8. Medida del ángulo cervical posterior

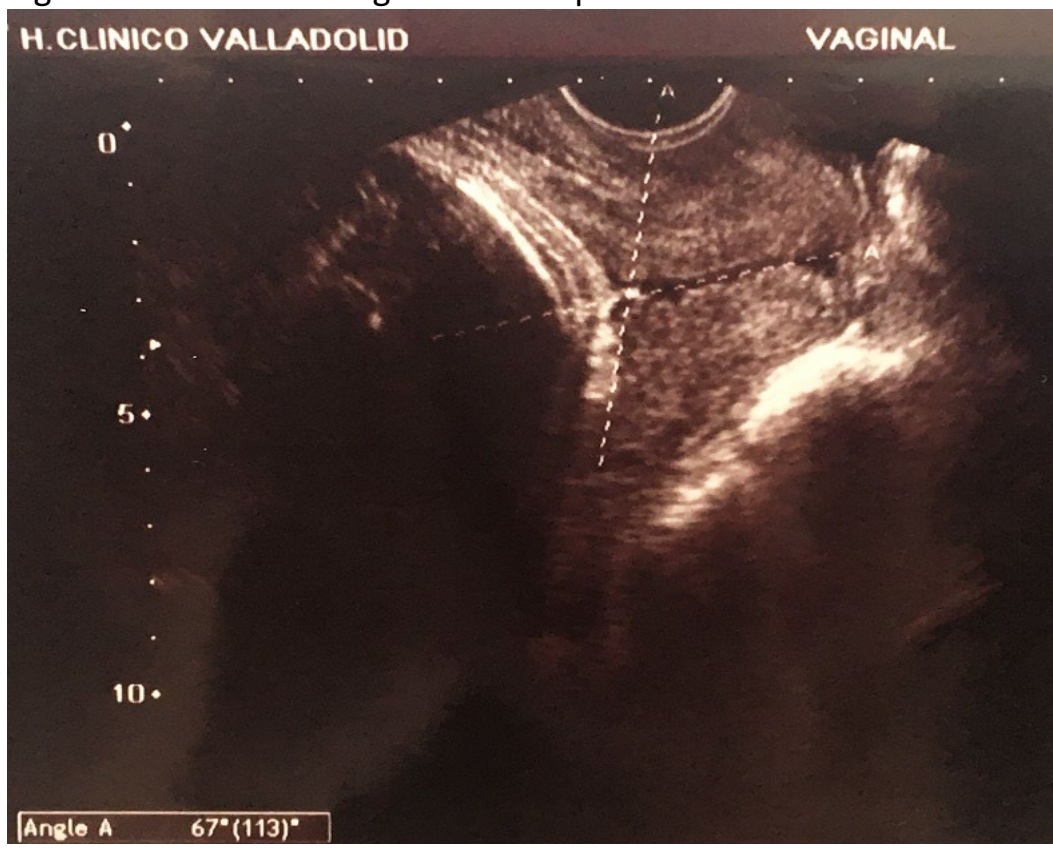

La dilatación ecográfica se define como la banda hipoecoica que existe entre $\mathrm{OCl}$ y OCE, y podría ser comparada con la dilatación que forma parte de la puntuación Bishop, que es subjetiva. Se obtiene con la sonda ecográfica endovaginal, obteniendo un corte sagital centrado en el cérvix, como si buscáramos la LC. Es un parámetro que no suele cuantificarse, debido a que no existe mucha correlación entre la medida ecográfica del canal endocervical y la dilatación cervical mediante tacto vaginal ${ }^{83}$. Esto puede deberse a la consistencia blanda de los cuellos a término, que pueden presentar algo de dilatación ecográfica, y no parecer dilatados mediante el tacto vaginal.

Figura 9. Dilatación ecográfica del cérvix.

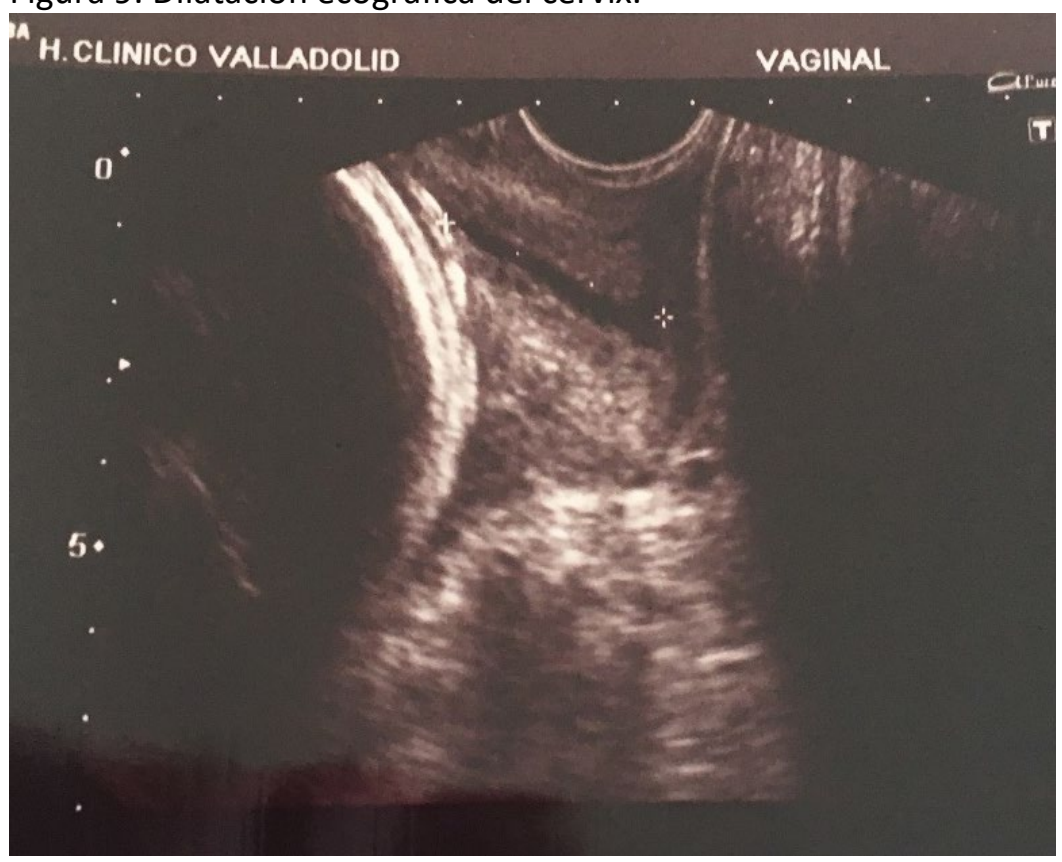


El patrón de acuñamiento cervical es la forma que tiene el $\mathrm{OCl}$, al realizar un corte sagital del cérvix uterino mediante ecografía endovaginal. Puede simular una $\mathrm{V}$, una $\mathrm{U}$ o una $\mathrm{T}^{51}$ (Figuras 10, 11 y 12).

Figura 10. Patrón de acuñamiento cervical ecográfico tipo V

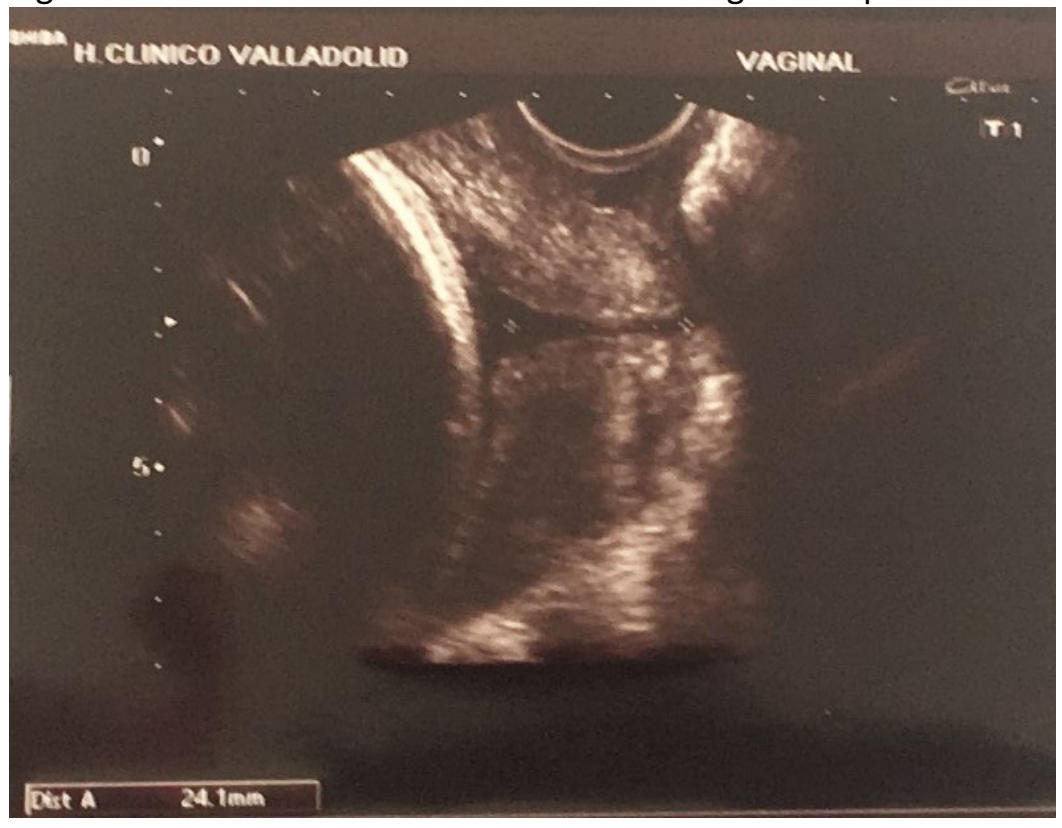

Figura 11. Patrón de acuñamiento cervical ecográfico tipo U

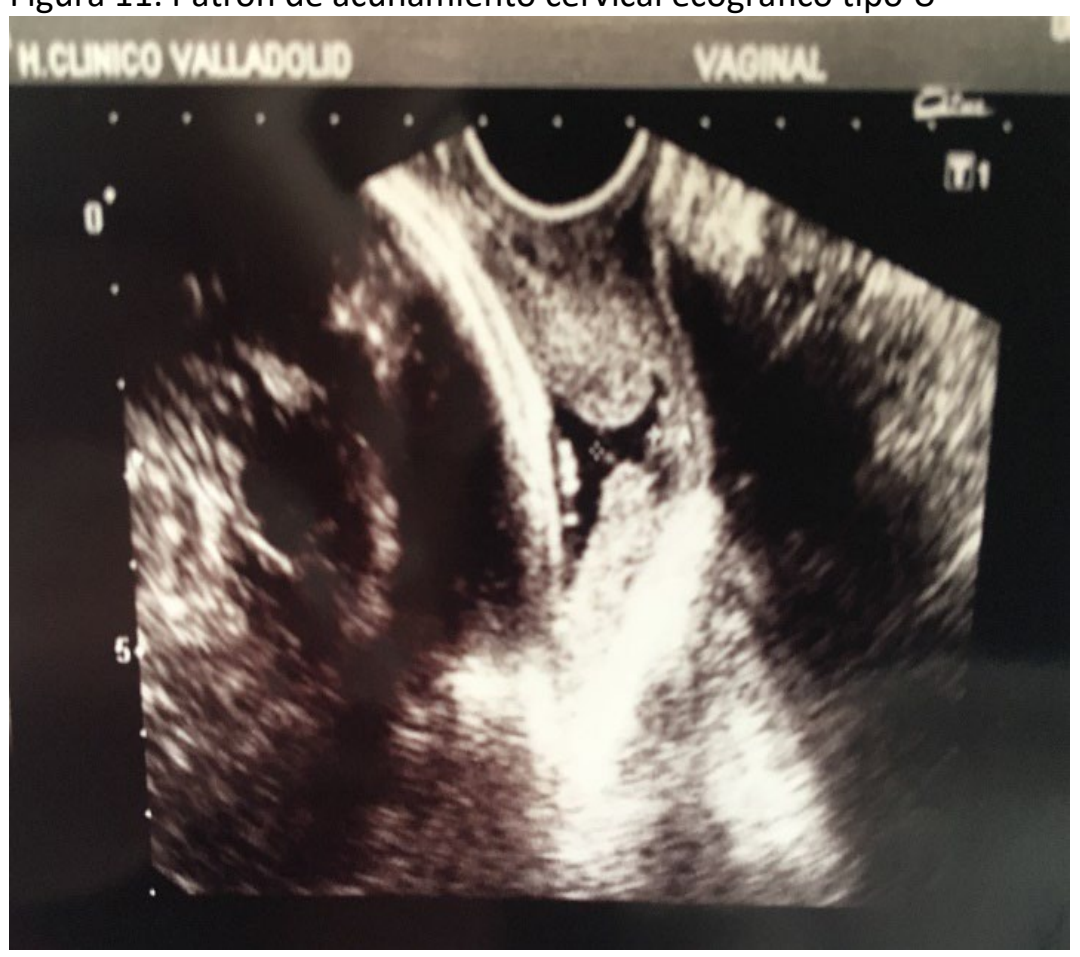


Figura 12. Patrón de acuñamiento cervical ecográfico tipo T

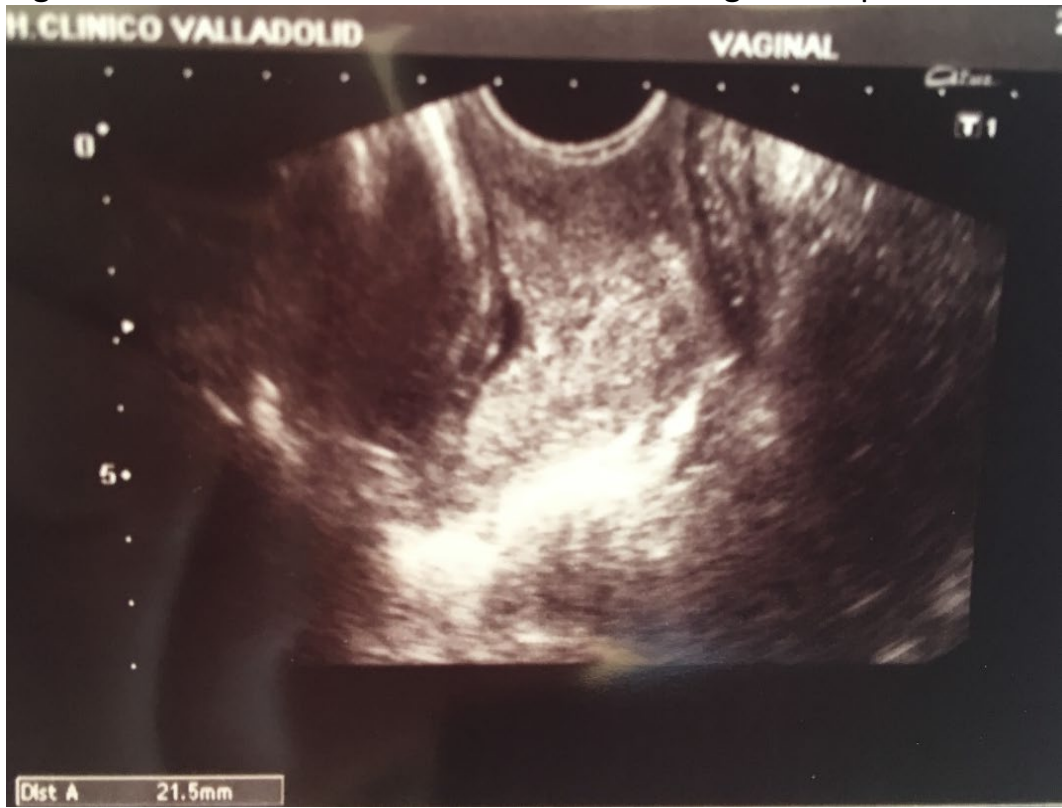

La presencia de embudización o funneling, mediante sonda endovaginal y corte sagital del cérvix, consiste en la dilatación del $\mathrm{OCl}$, generando un triángulo cuyo vértice está en el canal cervical, y que correspondería con el patrón de acuñamiento $\mathrm{V}$ o $\mathrm{U}^{50}$, ya que el patrón en $\mathrm{T}$, por definición, no se acompañaría de dilatación del OCI (Figura 13).

Figura 13. Cérvix con presencia del signo de Funnel ecográfico

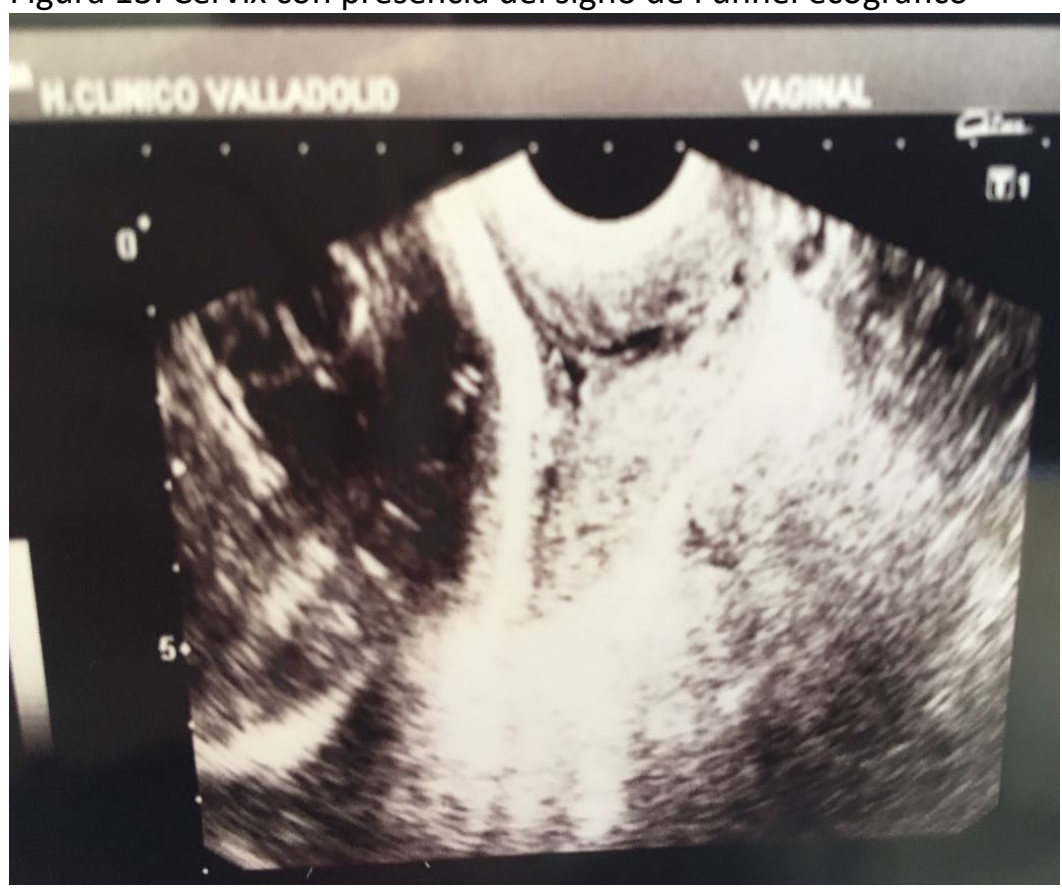


Todas estas mediciones ecográficas se imprimen desde el ecógrafo en papel fotográfico y se adjuntan al Anexo 4 de HRD de la paciente. Todos estos documentos son correctamente custodiados

- Exploración física

Se realiza mediante tacto vaginal por un profesional con suficiente experiencia en la valoración de la puntuación Bishop ${ }^{50}$. Estos profesionales (matrona, ginecólogo o MIR de tercer/cuarto año) son distintos de los 4 investigadores principales y no han estado presentes durante la exploración ecográfica desarrollada por los uno de los 4 observadores. Apuntan en la HRD los resultados del tacto vaginal, en cuanto a dilatación, posición, consistencia y borramiento cervical ${ }^{50}$ y grado de encajamiento de la cabeza fetal según los planos de Hodge ${ }^{135}$.

Figura 14. Grado de encajamiento de la cabeza fetal según planos de Hodge (imagen tomada de Cunningham M. Williams Obstetricia. 20a ed. Médica Panamericana $1998^{135}$ ).

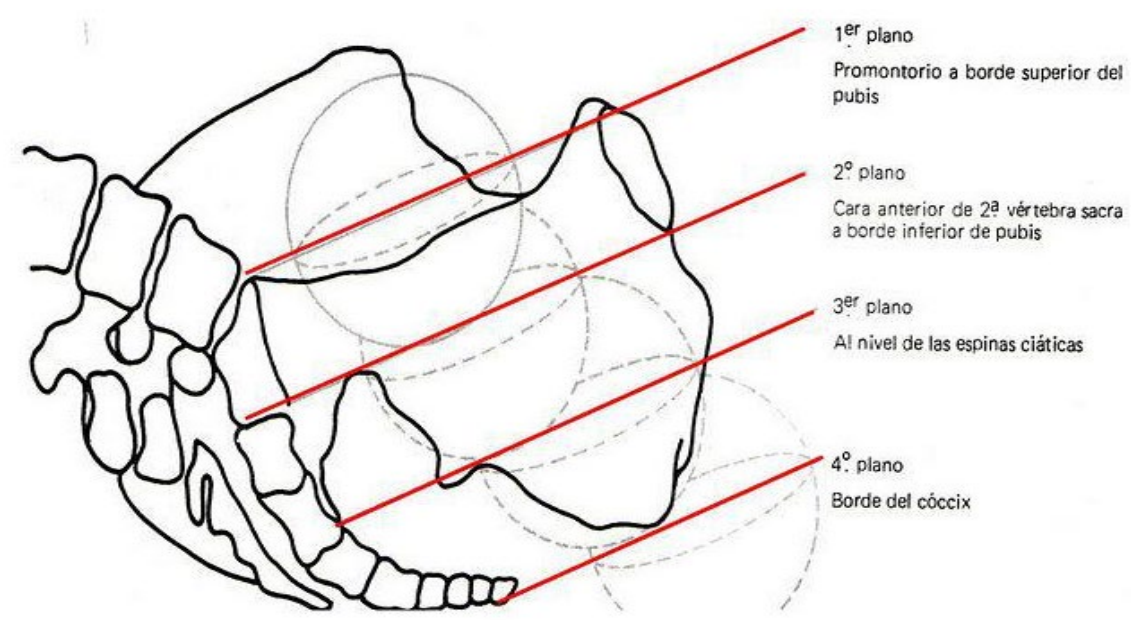

\subsubsection{PROTOCOLO DE INDUCCIÓN}

Se ha seguido el protocolo de inducción vigente en el Servicio de Obstetricia y Ginecología del Hospital Clínico Universitario durante el período de estudio (Figura 15). El protocolo contempla los siguientes pasos:

- Tras la recogida de datos, realizadas las exploraciones ecográficas y mediante tacto vaginal, se decide el método de inducción según la puntuación Bishop, tras confirmación del bienestar fetal con un RCTG reactivo de 20-30 min de duración.

- Cuando un cuello se considera maduro $(B>7)$ se inicia la inducción directamente con oxitocina (Syntocinon ${ }^{\circledR}$ ) en bomba de perfusión continua ( 1 ampolla de $10 \mathrm{~mL}$ de Syntocinon ${ }^{\circledast}$ en $500 \mathrm{~mL}$ de suero cristaloide) con dosis de $1 \mathrm{mU} / \mathrm{min}$, que se va doblando cada 20-30 min hasta alcanzar una dinámica regular de 3-4 contracciones cada $10 \mathrm{~min}$. La inducción con oxitocina requiere una monitorización materno-fetal continua (RCTG) y la estancia de la paciente en el área de Paritorio. La amniotomía (rotura de la bosa amniótica) se realiza en cuanto es posible, en condiciones de asepsia y con una lanceta apropiada para este uso. Precisa que el cuello uterino tenga al menos $1 \mathrm{~cm}$ de dilatación, independientemente del grado de borramiento.

- $\mathrm{Si}$, por el contrario, el cérvix es desfavorable ( $\mathrm{B} \leq 7)$, precisa ser madurado. Para ello, se utiliza Dinoprostona en dispositivo vaginal de liberación lenta (Propess ${ }^{\circledR} 10$ 
$\mathrm{mg}$ ). Se coloca intravaginalmente durante un máximo de 24 horas. La paciente permanece en el área de Hospitalización mientras se realiza la maduración cervical. El primer control se realiza a la hora de la inserción mediante un RCTG. Posteriormente los controles con RCTG son espaciados cada 3-4 horas o según sintomatología de la paciente, que acudirá al área de paritorio para valoración si presenta dinámica uterina regular, amniorrexis, sangrado o cualquier otro síntoma.

- El dispositivo vaginal de maduración se retirará en los siguientes supuestos:

- polisistolia uterina ( $\geq 6$ contracciones cada $10 \mathrm{~min}$ )

- repercusión fetal con un patrón de RCTG no tranquilizador

- inicio de la fase activa de parto $(\geq 3 \mathrm{~cm}$ de dilatación, con cérvix borrado $\geq 80 \%$ y dinámica uterina regular de 2-3 contracciones cada $10 \mathrm{~min}$ )

- La paciente se valora a las 24 horas, si antes no ha iniciado la fase activa del parto, y si el cérvix continúa desfavorable, se retira el dispositivo y se coloca uno nuevo, que se dejará otras 24 horas, realizando los mismos controles y permaneciendo aún en el área de hospitalización. En caso de $B>7$, se retirará el primer dispositivo y a los 30 min se iniciará la perfusión de oxitocina como en el caso de cérvix maduro, procediendo a la amniotomía en cuanto sea posible.

- Durante la fase latente del parto, durante la maduración cervical, el dolor puede mitigarse con la administración parenteral del derivado mórfico Meperidina (Dolantina ${ }^{\circledR}$ Solución inyectable $50 \mathrm{mg} / \mathrm{mL}$, Kern Pharma, S.L.) asociado a Haloperidol (Haloperidol ${ }^{\circledR}$ Esteve solución inyectable $5 \mathrm{mg}$ ).

- Si tras 2 dosis de Propess $^{\circledR}$ en 48 horas, el cérvix no ha madurado, se retira el segundo dispositivo y a los $30 \mathrm{~min}$ se inicia perfusión de oxitocina, independientemente de la puntuación de Bishop, con amniotomía en cuanto sea posible.

- Cuando la gestante inicia la fase activa de parto, la monitorización fetal es continua en el área de paritorio, con instauración de vía venosa y se sigue el protocolo de atención al parto de alto riesgo, controlando la evolución del parto mediante el partograma.

- En mujeres con indicación de inducción por RPM, se realiza manejo expectante durante 24 horas, con administración de antibiótico intravenoso a las 18 horas desde que se rompió la bolsa. A las 24 horas se inicia inducción oxitócica, independientemente del estado cervical.

- Se considera un fracaso de inducción cuando no se han conseguido las condiciones de parto en curso tras la administración de oxitocina durante al menos 12 horas acompañada de amniotomía, y la dinámica ha sido regular con al menos 4 contracciones cada $10 \mathrm{~min}{ }^{1}$ durante todo el proceso. En estos casos, se indica una cesárea por fracaso de inducción. Es muy importante ser rígido en la aplicación de estas normas, puesto que la fase latente requiere tiempo y dinámica uterina con amniorrexis, y realizar una cesárea antes de tiempo genera consecuencias posteriores.

- Desde el punto de vista clínico, las cesáreas realizadas por indicación intraparto no se consideran fracaso de inducción, aunque el inicio del parto haya sido inducido. 
Figura 15. Protocolo de inducción del Servicio de Obstetricia y Ginecología del Hospital Clínico Universitario durante el período de estudio.

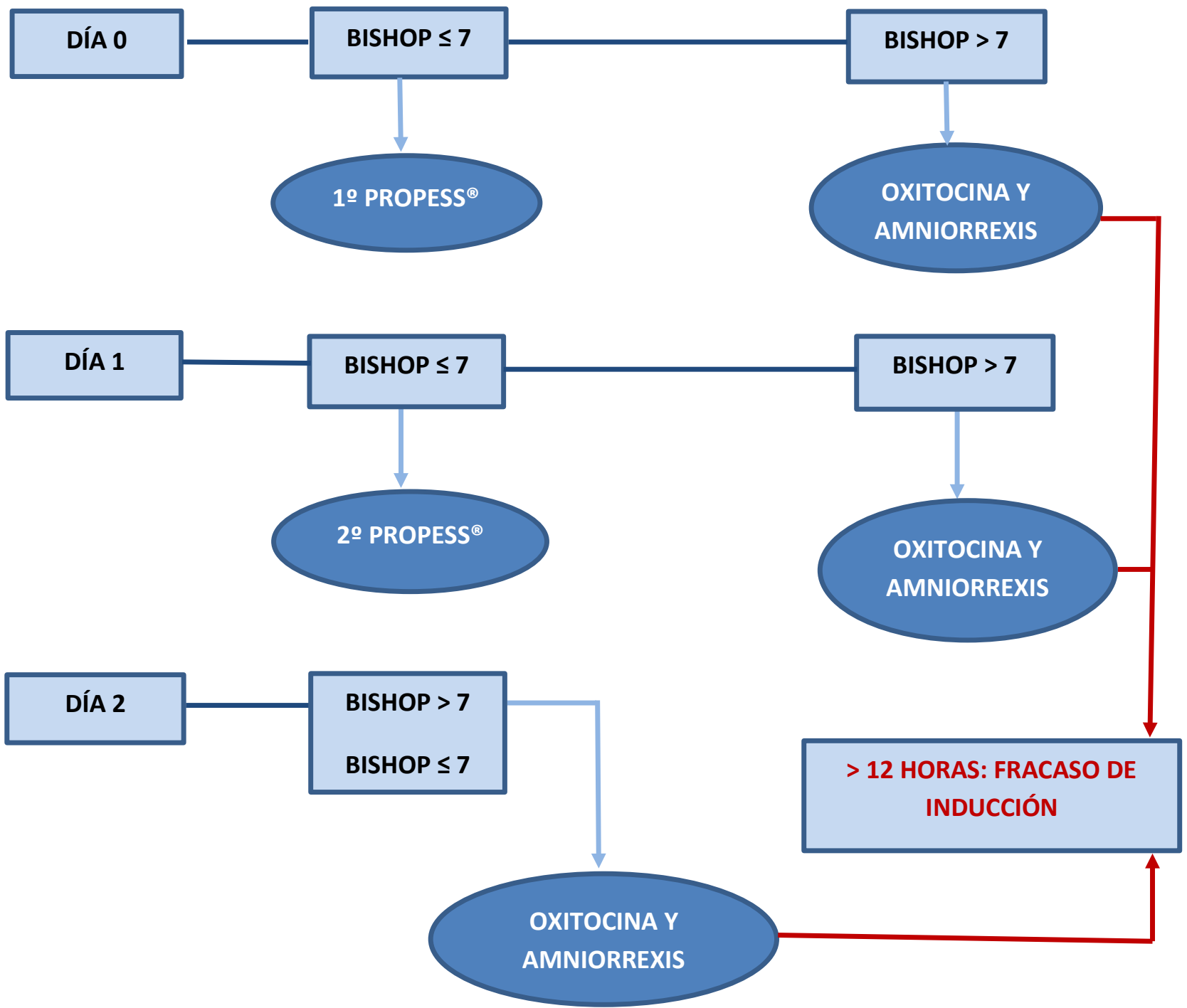

\subsubsection{DURACIÓN DEL PROCEDIMIENTO}

En la HRD se incluye la fecha y hora tanto del comienzo de la inducción, de la fase activa del parto y del momento final del parto. Se calcula la duración en min de esas 3 fases:

- inducción: tiempo desde que se inicia cualquier método, ya sea farmacológico (PG E2 u oxitocina) o con amniotomía, hasta la expulsión fetal

- fase latente: tiempo que trascurre entre el comienzo de la inducción y el inicio de la fase activa del parto (dilatación cervical $\geq 3 \mathrm{~cm}$ con cérvix borrado $\geq 80 \%$ y dinámica uterina regular)

- fase activa del parto: tiempo entre el inicio clínico del parto y el nacimiento

\subsubsection{NECESIDAD DE ANALGESIA}

Se diferencia entre fase latente y fase activa, recogiendo la analgesia empleada en cada caso, habitualmente meperidina en la fase latente y analgesia epidural durante el trabajo de parto. 


\subsubsection{NECESIDAD DE ESTIMULACIÓN}

Como cualquier trabajo de parto, ya sea de inicio espontáneo o inducido, la progresión de este puede precisar la perfusión de oxitocina.

\subsubsection{MODALIDAD DE PARTO}

Se detalla si es vaginal o cesárea. Si es un parto vaginal, se especifica además si es eutócico o instrumentado con fórceps, ventosa tipo Kiwi ${ }^{\mathrm{TM}}$ (Corporativo Neomédica, México) o espátulas.

\subsubsection{PESO DEL RECIÉN NACIDO (en gramos)}

Además de la HRD (Anexo 3), se creó una base de datos en Access para el almacenamiento y explotación de los datos (Anexo 4).

\subsection{VARIABLE DE ESTUDIO}

Como variable de resultado primaria del estudio se ha elegido la vía del parto, es decir vaginal o cesárea, independientemente del tiempo trascurrido desde el inicio de la inducción

\subsection{CONSIDERACIONES ÉTICAS Y LEGALES}

Tras valorar los criterios de inclusión, si la paciente que va a ser inducida es reclutada para el estudio, uno de los cuatro investigadores explica de forma detallada el objetivo del estudio y la metodología de este, con un vocabulario que sea fácilmente entendible por la paciente, otorgando así su consentimiento de participar, dejándolo reflejado en el $\mathrm{Cl}$ (Anexo 2). Se respetan las normas internacionales de protección de datos, así como la legislación vigente española (Ley Orgánica 15/1999 del 13/12/99 de Protección de Datos de Carácter Personal, BOE 298 de 14/12/99).

Se han respetado los principios éticos para las investigaciones médicas en seres humanos según la Declaración de Helsinki de la Asociación Médica Mundial, en su última revisión (59a Asamblea General, Seúl, Corea, octubre 2008).

Asimismo, tanto el presente estudio, como el estudio piloto previo que generó el modelo matemático de predicción de parto de Álvarez-Colomo y cols., han sido aprobados por la Comisión de Investigación del Hospital Clínico Universitario de Valladolid, en la reunión celebrada el 26 de Febrero de 2009 (Anexo 5).

\subsection{ANÁLISIS ESTADÍSTICO}

El estudio estadístico descriptivo se ha realizado mediante la determinación de los estadísticos descriptivos para las variables continúas aplicando la prueba de Kolmogorov-Smirnov para determinar la normalidad de su distribución. En dicho caso los datos se han expresado mediante la media, rango y desviación estándar y representados mediante histogramas. Para variables de distribución no-normal, se empleó la mediana y el intervalo intercuartílico (Q1Q3). Las variables cuantitativas discretas y las categóricas se han descrito por medio de distribución de frecuencias y representaciones gráficas mediante diagramas de sectores o de barras.

La comparación de medias se ha realizado mediante la prueba de t de Student para muestras independientes en variables con distribución normal y la de $U$ de Mann-Whitney en caso de distribución no normal. La comparación de proporciones se ha realizado mediante la prueba de Chi-cuadrado (2א), aplicando la corrección de Yates para tablas $2 \times 2$ y la prueba exacta de Fisher cuando las frecuencias observadas fueron inferiores a 5 en el $20 \%$ o más de las casillas de la tabla de contingencia. 
Para el cálculo de riesgo se ha empleado el riesgo relativo, con intervalos de confianza del 95\%.

El análisis de la prueba diagnóstica (ecografía) se ha realizado mediante el cálculo de la sensibilidad, especificidad, valor predictivo positivo y negativo y razones de verosimilitud con intervalos de confianza del $95 \%$.

En todos los casos, la diferencia se ha considerado estadísticamente significativa a partir de valores de $p$ inferiores a 0,05. Los cálculos se han realizado por medio del programa SPSS v.19 (IBM, licencia para la Universidad de Valladolid). 
RESULTADOS 


\section{RESULTADOS}

Durante el período de estudio se atendieron 2710 partos, de los cuales 735 fueron inducidos (27.1\%). La tasa global de cesárea fue $23.4 \%$. Si consideramos aisladamente los partos de inicio espontáneo, el porcentaje de cesárea para este grupo fue del $10.7 \%$.

De las 735 IP, 219 (29.8\%) finalizaron mediante cesárea y 516 mediante parto vaginal.

Nuestro estudio incluye 231 inducciones (grupo 2), que suponen el $31.4 \%$ del total de inducciones durante el período de estudio.

El estudio piloto previo de Álvarez-Colomo y cols., que se utiliza como grupo control del presente estudio (grupo 1), y dio lugar al modelo predictivo de parto que se pretende validar en condiciones clínicas reales incluyó 151 pacientes ${ }^{126}$.

\subsection{ESTUDIO COMPARATIVO ENTRE LOS DOS GRUPOS DE ESTUDIO (Tabla 16).}

Las características de las pacientes de los dos grupos son homogéneas, ya que no se encontraron diferencias estadísticamente significativas en cuanto a la edad, medidas antropométricas ni antecedentes obstétricos.

Tampoco existe una diferencia en la EG del momento del parto, la frecuencia de las diferentes indicaciones de la inducción ni en la exploración física al inicio de esta (puntuación de Bishop).

Respecto al tamaño de los fetos, los dos grupos son comparables, ya que no se encontraron diferencias estadísticamente significativas en relación con el peso fetal estimado por ecografía antes del parto, con el DBP o con el peso del RN.

Puesto que ambas muestras estudiadas son comparables y el protocolo de inducción fue el mismo, lo esperable es que no se encuentren diferencias en el porcentaje de parto vaginal, que coincide en ambos grupos $(69,7 \%)$. 
Tabla 16. Comparación de variables entre los grupos 1 y 2.

\begin{tabular}{|c|c|c|c|}
\hline VARIABLE & $\begin{array}{c}\text { GRUPO } 1 \\
(n=151)\end{array}$ & $\begin{array}{c}\text { GRUPO } 2 \\
(n=231)\end{array}$ & $p$ \\
\hline $\begin{array}{l}\text { Edad (años) } \\
\text { Mediana (Rango Q1-Q3) }\end{array}$ & $\begin{array}{c}33 \\
(30-36) \\
\end{array}$ & $\begin{array}{c}33 \\
(30-36) \\
\end{array}$ & $0.775^{*}$ \\
\hline $\begin{array}{l}\text { Peso (kg) } \\
\text { Mediana (Rango Q1-Q3) }\end{array}$ & $\begin{array}{c}75.100 \\
(66.125-83.350)\end{array}$ & $\begin{array}{c}74.200 \\
(67.000-84.000)\end{array}$ & $0.941 *$ \\
\hline $\begin{array}{l}\text { Talla }(\mathrm{m}) \\
\text { Mediana (Rango Q1-Q3) }\end{array}$ & $\begin{array}{c}1.62 \\
(1.58-1.65)\end{array}$ & $\begin{array}{c}1.62 \\
(1.58-1.66) \\
\end{array}$ & $0.346 *$ \\
\hline $\begin{array}{l}\left.\text { IMC (kg/ } \mathbf{m}^{2}\right) \\
\text { Mediana (Rango Q1-Q3) }\end{array}$ & $\begin{array}{c}28.12 \\
(25.61-31.59)\end{array}$ & $\begin{array}{c}27.97 \\
(25.66-31.47)\end{array}$ & $0.411 *$ \\
\hline Nuliparidad $\mathrm{n}(\%)$ & $114(75 \%)$ & $179(78.2 \%)$ & $0.474^{* *}$ \\
\hline Cesárea previa n (\%) & $14(9.2 \%)$ & $35(15.2 \%)$ & $0.083^{* *}$ \\
\hline $\begin{array}{l}\text { DBP (mm) } \\
\text { Mediana (Rango Q1-Q3) }\end{array}$ & $\begin{array}{c}91 \\
(88.25-94)\end{array}$ & $\begin{array}{c}91.70 \\
(89-94.20)\end{array}$ & $0.615^{*}$ \\
\hline $\begin{array}{l}\text { PFE (gr) } \\
\text { Media } \pm \text { DS }\end{array}$ & $3091.75 \pm 464.44$ & $3149.38 \pm 468.37$ & $0.197 *$ \\
\hline Puntuación Bishop n (\%): & $\begin{array}{c}126(82.80 \%) \\
79(52.30 \%)\end{array}$ & $\begin{array}{l}199(86.15 \%) \\
130(56.28 \%)\end{array}$ & $0.295^{* *}$ \\
\hline $\begin{array}{l}\text { Duración de la gestación (días) } \\
\text { Mediana (Rango Q1-Q3) }\end{array}$ & $\begin{array}{c}277 \\
(270-289) \\
\end{array}$ & $\begin{array}{c}280.50 \\
(271.15-289.25)\end{array}$ & $0.229 *$ \\
\hline $\begin{array}{r}\text { Indicación de la inducción } \mathrm{n}(\%): \\
\text { RPM } \\
\text { GCP } \\
\text { DIABETES } \\
\text { CIR } \\
\text { PREECLAMPSIA } \\
\text { OTRAS }\end{array}$ & $\begin{array}{c}33(21.7 \%) \\
32(21.1 \%) \\
25(16.4 \%) \\
26(17.1 \%) \\
8(5.8 \%) \\
27(17.9 \%)\end{array}$ & $\begin{array}{l}48(20.8 \%) \\
57(24.7 \%) \\
37(16 \%) \\
34(14.7 \%) \\
6(2.6 \%) \\
49(21.2 \%)\end{array}$ & $0.101^{* *}$ \\
\hline $\begin{array}{l}\text { Método de inducción } \mathrm{n}(\%) \text { : } \\
\qquad \begin{array}{r}1 \text { dosis PG E2 } \\
2 \text { dosis PG E2 } \\
\text { Amniotomía } \\
\text { Oxitocina }\end{array}\end{array}$ & $\begin{array}{c}109(72.2 \%) \\
24(15.9 \%) \\
9(6 \%) \\
9(6 \%)\end{array}$ & $\begin{array}{c}176(76.19 \%) \\
21(9.09 \%) \\
1(0.43 \%) \\
34(14.72 \%) \\
\end{array}$ & $0.321^{* *}$ \\
\hline $\begin{array}{r}\text { Modo de finalización del parto } \mathrm{n}(\%): \\
\text { Parto vaginal } \\
\text { Cesárea }\end{array}$ & $\begin{array}{c}106(69.7 \%) \\
46(30.3 \%)\end{array}$ & $\begin{array}{c}161(69.7 \%) \\
70(30.3 \%)\end{array}$ & $0.993^{* *}$ \\
\hline $\begin{array}{l}\text { Peso del RN (gr) } \\
\text { Mediana (Rango Q1-Q3) }\end{array}$ & $\begin{array}{c}3160 \\
(2855-3500) \\
\end{array}$ & $\begin{array}{c}3160 \\
(2800-3540) \\
\end{array}$ & $0.844^{*}$ \\
\hline
\end{tabular}

*U de Mann-Whitney ${ }^{* *}$ Chi-cuadrado

\subsection{VARIABLES Y RELACIÓN CON EL MODO DE PARTO}

Las variables que mostraron asociación con la vía del parto en el grupo 1, se mantienen en el grupo 2. Estos factores, que se relacionaron de forma significativa con el PV en ambas muestras, son los siguientes: talla, Bishop, cesárea previa, PV previo, DCP y LC (Tablas 17, 18 y 19). 
Tabla 17. Variables continúas relacionadas con la vía del parto.

\begin{tabular}{|c|c|c|c|}
\hline \multicolumn{3}{|c|}{ TALLA (m) } & $\mathrm{p}$ \\
\hline \multirow[t]{3}{*}{ GRUPO 1} & Parto vaginal $(n)$ & (105) & \multirow[t]{3}{*}{$0.032^{*}$} \\
\hline & Cesárea (n) & (46) & \\
\hline & Media \pm DS & $1.60 \pm 0.57$ & \\
\hline \multirow[t]{4}{*}{ GRUPO 2} & Parto vaginal $(n)$ & (159) & \multirow[t]{4}{*}{$0.028^{*}$} \\
\hline & Media \pm DS & $1.63 \pm 0.60$ & \\
\hline & Cesárea (n) & (72) & \\
\hline & Media \pm DS & $1.61 \pm 0.64$ & \\
\hline \multicolumn{3}{|c|}{ BISHOP } & $\mathrm{p}$ \\
\hline \multirow[t]{4}{*}{ GRUPO 1} & Parto vaginal $(n)$ & $(105)$ & \multirow[t]{4}{*}{$<0.0001^{*}$} \\
\hline & Media \pm DS & $3.97 \pm 2.03$ & \\
\hline & Cesárea $(n)$ & (46) & \\
\hline & Media \pm DS & $2.78 \pm 1.56$ & \\
\hline \multirow[t]{4}{*}{ GRUPO 2} & Parto vaginal $(n)$ & (159) & \multirow[t]{4}{*}{$0.009 *$} \\
\hline & Media \pm DS & $3.62 \pm 1.76$ & \\
\hline & Cesárea $(n)$ & (72) & \\
\hline & Media \pm DS & $2.96 \pm 1.74$ & \\
\hline \multicolumn{3}{|c|}{ DISTANCIA CÉFALO-PERINEAL (mm) } & $\mathrm{p}$ \\
\hline \multirow[t]{4}{*}{ GRUPO 1} & Parto vaginal $(n)$ & $(105)$ & \multirow[t]{4}{*}{$<0.0001^{*}$} \\
\hline & Media \pm DS & $44.70 \pm 7.45$ & \\
\hline & Cesárea (n) & (46) & \\
\hline & Media \pm DS & $51.26 \pm 7.41$ & \\
\hline \multirow[t]{4}{*}{ GRUPO 2} & Parto vaginal $(n)$ & (159) & \multirow[t]{4}{*}{$0.001^{*}$} \\
\hline & Media \pm DS & $47.56 \pm 8.22$ & \\
\hline & Cesárea (n) & (72) & \\
\hline & Media \pm DS & $52.35 \pm 10.65$ & \\
\hline \multicolumn{3}{|c|}{ LONGITUD CERVICAL (mm) } & $p$ \\
\hline \multirow[t]{4}{*}{ GRUPO 1} & Parto vaginal $(n)$ & $(105)$ & \multirow[t]{4}{*}{$0.003^{*}$} \\
\hline & Media \pm DS & $26.06 \pm 9.80$ & \\
\hline & Cesárea (n) & (46) & \\
\hline & Media \pm DS & $31.40 \pm 10.23$ & \\
\hline \multirow[t]{4}{*}{ GRUPO 2} & Parto vaginal $(n)$ & (159) & \multirow[t]{4}{*}{$0.010^{*}$} \\
\hline & Media \pm DS & $25.18 \pm 9.79$ & \\
\hline & Cesárea (n) & (72) & \\
\hline & Media \pm DS & $29.07 \pm 10.78$ & \\
\hline
\end{tabular}

* t de Student

Tabla 18. Relación del antecedente de cesárea con la vía del parto.

\begin{tabular}{|l|l|l|l|l|}
\hline \multirow{2}{*}{} & \multicolumn{2}{|c|}{ CESÁREA PREVIA } & \multicolumn{2}{c|}{ p } \\
\cline { 2 - 4 } & GRUPO 1 (14) & GRUPO 2 (35) & GRUPO 1 & GRUPO 2 \\
\hline Vaginal n (\%) & $6(42.85 \%)$ & $18(51.4 \%)$ & $0.023^{*}$ & $0.018^{*}$ \\
\hline Cesárea n (\%) & $8(57.15 \%)$ & $17(48.6 \%)$ & & \\
\hline
\end{tabular}

* Chi-cuadrado 
Tabla 19. Relación del parto vaginal previo con la vía del parto.

\begin{tabular}{|l|l|l|l|l|}
\hline \multirow{2}{*}{} & \multicolumn{2}{|c|}{ PARTO VAGINAL PREVIO } & \multicolumn{2}{c|}{ p } \\
\cline { 2 - 3 } & GRUPO 1 (37) & GRUPO 2 (50) & GRUPO 1 & GRUPO 2 \\
\hline Vaginal n (\%) & $34(91.89 \%)$ & $46(92 \%)$ & $<0.001^{*}$ & $0.000^{* *}$ \\
\hline Cesárea n (\%) & $3(8.11 \%)$ & $4(8 \%)$ & & \\
\hline
\end{tabular}

* Estadísitico de Fisher. ${ }^{* *}$ Chi-cuadrado

\subsection{PREDICCIÓN DEL RESULTADO DE LA INDUCCIÓN APLICANDO EL MODELO PILOTO AL GRUPO 2}

Al aplicar la fórmula predictiva derivada del estudio piloto previo de Álvarez-Colomo y cols., que integra las variables que se asociaron de forma significativa con la vía del parto, a la muestra de estudio (Tabla 20), el modelo consiguió una correcta predicción de cesárea en un $70.74 \%$, con una tasa de FP del $15 \%$ (Tabla 21). Dicha tasa de predicción es muy inferior a la del modelo piloto $(82.8 \%$, con una tasa de FP del $15 \%){ }^{126}$.

Tabla 20. Fórmula matemática predictora del modo de finalización del parto por cesárea, según Álvarez-Colomo y cols. ${ }^{126}$.

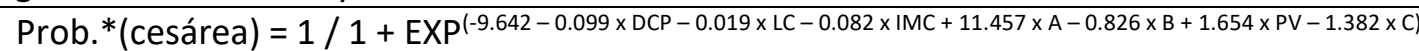

Variables cuantitativas continuas: DCP $(\mathrm{mm})$. LC $(\mathrm{mm})$. Altura materna $(\mathrm{cm})$.

Variables dicotómicas: B (<4), PV previo y Cesárea previa. Su presencia se corresponde con 1 y su ausencia con 0.

* Predice mejor los partos que finalizarán por PV que por cesárea. Si el valor calculado de Prob. es $<0.5$ se pronostica un PV y si es $\geq 0.5$ se predice una cesárea.

Tabla 21. Aplicación del modelo piloto ${ }^{126}$ al grupo 2 . Tasa de predicción correcta del modo de parto en la muestra 2.

\begin{tabular}{|c|c|c|c|c|c|}
\hline & & \multicolumn{2}{|c|}{ Observado } & \multirow[b]{2}{*}{ Total } & \multirow[b]{2}{*}{ Aciertos \% } \\
\hline & & Vaginal & Cesárea & & \\
\hline \multirow{2}{*}{ Predicción } & Vaginal & 126 & 32 & 158 & 63.29 \\
\hline & Cesárea & 35 & 36 & 71 & 50.70 \\
\hline Total & & 161 & 68 & 229 & 70.74 \\
\hline
\end{tabular}

A continuación, se expone la detección correcta de eventos al aplicar la fórmula de ÁlvarezColomo y cols. en ambos grupos, con sus consiguientes S, E, VPP y VPN para una determinada tasa de FP (Tabla 22). 
Tabla 22. Tasa de detección, Sensibilidad, Especificidad, Valor Predictivo Positivo y Valor Predictivo Negativo del modelo piloto ${ }^{126}$ y de su aplicación al grupo 2.

\begin{tabular}{|l|c|c|}
\hline & GRUPO 1 (n=151) & GRUPO 2 (n=231) \\
\hline Tasa de detección & $82.80 \%$ & $70.74 \%$ \\
\hline S (IC 95\%) & $76.3 \%(62.8-89.8)$ & $78.3 \%(71.9-84.6)$ \\
\hline E (IC 95\%) & $85 \%(78.4-91.5)$ & $52.9 \%(41.1-64.8)$ \\
\hline VPP (IC 95\%) & $63 \%(49.1-77)$ & $79.9 \%(73.5-86)$ \\
\hline VPN (IC 95\%) & $91.4 \%(86.1-96.8)$ & $50.7 \%(39.1-62.3)$ \\
& & $15 \%$ \\
\hline FP & $15 \%$ & \\
\hline
\end{tabular}

\subsection{ANÁLISIS INDIVIDUAL DE LOS PARAMETROS ECOGRAFICOS QUE COMPONEN EL MODELO PREDICTIVO PILOTO EN AMBOS GRUPOS}

Con el objetivo de discutir en el siguiente apartado de este trabajo (DISCUSIÓN) las posibles explicaciones de la diferencia existente entre el valor predictivo obtenido en el estudio piloto previo, y el presente estudio de validación clínica, hemos analizado individualmente en ambos grupos los parámetros ecográficos que se integran en el modelo matemático aplicado, para comprobar si existe alguna diferencia en las mediciones que pudiera justificar, al menos en parte, la pérdida de capacidad predictiva registrada en el presente estudio de validación.

Respecto de las medidas ecográficas objetivas y cuantificables, la DCP y el ACP resultaron significativamente mayores en el grupo 2 (Figura 16), siendo la DCP media de $46.65 \mathrm{~mm} \pm 8.01$ $\mathrm{mm}$ en grupo 1 vs $49.03 \mathrm{~mm} \pm 9.30 \mathrm{~mm}$ en grupo $2(\mathrm{p}=0.013)$ y la mediana del ACP de $110^{\circ}$ en grupo 1 vs $113^{\circ}$ en grupo 2 ( $p=0.048$ ) (Tabla 23 ).

En cambio, no hubo diferencias entre grupos en la medida de la LC (Tabla 23).

Figura 16. Medidas ecográficas DCP y ACP de ambos grupos, según su media y mediana, respectivamente.

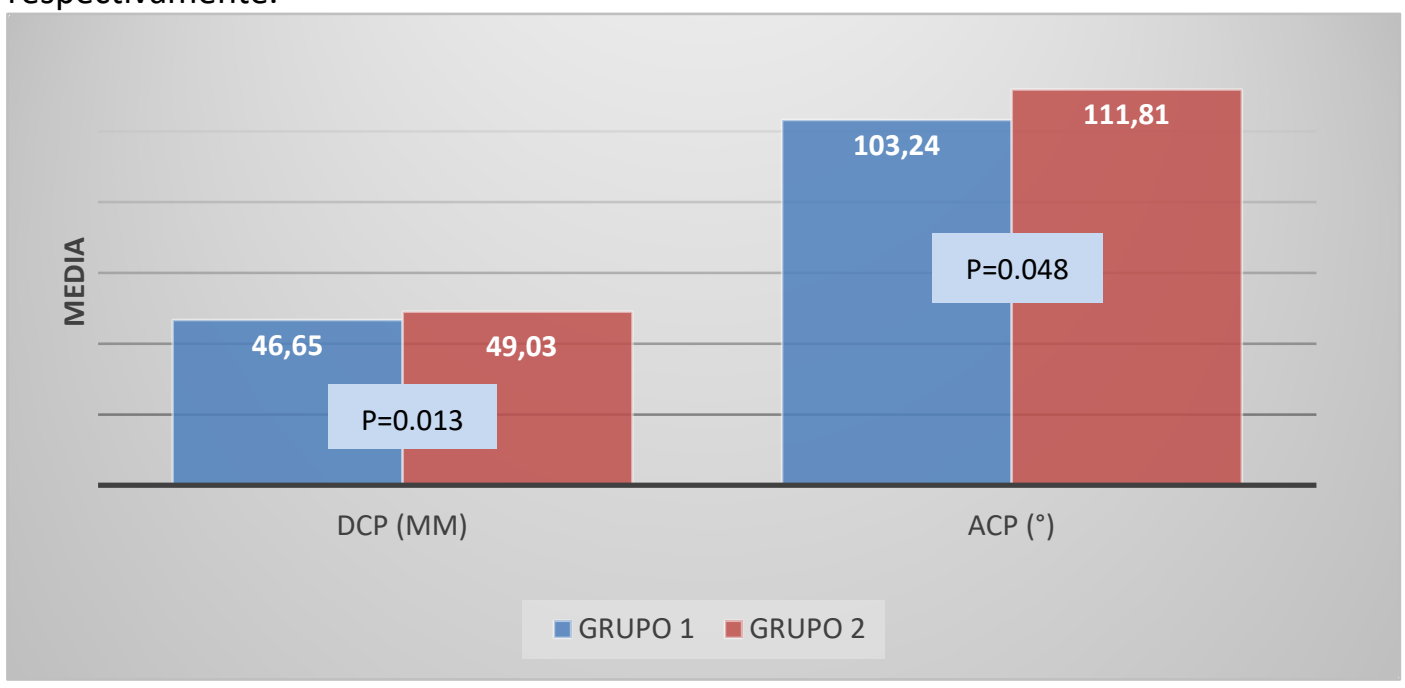


En lo que se refiere a los parámetros ecográficos de valoración subjetiva (patrón de acuñamiento cervical, existencia de funneling y dilatación ecográfica), no se registraron diferencias significativas con respecto al patrón de acuñamiento cervical y la dilatación (Tabla 23). El patrón de acuñamiento cervical más frecuente en ambas muestras fue el tipo $T$, seguido del $\mathrm{V}$ y del $\mathrm{U}$. Sin embargo, el porcentaje de mujeres con signo de funnel fue significativamente mayor en el grupo $1(24.3 \%$ vs $8.2 \%, p=0.000)$ (Figura 17$)$.

Figura 17. Porcentaje de mujeres con funneling en ambos grupos.

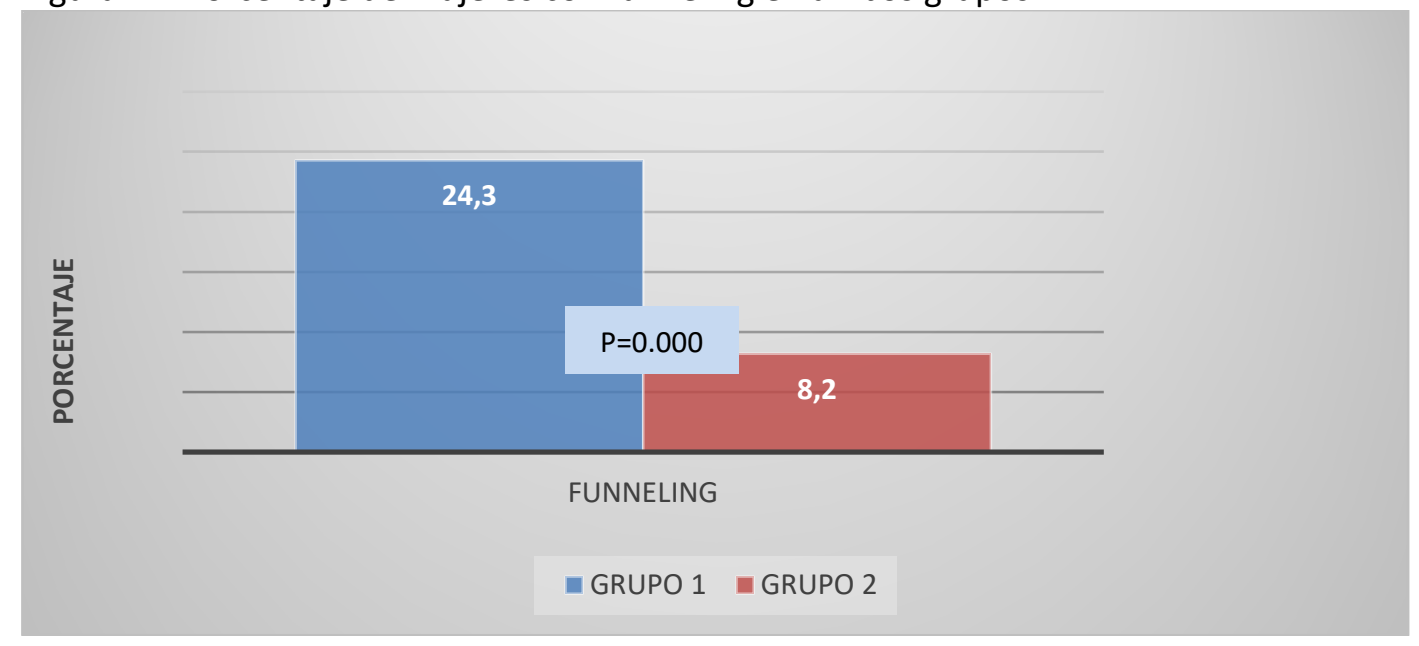

Tabla 23. Comparación de las medidas ecográficas entre ambos grupos.

\begin{tabular}{|c|c|c|c|}
\hline VARIABLE & $\begin{array}{l}\text { GRUPO } 1 \\
(n=151)\end{array}$ & $\begin{array}{l}\text { GRUPO } 2 \\
(n=231)\end{array}$ & $\mathbf{p}$ \\
\hline $\begin{array}{l}\text { DCP }(\mathbf{m m}) \\
\text { Media } \pm \text { DS }\end{array}$ & $46.65 \pm 8.01$ & $49.03 \pm 9.30$ & $0.013 *$ \\
\hline $\begin{array}{l}\text { LC }(\mathbf{m m}) \\
\text { Media } \pm \text { DS }\end{array}$ & $27.61 \pm 10.21$ & $26.45 \pm 10.24$ & $0.276^{*}$ \\
\hline $\begin{array}{l}\mathbf{A C P}\left(\mathbf{(}^{\circ}\right) \\
\text { Mediana (Rango Q1-Q3) }\end{array}$ & $\begin{array}{c}110 \\
(91.25-124)\end{array}$ & $\begin{array}{c}113 \\
(99-129)\end{array}$ & $0.048 *$ \\
\hline $\begin{array}{ll}\text { Acuñamiento cervical } \mathbf{n}(\%): & \\
& \text { Tipo T } \\
& \text { Tipo V } \\
& \text { Tipo U }\end{array}$ & $\begin{array}{c}82(53.9 \%) \\
58(38.2 \%) \\
11(7.2 \%)\end{array}$ & $\begin{array}{l}125(54.1 \%) \\
73(31.6 \%) \\
31(13.4 \%)\end{array}$ & $0.221 *$ \\
\hline Funneling $\mathrm{n}(\%)$ & $37(24.3 \%)$ & $19(8.2 \%)$ & $0.000^{*}$ \\
\hline Dilatación ecográfica n (\%) & $76(50 \%)$ & $105(45.5 \%)$ & $0.383 *$ \\
\hline
\end{tabular}

* U de Mann-Whitney

De estas medidas ecográficas, las incluidas en la fórmula matemática del modelo piloto ${ }^{126}$ son la DCP y la LC. Tal y como se desprende de la Tabla 23, sólo hubo diferencias estadísticamente significativas entre grupos en la DCP (Tabla 23). No hubo diferencias significativas en las variables clínicas que integran la fórmula (TM, PV previo, cesárea previa, IMC y Bishop) (Tabla $16)$. 
DISCUSIÓN 


\section{DISCUSIÓN}

\subsection{VALORACIÓN DE LOS RESULTADOS DEL ESTUDIO}

Los resultados del presente estudio son en parte contradictorios con los del estudio piloto previo en el que está basado (Álvarez-Colomo y cols.). En concreto, la tasa de predicción de la vía de parto disminuye significativamente con respecto al mismo, lo cual disminuye de forma drástica su utilidad clínica.

Globalmente, se puede considerar por tanto que la validación clínica del modelo piloto ha fracasado. Sin embargo, la asociación de las variables clínicas que lo componen, con la posibilidad de éxito de la IP, sí ha mantenido en ambos estudios su potencial predictivo, con pequeñas variaciones, tal y como se expone a continuación:

\subsubsection{PARIDAD}

En ambos grupos, presentar algún parto vaginal aumentaba la probabilidad de PV y en cambio, el antecedente de cesárea reducía esta posibilidad, de forma significativa.

Si la gestante había parido previamente, la probabilidad de PV en el grupo 1 era del $91.9 \%$ y en el grupo 2 del $92 \%$. Y cuando la paciente contaba con un parto previo por cesárea, el porcentaje de PV disminuía al $42.8 \%$ en el modelo piloto y al $51.4 \%$ en nuestro trabajo.

Otros autores también otorgan a la paridad una gran capacidad predictiva del resultado de inducción. Bueno y cols. ${ }^{116}$ integran las variables LC, Bishop y paridad en un organigrama, y encuentran que la mejor predicción resulta al introducir la paridad en primer lugar de la secuencia estadística que crean. Pitarello y cols. ${ }^{96}$ exponen que, el AUC conseguido con medidas ecográficas aumenta al añadir la paridad y la puntuación Bishop. Gran importancia otorga Ivars y cols. ${ }^{95}$ a la paridad, estableciendo una mejoría de su capacidad predictiva cuando se asocia a la puntuación Bishop simplificada (dilatación, borramiento y estación).

No se observaron diferencias significativas respecto a la paridad ni al antecedente de cesárea entre las muestras del modelo piloto y la nuestra (nuliparidad: grupo 1, 75\% y grupo $2,78.2 \%$ y cesárea anterior: grupo $1,9.2 \%$ y grupo $2,15.2 \%$ ).

\subsubsection{TALLA MATERNA}

En ambos grupos, la altura materna resultó significativamente menor en las gestantes que finalizaron mediante cesárea. En el modelo piloto, la talla $(\mathrm{m}) 1.62 \pm 0.63$ se relacionó con PV y la talla $1.60 \pm 0.57$ se asoció con parto abdominal. $Y$ en nuestra muestra, la altura $(\mathrm{m})$ $1.63 \pm 0.60$ se relacionó con PV mientras que una altura de $1.61 \pm 0.64$ se asoció a cesárea.

Levine y cols. ${ }^{128}$ calculan un modelo predictivo donde obtienen que la altura materna es un predictor significativo del riesgo de cesárea, categorizando la talla en: $<157 \mathrm{~cm}, 157-$ $162 \mathrm{~cm}, 163-167 \mathrm{~cm}$ y $\geq 168 \mathrm{~cm}$ (aOR=1.38, IC 95\% 1.09-1.74, p=0.007).

Isono y cols. ${ }^{124}$ en Japón, tras un análisis multivariante previo al cálculo de un modelo predictivo, otorgan a la altura materna capacidad predictiva para el resultado de la inducción mediante cesárea. La diferencia es que en su estudio la altura media fue $158 \mathrm{~cm}$ frente a $165 \mathrm{~cm}$ que es la talla media de los estudios occidentales.

Resultados similares se refieren en el estudio piloto previo realizado por nuestro grupo ${ }^{126}$, donde se describe que una talla materna inferior a $1.51 \mathrm{~m}$ se asocia de forma significativa a la cesárea como resultado de la inducción. 
Al comparar la talla materna entre ambos grupos, modelo piloto y nuestro trabajo, no se encontraron diferencias (mediana de $1.62 \mathrm{~m}$ en ambas muestras).

\subsubsection{PUNTUACIÓN BISHOP}

Tanto en la muestra del modelo piloto como en la nuestra, se encontraron puntuaciones medias de la puntuación Bishop significativamente más altas (cérvix más favorables) en el grupo de gestantes con PV (3.97 en grupo 1 y 3.62 en grupo 2 ) en comparación con las mujeres que finalizaban mediante cesárea ( 2.78 y 2.96 , respectivamente). Pero no hubo diferencias significativas en la puntuación Bishop entre ambos grupos.

Aunque tradicionalmente se ha utilizado la puntuación Bishop para la evaluación del estado cervical pre-inducción así como para intentar predecir el resultado de la misma, muchos autores están reconociendo limitaciones a estos sistemas de puntuación clínica ${ }^{50,}$ ${ }^{85}$. Son muchas la razones que aluden, como la molestia que genera a la paciente, la subjetividad de la exploración, menor capacidad predictiva en comparación con medidas ecográficas ${ }^{80,96,97,100}$ y la gran variabilidad intra e interobservador.

\subsubsection{PARÁMETROS ECOGRÁFICOS}

La valoración ecográfica cómo método de valoración preinducción engloba muchos parámetros: longitud cervical, dilatación cervical, forma de acuñamiento del orificio cervical interno, ángulo cervical posterior, distancia céfaloperineal, ...

Este método pretende ser más objetivo que el examen digital (puntuación Bishop) para intentar reducir las diferencias intra e interobservador.

Las medidas incluidas en la fórmula del modelo piloto son: la LC, que pretende cuantificar el grado de borramiento cervical y la DCP, que evalúa el encajamiento fetal de forma más objetiva que mediante el tacto digital.

Ambas variables demuestran asociación significativa con el modo de parto en ambos grupos 1 y 2 (punto 2 de resultados).

En relación con la $L C$, no se observan diferencias entre ambos grupos $(27.61 \mathrm{~mm}$ vs 26.45 $\mathrm{mm}, \mathrm{p}=0.276$ ). Sin embargo, si se demostraron diferencias estadísticamente significativas en la variable ecográfica DCP, resultando mayor en el grupo $2(46.65 \mathrm{~mm}$ vs $49.03 \mathrm{~mm}$, $\mathrm{p}=0.013$ ).

Respecto del resto de variables ecográficas estudiadas, se encontraron diferencias significativas entre ambos grupos en el ACP (mayor en el grupo $2,113^{\circ}$ vs $110^{\circ}, p=0.048$ ) y en la existencia de funnel (más presente en el grupo $1,24.3 \%$ vs $8.2 \%, p=0.000$ ), pero estos parámetros no influyen en la diferencia de predicción puesto que no forman parte de la fórmula matemática.

Siguiendo nuestro principal objetivo, aplicamos la fórmula del modelo piloto $(n=151)$ a la muestra de estudio $(n=231)$, con los mismos criterios de inclusión y exclusión, obteniendo una predicción de cesárea del $70.74 \%$, inferior al $82.3 \%$ del estudio piloto previo ${ }^{124}$. Dado que las características demográficas, antropométricas, así como los antecedentes obstétricos son similares en ambas poblaciones, cabe pensar que la diferente predicción sea debida a los parámetros ecográficos incluidos en la fórmula (DCP y LC). De hecho, solo se han encontrado diferencias significativas en la DCP.

La DCP trata de describir de forma objetiva la altura de la presentación fetal. 
La evaluación del encajamiento fetal mediante tacto vaginal en relación a la espina ciática, es inexacta y pobremente reproducible, además de producir disconfort a la paciente, por lo cual se han propuesto diferentes medidas realizadas por ecografía, como la DCP mediante ecografía transperineal. La metodología de adquisición de la DCP fue descrita por Eggebo y cols. ${ }^{107}$, que emplearon el final del canal del parto como una línea de referencia más fácil de visualizar en comparación con la sínfisis del pubis.

Las diferencias encontradas en la DCP (mayor en el grupo 2) pueden estar relacionadas con la adquisición de esta medida, influida por varios factores ${ }^{107,145}$ :

- Existencia de gas en el recto.

- Dificultad para localizar el OCI.

- Deficiente compresión del tejido blando del periné (la compresión debe ser firme sin producir molestia o dolor).

- Angulación inadecuada de la sonda convex, puesto que el US debe dirigirse perpendicular al cráneo fetal, para que este se visualice lo más nítidamente posible.

- Escasa o nula fiabilidad si la cabeza no está encajada, debido a los movimientos fetales (problema común para el resto de los métodos que evalúan el encajamiento fetal).

La medida de la DCP depende también de la experiencia de los examinadores y del propio aparato ecográfico, según se usen tamaños diferentes de la sonda convex y según la calibración del equipo ${ }^{145}$.

La medida de la DCP fue adquirida con un único ecógrafo y explorada por 4 observadores diferentes, aunque con amplia experiencia ecográfica (frente al estudio piloto en el que hubo un único observador).

En este punto debería valorarse la variabilidad interobservador de la medición ecográfica de la DCP para investigar la diferencia que existe entre ambos grupos.

La variabilidad o dispersión de los resultados es determinada por estudios de repetibilidad y reproducibilidad, que señalan que parte de la variación observada en el proceso se debe al sistema de medición usado ${ }^{146}$.

La repetibilidad se define como la proximidad de concordancia entre los resultados de mediciones sucesivas de la misma variable bajo las mismas condiciones de medición, que incluyen: mismo procedimiento, mismo observador, mismo instrumento de medición, mismo lugar y repetición en un período corto de tiempo.

En cambio, la reproducibilidad es la proximidad de concordancia entre los resultados de mediciones sucesivas de la misma variable bajo condiciones de medición que cambian. Debe especificarse la condición que cambia, como el principio de medición, el método, el observador, el lugar o el tiempo. Por tanto, se entiende que los resultados sean corregidos.

No es posible estudiar la repetibilidad de la DCP en el grupo 2, puesto que un único observador medía la DCP en cada paciente. Para obtener la variabilidad interobservador, se precisaría que varios ecografistas midieran la DCP a una misma paciente. $Y$ a posteriori, son parámetros que no se pueden conseguir. 
Aunque nosotros no podemos asegurar una buena reproducibilidad de la medida ecográfica DCP, otros autores sí la han demostrado:

- Eggebo y cols. 2006 107: estudiando la DCP con relación al resultado de la IP, demuestran una baja variabilidad intra e interobservador, con una variación intraobservador de $3 \mathrm{~mm}$ (87\%) e interobservador de $3 \mathrm{~mm}$ (61\%). (Se han establecido como límites de acuerdo para la variación intraobservador un rango de -8.5 a $5.3 \mathrm{~mm}$ y para la variación interobservador un rango de -8.5 a $12.3 \mathrm{~mm}$ ).

- Toskildsen y cols. $2012{ }^{147}$ : demuestran una buena repetibilidad intraobservador para la medida de la DCP en relación con la primera etapa del parto, definida como la diferencia entre las medidas más altas y más bajas, que se expresó como el coeficiente de correlación intraclase (ICC), aceptable cuando es superior a 0.75 . Así, el coeficiente de repetibilidad fue $\pm 4.1 \mathrm{~mm}$ y el ICC fue 0.97 (IC 95\%: 0.920.96).

- Benediktsdottir y cols. $2018^{145}$ : valorando la DCP en mujeres con trabajo de parto, estudian la repetibilidad intraobservador. Obtiene un ICC intraobservador excelente (ICC=0.97, IC 95\%: 0.95-0.98, p<0.01) y explica que los ICC dependen de variaciones en la población y son insuficientes para investigar repetibilidad y acuerdo.

- Kasboui y cols. 2017 (148): investigando la DCP para predecir la dificultad del parto operatorio, obtienen un ICC interobservador de 0.96 (IC 95\%: 0.95-0.97, $\mathrm{p}<0.0001)$.

\subsection{POBLACIÓN INCLUIDA EN EL ESTUDIO}

Tal y como se ha referido en el apartado de "Material y Métodos", la cohorte de nuestro estudio se seleccionó por muestreo de oportunidad, durante la jornada ordinaria de trabajo de los 4 observadores. En cambio, en la cohorte del estudio piloto previo, sólo un ecografista realizó las mediciones.

El tamaño muestral fue 231, similar o incluso superior a otros autores $82,96,102,109,110,116,119,122$, incluyendo el modelo piloto (151 gestantes). 3,Pero también encontramos otros estudios con mayor población $83,106,120,123,125,128$. Durante el período de estudio, se atendieron 2710 partos de los cuales 735 fueron inducidos (31.4\%).

Al igual que en el estudio piloto previo, no se seleccionó la muestra según los antecedentes obstétricos, por lo que la distribución gestacional tuvo unas características similares a la población general.

Se incluyeron tanto nulíparas como multíparas, sin diferencias en los porcentajes entre ambos grupos (Grupo 1: N 75\%/M 25\% y Grupo 2: N 78.2\%/M 21.8\%).

De los diferentes trabajos consultados, algunos incluyen nulíparas y multíparas ${ }^{83,95,96,118,128}$, algunos solo nulíparas ${ }^{98,103}$ y otros solo multíparas ${ }^{51}$.

Hafik y cols. en 2014 excluyeron a grandes multíparas, pero no aclaran con qué número de partos previos se corresponden esas pacientes ${ }^{110}$.

Nuestra tasa de inducción durante el período de estudio fue $27.1 \%$, muy similar al porcentaje de IP del trabajo previo (26.18\%). Se incluyeron mujeres con bolsa rota, tanto en el modelo piloto como en el grupo de estudio, suponiendo un porcentaje alto de las IP, $22 \%$ y $21 \%$ respectivamente. La mayor parte de las publicaciones no incluyen RPM ${ }^{51,96,102,116,128}$ y solo algunas lo hacen ${ }^{109,110}$. 
Se incluyeron en ambos grupos pacientes con cesárea previa, antecedente que se convierte en criterio de exclusión en la mayoría de los estudios revisados $82,96,102,110,116,128$, encontrando solo uno que permite participar a mujeres con cesárea anterior ${ }^{129}$.

Aun así, el número de mujeres con cesárea previa en ambos grupos fue bajo, 14 en el grupo 1 (9.2\%) y 35 en el grupo 2 (15.2\%), similar al porcentaje de mujeres con cesárea anterior que se inducen en la población de referencia (10.2\%). Durante el período de estudio el porcentaje de cesárea electiva fue de $9.2 \%$, muy similar al modelo piloto (9.5\%).

Por lo tanto, las características de las mujeres incluidas fueron similares en el modelo piloto y el de estudio, y vemos cómo éstas son muy diferentes entre los distintos estudios, lo cual dificulta la comparación de resultados.

\subsection{INDICACIONES DE LA INDUCCIÓN DEL PARTO}

Las situaciones clínicas que con mayor frecuencia supusieron una IP fueron la GCP (25\%) y la RPM (21\%), al igual que en el estudio piloto previo (21\% GCP y $21 \%$ RPM).

Esto difiere de lo encontrado en la literatura (tabla 25). Por una parte, por la razón expuesta en el apartado anterior, puesto que la mayoría de los autores no incluyen la bolsa rota anteparto en sus estudios.

Rane y cols. ${ }^{106}$ y Verhoeven y cols. ${ }^{123}$, que inducen por RPM anteparto, presentan unas cifras inferiores a la nuestra ( $9 \%$ y $15 \%$ respectivamente vs $21 \%$ en nuestro trabajo), que podría explicarse por la política de inducción precoz tras 6-12 horas de bolsa rota, que se realiza en nuestro centro tras la publicación Cochrane de 2006, posteriormente revisada en $2017^{34}$.

El bajo porcentaje de inducciones por GCP, puede deberse a que, en nuestro centro, durante el período de estudio, el protocolo de seguimiento de la gestación en vías de prolongación supone, a partir de las 41 semanas, control del bienestar fetal cada 48-72 horas mediante perfil biofísico modificado, para finalizar a la EG de 41+6 si antes no ha surgido ningún contratiempo. En cambio, otro protocolo de actuación propondría la inducción a partir de las 41 semanas de gestación ${ }^{30}$. Incluso Levine y cols. ${ }^{128}$ publican un menor porcentaje de inducción por GCP (13\%), pero no explican el protocolo que utilizan ni la EG máxima a la que finalizan la gestación. 
Tabla 25. Frecuencia de las indicaciones de inducción del parto en nuestro trabajo, en el estudio piloto previo y en el resto de la literatura.

\begin{tabular}{|c|c|c|c|c|c|c|c|c|c|}
\hline AUTOR & $n$ & GCP & EHE & DM & CIR & RPM & OLIGOA & ELECTIVA & OTRAS \\
\hline $\begin{array}{l}\text { Rane y cols. } \\
2004\end{array}$ & 604 & $\begin{array}{l}221 \\
(37 \%)\end{array}$ & 85 & 16 & 73 & $\begin{array}{l}57 \\
(9 \%)\end{array}$ & & 44 & 108 \\
\hline $\begin{array}{l}\begin{array}{l}\text { Bartha y cols. } \\
2005\end{array} \\
\end{array}$ & 80 & $\begin{array}{l}22 \\
(28 \%) \\
\end{array}$ & & & 13 & & 23 & 7 & 15 \\
\hline $\begin{array}{l}\text { Bueno y cols. } \\
2007\end{array}$ & 196 & $\begin{array}{l}107 \\
(55 \%)\end{array}$ & 3 & 10 & 18 & $\begin{array}{l}11 \\
(6 \%)\end{array}$ & 12 & & 35 \\
\hline $\begin{array}{l}\text { Verhoeven } \\
\text { cols. } 2009\end{array}$ & 240 & $\begin{array}{l}83 \\
(35 \%)\end{array}$ & 35 & & 15 & $\begin{array}{l}35 \\
(15 \%)\end{array}$ & 20 & 21 & 31 \\
\hline $\begin{array}{l}\text { Álvarez-Colomo } \\
\text { y cols. } 2016\end{array}$ & 151 & $\begin{array}{l}32 \\
(21 \%)\end{array}$ & 8 & 25 & 27 & $\begin{array}{l}32 \\
(21 \%)\end{array}$ & 8 & 1 & 18 \\
\hline $\begin{array}{l}\text { Leviney y cols. } \\
2018^{*}\end{array}$ & 491 & $\begin{array}{l}64 \\
(13 \%) \\
\end{array}$ & & & & & & 54 & \\
\hline Nuestro trabajo & 231 & $\begin{array}{l}57 \\
(25 \%)\end{array}$ & 6 & 37 & 34 & $\begin{array}{l}48 \\
(21 \%)\end{array}$ & 12 & & 37 \\
\hline \multicolumn{10}{|c|}{$\begin{array}{l}\text { GCP: gestación cronológicamente prolongada. EHE: estados hipertensivos del embarazo. DM: } \\
\text { Diabetes Mellitus. CIR: restricción del crecimiento intrauterino. RPM: rotura prematura de } \\
\text { membranas. OLIGOA: oligoamnios. } \\
\text { *Indicación por causas maternas: } 148 \text { y por causas fetales: } 225 \text {, no especifica cuáles, no } \\
\text { incluye RPM. }\end{array}$} \\
\hline
\end{tabular}

En relación con las indicaciones de la IP, no se encuentran diferencias entre este trabajo y el modelo piloto, pero si se observan distintas causas que justifican la finalización de la gestación entre autores, lo cual podría influir en el resultado de la inducción.

\subsection{MÉTODO DE INDUCCIÓN}

Todas las pacientes incluidas en el estudio fueron sometidas al mismo protocolo de inducción del parto, vigente en nuestro centro durante el período de estudio (01-09-2010 y 31-07-2012). Dicho procedimiento ha sido expuesto previamente (figura 15) y coincide con el protocolo de inducción que fue empleado por Álvarez-Colomo y cols. en el estudio piloto previo.

La selección del método inductivo se realizó mediante la exploración física, asignando una puntuación Bishop ${ }^{50}$ al estado cervical.

El 85\% de las gestantes precisaron maduración cervical con dispositivo de liberación lenta de PG E2 (puntuación Bishop $\leq 7$ ), la mayoría de las ocasiones consistió en una única dosis $(76 \%)$, precisando 2 dosis separadas 24 horas en aquellos casos que no hubieran iniciado el trabajo de parto y continuaran con la bolsa íntegra (9\%).

En 34 pacientes (15\%) el cérvix se consideró maduro (puntuación Bishop > 7) y se inició la inducción con perfusión de oxitocina. Solo una paciente con cérvix maduro recibió la amniotomía como primer método de inducción.

En el modelo piloto, el $90 \%$ de las pacientes necesitaron maduración cervical con dispositivo de liberación lenta de PG E2, consistiendo mayoritariamente en una dosis (72\%), repitiendo algunos casos una segunda dosis al día siguiente al no iniciar la fase activa de parto (16\%).

En cuanto a las gestantes con cérvix maduro del estudio piloto previo, el $6 \%$ iniciaron el procedimiento con oxitocina y otro $6 \%$ con amniotomía como primer método de inducción. 
No hubo diferencias significativas entre el grupo 1 y el nuestro en relación con el método empleado en la IP, lo cual supone una ventaja a lo hora de comparar resultados y facilitar la validación interna.

En cambio, la literatura revisada refleja diversos procedimientos, en cuanto al tipo de fármaco, dosis y vía de administración. Hay autores que no tienen en cuenta la puntuación Bishop $95,101,120,136$ y emplean el mismo método de inducción para todas las pacientes y otros, que en función del estado cervical, inician el procedimiento mediante la maduración cervical con PG $83,96,110,116,126$, como en nuestro caso. Las PG empleadas para la maduración cervical son la E1 y la E2. Durante el período de reclutamiento del estudio, en nuestro centro no empleábamos la PGE1 o misoprostol, pero varias publicaciones sí la han administrado vía vaginal en diferentes dosis ${ }^{83,96,110,136}$. La PG más ampliamente utilizada es la PG E2 o dinoprostona, por vía vaginal en forma de gel ${ }^{116,120}$, óvulo ${ }^{95,137}$ o dispositivo de liberación lenta ${ }^{126,138,139}$ como en nuestro caso, también con variaciones en las dosis empleadas.

Un único estudio comenzaba directamente la IP mediante perfusión intravenosa de oxitocina independientemente de la puntuación Bishop ${ }^{140}$. Esta publicación aporta dos ventajas: que siempre se inducía con oxitocina y que un único observador realizaba las exploraciones, pero describe una tasa muy alta de cesárea (60.8\%), superior a lo revisado en la literatura.

Esta variedad de protocolos en relación con el modo de IP también puede incidir en la falta de concordancia entre estudios.

\subsection{DEFINICIONES DE ÉXITO Y FRACASO DE LA INDUCCIÓN DEL PARTO}

En nuestro estudio, el éxito de la IP y objetivo principal era conseguir el parto vaginal independientemente del tiempo, al igual que en el modelo piloto.

La definición del éxito de la inducción en la literatura varía mucho. Generalmente se consigue, cuando se alcanza un parto vaginal no complicado dentro de las primeras 24 horas de comenzar con la oxitocina ${ }^{94,104,114,118,138,139}$. Aunque dependiendo del estudio, el resultado de éxito puede ser definido como el parto vaginal en el período de 48 horas o globalmente $81,93,104,116,124,140$, la tasa de cesárea en menos de 24 horas ${ }^{104,108,126}$ o sin relación con el tiempo de inducción ${ }^{137}$, alcanzar una dilatación cervical mayor de $5 \mathrm{~cm}{ }^{50}$ o una puntuación Bishop mayor de 7 a las 24 horas ${ }^{150}$.

Otros resultados que pueden considerarse en la evaluación del éxito de la inducción incluyen: la dosis/duración de oxitocina, tiempo desde la maduración cervical hasta el parto vaginal, tiempo desde la inducción oxitócica al parto vaginal y morbilidad materna y neonatal.

Así es comprensible como las tasas de éxito y fracaso sean diferentes, siendo muy complicado comparar la capacidad predictiva de los factores estudiados.

La SEGO define el fracaso de inducción como la no consecución de las condiciones de un parto activo tras 12 horas de infusión oxitócica, con bolsa rota y dinámica uterina regular ${ }^{1}$, siguiendo las recomendaciones del Colegio Americano de Obstetras y Ginecólogos que durante una reunión con otras asociaciones ${ }^{79}$ se basaron en las siguientes evidencias:

- Dos estudios de gran tamaño que requirieron una administración de oxitocina de mínimo 12 horas tras la rotura de membranas antes de diagnosticar un fracaso de inducción, describen que ${ }^{141,142}$ :

○ El $75 \%$ de las nulíparas tienen un parto vaginal. 
- La tasa de parto vaginal para nulíparas con cérvix desfavorable fue del $63 \%$.

- Para las multíparas, no se consideró una indicación de cesárea el fracaso de inducción.

- Otro estudio evaluó 978 nulíparas con rotura de membranas espontánea o artificial e inducción con oxitocina. Tras 10 horas de oxitocina, el $8 \%$ de mujeres que no entraron en la fase activa del parto, tuvieron una tasa de cesárea del 75\%. Pero tras 12 horas de oxitocina, la tasa de cesárea fue casi de un $90 \%{ }^{143}$. Por tanto, parece razonable prolongar la inducción oxitócica durante al menos 10 horas en las mujeres que no alcanzan la fase activa del parto, pero no aclara si existe beneficio en prolongar la oxitocina 12 horas o más.

- Otro estudio retrospectivo informó que una fase latente de 12-18 horas durante la inducción en nulíparas permitió a la mayoría de estas mujeres lograr un parto vaginal, sin aumentos en la morbilidad materna y neonatal ${ }^{144}$.

En el período de estudio la tasa global de cesárea fue $23.4 \%$, y si el inicio del parto era espontáneo, la tasa disminuía al $10.7 \%$. Al contrario, si el inicio era artificial, el porcentaje ascendía al 29.8\%. La tasa de cesárea por cualquier indicación en nuestra muestra fue del $30.3 \%$ (70 pacientes), cifra que no difiere con la tasa global de cesárea del grupo 1 (30.3\%).

Las tasas de PV son muy variables entre estudios, en parte debido a si tienen en cuenta o no el tiempo que transcurre desde la inducción al parto, al método de inducción empleado y al tipo de población que incluyen (nulíparas y multíparas, o solo nulíparas). Está reconocido que la tasa de PV es mayor en las multíparas, y que el riesgo de cesárea en nulíparas es el doble si el parto es inducido en comparación a si el inicio es espontáneo ${ }^{8}$.

En la siguiente tabla (Tabla 26) se exponen las tasas de cesárea de distintos estudios, en relación con el porcentaje de nulíparas de los mismos. 
Tabla 26. Tasa de cesárea y porcentaje de nulíparas de nuestro estudio, del estudio piloto y de varios estudios.

\begin{tabular}{|l|l|l|}
\hline $\begin{array}{l}\text { AUTOR } \\
\text { (n total, método inducción) }\end{array}$ & \% NULíPARAS & \% CESÁREAS \\
\hline $\begin{array}{l}\text { Pandis y cols. 2001 } \\
\text { (240, PG E2+Oxitocina) }\end{array}$ & $53.3 \%$ & $19.2 \%$ \\
\hline $\begin{array}{l}\text { Rane y cols. 2003 } \\
\text { (382, PG+Oxitocina) }\end{array}$ & $50.3 \%$ & $18.6 \%$ \\
\hline $\begin{array}{l}\text { Gomes y cols. 2006 } \\
\text { (191, PG E2+Oxitocina) }\end{array}$ & $68 \%$ & $27.2 \%$ \\
\hline $\begin{array}{l}\text { Yanik y cols. 2007 } \\
\text { (73, Oxitocina) }\end{array}$ & $59 \%$ & $61 \%$ \\
\hline $\begin{array}{l}\text { Bueno y cols. 2007 } \\
\text { (196, PG E2+Oxitocina) }\end{array}$ & $75 \%$ & $26.5 \%$ \\
\hline $\begin{array}{l}\text { Keepanasseril y cols. 2007 } \\
(138, \text { PG+Oxitocina) }\end{array}$ & $100 \%$ & $23.2 \%$ \\
\hline $\begin{array}{l}\text { Tanir y cols. 2008 } \\
\text { (43, PG E1+Oxitocina) }\end{array}$ & $100 \%$ & $48.9 \%$ \\
\hline $\begin{array}{l}\text { Park y cols. 2009 } \\
\text { (110, PG E2+Oxitocina) }\end{array}$ & $100 \%$ & $21 \%$ \\
\hline $\begin{array}{l}\text { Pitarello y cols. 2013 } \\
\text { (190, PG E1+Oxitocina) }\end{array}$ & $54 \%$ & $30 \%$ \\
\hline $\begin{array}{l}\text { Álvarez-Colomo y cols. 2016 } \\
\text { (151, PG E2+Oxitocina) }\end{array}$ & $75 \%$ & $30.3 \%$ \\
\hline $\begin{array}{l}\text { Nuestro trabajo } \\
\text { (231, PG E2+Oxitocina) }\end{array}$ & $78.2 \%$ & $30.3 \%$ \\
\hline
\end{tabular}

La comparación de nuestros resultados con los de otros estudios similares recogidos en la bibliografía es dificultosa, por la diferencia de criterios de inclusión, de indicación de la IP, y del método empleado para la propia IP. Finalmente, la propia definición de éxito o fracaso de la inducción de parto presenta diferencias entre los diversos estudios. 
CONCLUSIONES 


\section{CONCLUSIONES}

Todas las variables clínicas incluidas en el modelo piloto previo se asociaron de manera individual significativamente con la modalidad de parto tras inducción electiva en el presente estudio

No obstante, lo anterior, al incluir dichas variables en el modelo predictivo propuesto en el estudio piloto previo, los resultados fueron muy inferiores a los obtenidos en el mismo.

Las únicas diferencias entre ambos estudios se refirieron al número de observadores (un único observador en el estudio piloto, cuatro observadores diferentes en el estudio de validación), así como a las medidas ecográficas de DCP (pudiendo estas últimas, a su vez, deberse a diferencias interobservador).

Por todo lo anterior, debe concluirse que la validación en condiciones de rutina clínica del modelo predictivo propuesto por Álvarez-Colomo y colaboradores ha fracasado 


\section{BIBLIOGRAFÍA}




\section{BIBLIOGRAFÍA}

1. SEGO. Inducción del parto. In: SEGO, ed. Guías de asistencia práctica en Medicina Perinatal 2013.

2. Osterman MJ, Martin JA. Recent declines in induction of labor by gestational age. NCHS Data Brief. 2014 Jun;(155):1-8.

3. Martin JA, Hamilton BE, Osterman MJK, Driscoll AK, Drake P. Births: Final Data for 2016. Natl Vital Stat Rep. 2018 Jan;67(1):1-55.

4. Vogel JP, Souza JP, Gülmezoglu AM. Patterns and Outcomes of Induction of Labour in Africa and Asia: a secondary analysis of the WHO Global Survey on Maternal and Neonatal Health. PLoS One. 2013 Jun 3;8(6):e65612.

5. Murthy K, Grobman WA, Lee TA, Holl JL. Trends in induction of labor at early-term gestation. Am J Obstet Gynecol. 2011 May;204(5):435.e1-6.

6. Díaz Miguel V, Gonzalo I, Zapardiel I, de la Fuente J, Alario I, Berzosa J, Alonso E. Aplicación de indicadores de calidad asistencial durante el parto y el puerperio en un hospital de tercer nivel. Clínica e Investig en Ginecol Obstet. 2007 May;34(3):95-9.

7. Zeitlin J, Mohangoo A, Cuttini M; EUROPERISTAT Report Writing Committe et al. The European Perinatal Health Report: comparing the health and care of pregnant women and newborn babies in Europe. J Epidemiol Community Health. 2009 Sep;63(9):681-2.

8. Moore LE, Rayburn WF. Elective induction of labor. Clin Obstet Gynecol. 2006 Sep;49(3):698-704.

9. Rayburn WF, Zhang J. Rising rates of labor induction: present concerns and future strategies. Obstet Gynecol. 2002 Jul;100(1):164-7.2002;100(164).

10. National Institute for Health and Clinical Excellence. Induction of labour, clinical guideline 70. 20008.

11. ACOG. Practice Bulletin No. 107: Induction of labor. Obstet Gynecol. 2009 Aug;114(2 Pt 1):386-97.

12. Nicholson JM, Parry S, Caughey AB, Rosen S, Keen A, Macones GA. The impact of the active management of risk in pregnancy at term on birth outcomes: a randomized clinical trial. Am J Obstet Gynecol. 2008 May;198(5):511.e1-511.e15.

13. Mozurkewich E, Chilimigras J, Koepke E, Keeton K, King VJ. Indications for induction of labour: a best-evidence review. BJOG Int J Obstet Gynaecol. 2009 Apr;116(5):626-36.

14. ACOG. Practice Bulletin no. 561: Nonmedically indicated early-term deliveries. Obstet Gynecol. 2013 Apr;121(4):911-5.

15. Spong CY. Defining "Term" Pregnancy Recommendations From the Defining "Term" Pregnancy Workgroup. JAMA. 2013 Jun 19;309(23):2445-6.

16. Ehrenthal DB, Hoffman MK, Jiang X, Ostrum G. Neonatal outcomes after implementation of guidelines limiting elective delivery before 39 weeks of gestation. Obstet Gynecol. 2011 Nov;118(5):1047-55.

17. Walker KF, Bugg GJ, Macpherson M, McCormick C, Grace N, Wildsmith C, et al. Randomized Trial of Labor Induction in Women 35 Years of Age or Older. N Engl J Med. 2016 Mar 3;374(9):813-22.

18. Society of Maternal-Fetal (SMFM) Publications Committee. SMFM Statement on Elective Induction of Labor in Low-Risk Nulliparous Women at Term: the ARRIVE Trial. Am J Obstet Gynecol. 2019 Jul;221(1):B2-B4.

19. Nicholson JM, Stenson MH, Kellar LC, Caughey AB, Macones GA. Active management of risk in nulliparous pregnancy at term: association between a higher preventive labor induction rate and improved birth outcomes. Am J Obstet Gynecol. 2009 Mar;200(3):254.e1-254.e13.

20. Nicholson JM, Caughey AB, Stenson MH, Cronholm P, Kellar L, Bennett I, et al. The active management of risk in multiparous pregnancy at term: association between a 
higher preventive labor induction rate and improved birth outcomes. Am J Obstet Gynecol. 2009 Mar;200(3):250.e1-250.e13.

21. Cammu H, Martens G, Ruyssinck G, Amy JJ. Outcome after elective labor induction in nulliparous women: a matched cohort study. Am J Obstet Gynecol. 2002 Feb;186(2):240-4.

22. Ehrenthal DB, Jiang $X$, Strobino DM. Labor induction and the risk of a cesarean delivery among nulliparous women at term. Obstet Gynecol. 2010 Jul;116(1):35-42.

23. Mishanina E, Rogozinska E, Thatthi T, Uddin-Khan R, Khan KS, Meads C. Use of labour induction and risk of cesarean delivery: a systematic review and meta-analysis. CMAJ. 2014 Jun 10;186(9):665-73.

24. Middleton $\mathrm{P}$, Shepherd $\mathrm{E}$, Crowther CA. Induction of labour for improving birth outcomes for women at or beyond term. Cochrane Database Syst Rev. 2018 Sep;5:CD004945.

25. Saccone G, Berghella V. Induction of labor at full term in uncomplicated singleton gestations: a systematic review and metaanalysis of randomized controlled trials. Am J Obstet Gynecol. 2015 Nov;213(5):629-36.

26. Eisenberg Center at Oregon Health \& Science University. Elective Induction of Labor: Safety and Harms. Rockville (MD): Agency for Healthcare Research and Quality (US); 2007. AHRQ Comparative Effectiveness Reviews. 2009 Nov 30

27. Zhang $X$, Kramer MS. Variations in mortality and morbidity by gestational age among infants born at term. J Pediatr. 2009 Mar;154(3):358-62, 362.e1.

28. Escobar GJ, Greene JD, Hulac P, Kincannon E, Bischoff K, Gardner MN, et al. Rehospitalisation after birth hospitalisation: patterns among infants of all gestations. Arch Dis Child. 2005 Feb;90(2):125-31.

29. ACOG. Practice Bulletin No. 106: Intrapartum fetal heart rate monitoring: nomenclature, interpretation, and general management principles. Obstet Gynecol. 2009 Jul;114(1):192-202.

30. SEGO. Embarazo cronológicamente prolongado. In: SEGO, ed. Guías de asistencia práctica en Medicina Perinatal 2010.

31. Delaney $M$, Roggensack A. No. 214-Guidelines for the Management of Pregnancy at 41+0 to 42+0 Weeks. J Obstet Gynaecol Can. 2017 Aug;39(8):e164-74.

32. Ingemarsson I, Källén K. Stillbirths and rate of neonatal deaths in 76,761 postterm pregnancies in Sweden, 1982-1991: a register study. Acta Obstet Gynecol Scand. 1997 Aug;76(7):658-62.

33. Mandruzzato G, Alfirevic Z, Chervenak F, Gruenebaum A, Heimstad R et al; World Association of Perinatal Medicine. Guidelines for the management of postterm pregnancy. J Perinat Med. 2010 Mar;38(2):111-9.

34. Middleton P, Shepherd E, Flenady V, McBain RD, Crowther CA. Planned early birth versus expectant management (waiting) for prelabour rupture of membranes at term (37 weeks or more). Cochrane Database Syst Rev. 2017 Jan 4;1:CD005302.

35. ACOG. Practice Bulletin No. 184: Vaginal Birth After Cesarean Delivery. Obstet Gynecol. 2017 Nov;130(5):e217-e233.

36. Stock SJ, Ferguson E, Duffy A, Ford I, Chalmers J, Norman JE. Outcomes of induction of labour in women with previous caesarean delivery: a retrospective cohort study using a population database. PLoS One. 2013;8(4):e60404.

37. SEGO. Parto vaginal tras cesárea. In: SEGO, ed. Guías de asistencia práctica en Medicina Perinatal 2010.

38. Hofmeyr JG. Delivery of the singleton fetus in breech presentation. In: Lockwood CJ, Barss VA, editors. UpToDate. Waltham, UpToDate; 2019.

39. Bleu G, Demetz J, Michel S, Drain A, Houfflin-Debarge V, Deruelle P, Subtil D. Effectiveness and safety of induction of labor for term breech presentations. J Gynecol Obstet Hum Reprod. 2017 Jan;46(1):29-34. 
40. Macharey G, Ulander VM, Heinonen S, Kostev K, Nuutila M, Väisänen-Tommiska M. Induction of labor in breech presentations at term: a retrospective observational study. Arch Gynecol Obstet. 2016 Mar;293(3):549-55.

41. Hospital Clinic-Hospital Sant Joan de Dèu- Universitat de Barcelona. Defectos del crecimiento fetal. In: Hospital Clinic, ed. Protocolo de Medicina Maternofetal 2017.

42. SEGO. Muerte fetal anteparto. In: SEGO, ed. Guías de asistencia práctica en Medicina Perinatal 2008.

43. Magro-Malosso ER, Saccone G, Chen M, Navathe R, Di Tommaso M, Berghella V. Induction of labour for suspected macrosomia at term in non-diabetic women: a systematic review and meta-analysis of randomized controlled trials. BJOG. 2017 Feb;124(3):414-421.

44. Boulvain M, Irion O, Dowswell T, Thornton JG. Induction of labour at or near term for suspected fetal macrosomia. Cochrane Database Syst Rev. 2016 May 22;(5):CD000938.

45. Centre for Evidence-Based Medicine (CEBM) de Oxford. Disponible en: www.cebm.net/levels_of_evidence.asp

46. Lee VR, Darney BG1, Snowden JM, Main EK, Gilbert W, Chung J, Caughey AB. Term elective induction of labour and perinatal outcomes in obese women: retrospective cohort study. BJOG. 2016 Jan;123(2):271-8.

47. Wolfe H, Timofeev J, Tefera E, Desale S, Driggers RW. Risk of cesarean in obese nulliparous women with unfavorable cervix: elective induction vs expectant management at term. Am J Obstet Gynecol. 2014 Jul;211(1):53.e1-5.

48. ACOG. Patient Safety Checklist no. 5: scheduling induction of labor. Obstet Gynecol. 2011 Dec;118(6):1473-4.

49. Grobman W. Techniques for ripening the unfavorable cervix prior to induction. In: Lockwood CJ, Barss VA, editors. UpToDate. Waltham, UpToDate; 2019.

50. Bishop EH. PELVIC SCORING FOR ELECTIVE INDUCTION. Obstet Gynecol. 1964 Aug;24:266-8.

51. Roman H, Verspyck E, Vercoustre L, Degre S, Col JY, Firmin JM, et al. Does ultrasound examination when the cervix is unfavorable improve the prediction of failed labor induction? Ultrasound Obstet Gynecol. 2004 Apr;23(4):357-62.

52. Osmundson SS, Ou-Yang RJ, Grobman WA. Elective induction compared with expectant management in nulliparous women with a favorable cervix. Obstet Gynecol. 2010 Sep;116(3):601-5.

53. Boulvain M, Stan C, Irion O. Membrane sweeping for induction of labour. Cochrane Database Syst Rev. 2005 Jan 25;(1):CD000451.

54. Wing DA. Induction of labor. In: UpToDate, ed. 2016.

55. Cook $^{\circledR}$ Cervical Ripening Balloon. https://www.cookmedical.com/products/wh_crbs_webds/

56. Vaknin Z, Kurzweil Y, Sherman D. Foley catheter balloon vs locally applied prostaglandins for cervical ripening and labor induction: a systematic review and metaanalysis. Am J Obstet Gynecol. 2010 Nov;203(5):418-29.

57. Jozwiak M, Bloemenkamp KW, Kelly AJ, Mol BW, Irion O, Boulvain M. Mechanical methods for induction of labour. Cochrane Database Syst Rev. 2012 Mar 14;(3):CD001233.

58. Kavanagh J, Kelly AJ, Thomas J. Breast stimulation for cervical ripening and induction of labour. Cochrane Database Syst Rev. 2005 Jul 20;(3):CD003392.

59. Smith CA, Crowther CA. Acupuncture for induction of labour. Cochrane Database Syst Rev. 2004;(1):CD002962.

60. Smith CA. Homoeopathy for induction of labour. Cochrane Database Syst Rev. 2003;(4):CD003399. 
61. Análisis de situación de terapias naturales. Ministerio de Sanidad, Política Social e Igualdad. 19 de Diciembre de 2011.

http://www.msc.es/novedades/docs/analisisSituaciónTNatu.pdf

62. Kavanagh J, Kelly AJ, Thomas J. Sexual intercourse for cervical ripening and induction of labour. Cochrane Database Syst Rev. 2001;(2):CD003093.

63. Lydon-Rochelle M, Holt VL, Easterling TR, Martin DP. Risk of uterine rupture during labor among women with a prior cesarean delivery. N Engl J Med. 2001 Jul 5;345(1):38.

64. Manzanares S, Sánchez-Gila MM, Pineda A, Moh-García D, Durán MD, Moreno E. Resucitación fetal intrauterina. Clínica E Investig En Ginecol Obstet. 2013 Jan 1;40(1):20-5.

65. Thomas J, Fairclough A, Kavanagh J, Kelly AJ. Vaginal prostaglandin (PGE2 and PGF2a) for induction of labour at term. Cochrane Database Syst Rev. 2014 Jun 19;(6):CD003101.

66. Alfirevic Z, Aflaifel N, Weeks A. Oral misoprostol for induction of labour. Cochrane Database Syst Rev. 2014 Jun 13;(6):CD001338.

67. Keirse MJ. Prostaglandins in preinduction cervical ripening. Meta-analysis of worldwide clinical experience. J Reprod Med. 1993 Jan;38(1 Suppl):89-100.

68. Boulvain $M$, Kelly $A$, Irion $O$. Intracervical prostaglandins for induction of labour. Cochrane Database Syst Rev. 2008 Jan 23;(1):CD006971.

69. Neilson JP. Mifepristone for induction of labour. Cochrane Database Syst Rev. 2000;(4):CD002865.

70. Zhang $A$, Leng $W$, Zhang $X$, et al. Effect of mifepristone on ultrastructure of fetal kidney in second trimester of pregnancy. Journal of Jilin University. 2006;32(5):854-7.

71. Kavanagh J, Kelly AJ, Thomas J. Hyaluronidase for cervical ripening and induction of labour. Cochrane Database Syst Rev. 2006 Apr 19;(2):CD003097.

72. Howarth GR, Botha DJ. Amniotomy plus intravenous oxytocin for induction of labour. Cochrane Database Syst Rev. 2001;(3):CD003250.

73. Macones GA, Cahill A, Stamilio DM, Odibo AO. The efficacy of early amniotomy in nulliparous labor induction: a randomized controlled trial. Am J Obstet Gynecol. 2012 Nov;207(5):403.e1-5.

74. Grobman W. Induction of labor with oxytocin. In: Lockwood CJ, Barss VA, editors. UpToDate. Waltham, UpToDate; 2019.

75. Moen V, Brudin L, Rundgren M, Irestedt L. Hyponatremia complicating labour--rare or unrecognised? A prospective observational study. BJOG. 2009 Mar;116(4):552-61.

76. Landon MB, Hauth JC, Leveno KJ, et al. Maternal and perinatal outcomes associated with a trial of labor after prior cesarean delivery. N England J Med. 2004;351:2581-89.

77. Kramer MS, Rouleau J, Baskett TF, Joseph KS, Maternal Health Study Group of the Canadian Perinatal Surveillance System. Amniotic-fluid embolism and medical induction of labour: a retrospective, population-based cohort study. Lancet Lond Engl. 2006 Oct 21;368(9545):1444-8.

78. Rayburn WF. Prostaglandin E2 gel for cervical ripening and induction of labor: a critical analysis. Am J Obstet Gynecol. 1989 Mar;160(3):529-34.

79. Spong CY, Berghella V, Wenstrom KD, Mercer BM, Saade GR. Preventing the first cesarean delivery: summary of a joint Eunice Kennedy Shriver National Institute of Child Health and Human Development, Society... Obstet Gynecol. 2012 Nov;120(5):1181-93.

80. Crane JMG. Factors predicting labor induction success: a critical analysis. Clin Obstet Gynecol. septiembre de 2006;49(3):573-84.

81. Verhoeven CJM, Opmeer BC, Oei SG, Latour V, van der Post JA, Mol BWJ. Transvaginal sonographic assessment of cervical length and wedging for predicting outcome of 
labor induction at term: a systematic review and meta-analysis. Ultrasound Obstet Gynecol. 2013 Nov;42(5):500-8.

82. Bajpai N, Bhakta R, Kumar P, Rai L, Hebbar S. Manipal Cervical Scoring System by Transvaginal Ultrasound in Predicting Successful Labour Induction. J Clin Diagn Res. 2015 May;9(5):QC04-9.

83. Eggeb $\varnothing \mathrm{TM}, \varnothing$ kland I, Heien C, Gjessing LK, Romundstad P, Salvesen KA. Can ultrasound measurements replace digitally assessed elements of the Bishop score? Acta Obstet Gynecol Scand. 2009;88(3):325-31.

84. Calkins LA, Litzenberg JC, Plass ED. The length of labor. Am J Obstet Gynecol. 1931;22:604-14.

85. Cocks DP. Significance of initial condition of cervix uteri to subsequent course of labour. Br Med J. 1955 Feb 5;1(4909):327-8.

86. Fields H. Induction of labor. Readiness for induction. Am J Obstet Gynecol. 1966 Jun 1;95(3):426-9.

87. Kolkman DGE, Verhoeven CJM, Brinkhorst SJ, van der Post JA, Pajkrt E, Opmeer BC, Mol BW. The Bishop score as a predictor of labor induction success: a systematic review. Am J Perinatol. 2013 Sep;30(8):625-30.

88. Gibson KS, Waters TP. Measures of success: Prediction of successful labor induction. Semin Perinatol. 2015 Oct;39(6):475-82.

89. Burnett JE. Preinduction scoring: an objective approach to induction of labor. Obstet Gynecol. 1966 Oct;28(4):479-83.

90. Friedman EA, Niswander KR, Bayonet-Rivera NP, Sachtleben MR. Relation of prelabor evaluation to inducibility and the course of labor. Obstet Gynecol. 1966 Oct;28(4):495501.

91. Friedman EA, Niswander KR, Bayonet-Rivera NP, Sachtleben MR. Prelabor status evaluation. II. Weighted score. Obstet Gynecol. 1967 Apr;29(4):539-44.

92. Townshend B. Tissue viability. Clinical guidelines: a pilot study of pressure sore care. Nurs Stand. 1996 Jan 31;10(19):49-52.

93. Lange AP, Secher NJ, Westergaard JG, Skovgård I. Prelabor evaluation of inducibility. Obstet Gynecol. 1982 Aug;60(2):137-47.

94. Laughon SK, Zhang J, Troendle J, Sun L, Reddy UM. Using a simplified Bishop score to predict vaginal delivery. Obstet Gynecol. 2011 Apr;117(4):805-11.

95. Ivars J, Garabedian C, Devos P, Therby D, Carlier S, Deruelle P, et al. Simplified Bishop score including parity predicts successful induction of labor. Eur J Obstet Gynecol Reprod Biol. 2016 Aug;203:309-14.

96. Pitarello Pda R, Tadashi Yoshizaki C, Ruano R, Zugaib M. Prediction of successful labor induction using transvaginal sonographic cervical measurements. J Clin Ultrasound. 2013 Feb;41(2):76-83.

97. Hatfield AS, Sanchez-Ramos L, Kaunitz AM. Sonographic cervical assessment to predict the success of labor induction: a systematic review with metaanalysis. Am J Obstet Gynecol. 2007 Aug;197(2):186-92.

98. Keepanasseril A, Suri V, Bagga R, Aggarwal N. Pre-induction sonographic assessment of the cervix in the prediction of successful induction of labour in nulliparous women. Aust N Z J Obstet Gynaecol. 2007 Oct;47(5):389-93.

99. Sieroszewski $P$, Banach R. Comparison of the predictive value of digital examination (Bishop's score) and ultrasound evaluation for labor induction success. Ginekol Pol. 2010 Feb;81(2):105-10.

100. Valentin L, Bergelin I. Intra- and interobserver reproducibility of ultrasound measurements of cervical length and width in the second and third trimesters of pregnancy. Ultrasound Obstet Gynecol. 2002 Sep;20(3):256-62. 
101. Gómez Laencina AM, Sánchez FG, Gimenez JH, Martínez MS, Valverde Martínez JA, Vizcaíno VM. Comparison of ultrasonographic cervical length and the Bishop score in predicting successful labor induction. Acta Obstet Gynecol Scand. 2007;86(7):799-804.

102. Elghorori MR, Hassan I, Dartey W, Abdel-Aziz E, Bradley M. Comparison between subjective and objective assessments of the cervix before induction of labour. J Obstet Gynaecol. 2006 Aug;26(6):521-6.

103. Kehila M, Bougmiza I, Ben Hmid R, Abdelfatteh W, Mahjoub S, Channoufi MB. Bishop Score vs. ultrasound cervical length in the prediction of cervical ripening success and vaginal delivery in nulliparous women. Minerva Ginecol. 2015 Dec;67(6):499-505.

104. Kehila M, Abouda HS, Sahbi K, Cheour H, Chanoufi MB. Ultrasound cervical length measurement in prediction of labor induction outcome. J Neonatal Perinatal Med. 2016 May 17;9(2):127-31.

105. Prado CA, Araujo Júnior E, Duarte G, Quintana SM, Tonni G, Cavalli Rde C, Marcolin AC. Predicting success of labor induction in singleton term pregnancies by combining maternal and ultrasound variables. J Matern-Fetal Neonatal Med. 2016 Nov;29(21):3511-8.

106. Rane SM, Guirgis RR, Higgins B, Nicolaides KH. The value of ultrasound in the prediction of successful induction of labor. Ultrasound Obstet Gynecol. 2004 Oct;24(5):538-49.

107. Lewin D, Sadoul G, Beuret T. Measuring the height of a cephalic presentation: an objective assessment of station. Eur J Obstet Gynecol Reprod Biol. 1977;7(6):369-72.

108. Sherer DM. Intrapartum ultrasound. Ultrasound Obstet Gynecol. 2007 Aug;30(2):12339.

109. Eggeb $\varnothing$ TM, Gjessing LK, Heien C, Smedvig E, Økland I, Romundstad P, Salvesen KA. Prediction of labor and delivery by transperineal ultrasound in pregnancies with prelabor rupture of membranes at term. Ultrasound Obstet Gynecol. 2006 Apr;27(4):387-91.

110. Hafiz A. Fetal head-perineum distance measured by transperineal ultrasound imaging as a predictive factor for successful induction of labor. Evidence Based Women's Health Journal. 2014;4(2):105-107.

111. Garite TJ, Casal D, Garcia-Alonso A, Kreaden U, Jimenez G, Ayala JA, Reimbold T. Fetal fibronectin: a new tool for the prediction of successful induction of labor. Am J Obstet Gynecol. 1996 Dec;175(6):1516-21.

112. Tam WH, Tai SM, Rogers MS. Prediction of cervical response to prostaglandin E2 using fetal fibronectin. Acta Obstet Gynecol Scand. 1999 Nov;78(10):861-5.

113. Kurkinen-Räty $M$, Ruokonen $A$, Vuopala $S$, Koskela $M$, Rutanen $E M$, Kärkkäinen $T$, Jouppila P. Combination of cervical interleukin-6 and -8, phosphorylated insulin-like growth factor-binding protein-1 and transvaginal cervical ultrasonography in assessment of the risk of preterm birth. BJOG. 2001 Aug;108(8):875-81.

114. Nuutila M, Hiilesmaa V, Kärkkäinen T, Ylikorkala O, Rutanen EM. Phosphorylated isoforms of insulin-like growth factor binding protein-1 in the cervix as a predictor of cervical ripeness. Obstet Gynecol. 1999 Aug;94(2):243-9.

115. Vallikkannu N, Lam WK, Omar SZ, Tan PC. Insulin-like growth factor binding protein 1, Bishop score, and sonographic cervical length: tolerability and prediction of vaginal birth and vaginal birth within 24 hours following labour induction in nulliparous women. BJOG. $2017 \mathrm{Jul} ; 124(8): 1274-1283$.

116. Bueno B, San-Frutos L, Pérez-Medina T, Barbancho C, Troyano J, Bajo J. The labor induction: integrated clinical and sonographic variables that predict the outcome. J Perinatol. 2007 Jan;27(1):4-8.

117. Vrouenraets FP, Roumen FJ, Dehing CJ, van den Akker ES, Aarts MJ, Scheve EJ. Bishop score and risk of cesarean delivery after induction of labor in nulliparous women. Obstet Gynecol. 2005 Apr;105(4):690-7. 
118. Elghorori MR, Hassan I, Dartey W, Abdel-Aziz E. A way to lend objectivity to Bishop score. J Obstet Gynaecol. 2006 May;26(4):311-6.

119. Bartha JL, Romero-Carmona R, Martínez-Del-Fresno P, Comino-Delgado R. Bishop score and transvaginal ultrasound for preinduction cervical assessment: a randomized clinical trial. Ultrasound Obstet Gynecol. 2005 Feb;25(2):155-9.

120. Pandis GK, Papageorghiou AT, Ramanathan VG, Thompson MO, Nicolaides KH. Preinduction sonographic measurement of cervical length in the prediction of successful induction of labor. Ultrasound Obstet Gynecol. 2001 Dec;18(6):623-8.

121. Rane SM, Guirgis RR, Higgins B, Nicolaides KH. Models for the prediction of successful induction of labor based on pre-induction sonographic measurement of cervical length. J Matern-Fetal Neonatal. 2005 May;17(5):315-22.

122. Peregrine $E, O^{\prime} B$ rien $P$, Omar $R$, Jauniaux $E$. Clinical and ultrasound parameters to predict the risk of cesarean delivery after induction of labor. Obstet Gynecol. 2006 Feb;107(2 Pt 1):227-33.

123. Verhoeven CJ, Oudenaarden A, Hermus MA, Porath MM, Oei SG, Mol BW. Validation of models that predict Cesarean section after induction of labor. Ultrasound Obstet Gynecol. 2009 Sep;34(3):316-21.

124. Isono W, Nagamatsu T, Uemura Y, Fujii T, Hyodo H, Yamashita T, Kamei Y, Kozuma S, Taketani $Y$. Prediction model for the incidence of emergent cesarean section during induction of labor specialized in nulliparous low-risk women. J Obstet Gynaecol Res. 2011 Dec;37(12):1784-91.

125. Hiersch L, Borovich A, Gabbay-Benziv R, Maimon-Cohen M, Aviram A, Yogev Y, Ashwal E. Can we predict successful cervical ripening with prostaglandin E2 vaginal inserts? Arch Gynecol Obstet. 2017 Feb;295(2):343-9.

126. Alvarez-Colomo C, Gobernado-Tejedor JA. The validity of ultrasonography in predicting the outcomes of labour induction. Arch Gynecol Obstet. 2016 Feb;293(2):311-6.

127. Levine LD, Downes KL, Elovitz MA, Parry S, Sammel MD, Srinivas SK. Mechanical and Pharmacologic Methods of Labor Induction: A Randomized Controlled Trial. Obstet Gynecol. 2016;128(6):1357-64.

128. Levine LD, Downes KL, Parry S, Elovitz MA, Sammel MD, Srinivas SK. A validated calculator to estimate risk of cesarean after an induction of labor with an unfavorable cervix. Am J Obstet Gynecol. 2018 Feb;218(2):254.e1-254.e7.

129. Migliorelli F, Baños N, Angeles MA, Rueda C, Salazar L, Gratacós E, Palacio M. Clinical and Sonographic Model to Predict Cesarean Delivery after Induction of Labor at Term. Fetal Diagn Ther. 2018 Oct;1-9.

130. Meier K, Parrish J, D'Souza R. Prediction models for determining the success of labor induction: A systematic review. Acta Obstet Gynecol Scand. 2019 Sep;98(9):1100-1112.

131. Alavifard S, Meier K, D'Souza R. 2018 Oct;219(4):419-420. doi: 10.1016/j.ajog.2018.04.060. Epub 2018 May 9. Prediction calculator for induction of labor: no Holy Grail yet! Am J Obstet Gynecol. octubre de 2018;219(4):419-420.

132. Robson MS. Classification of caesarean sections. Fetal Matern Med Rev. 2001;12:2339.

133. Biometría fetal. In: Fleischer A, Manning F, Jeanty P, Romero R, eds. Ecografía en Obstetricia y Ginecología. Sexta Ed. Madrid: Marban 2002:139-56.

134. Hadlock FP, Harrist RB, Carpenter RJ, Deter RL, Park SK. Sonographic estimation of fetal weight. The value of femur length in addition to head and abdomen measurements. Radiology. 1984 Feb;150(2):535-40.

135. El parto. In: Cunningham M, MacDonald P, Gant N, Leveno K, eds. Williams Obstetricia. 20 ed. Buenos Aires: Panamericana 1998:241-93.

136. Tanir HM, Sener T, Yildiz Z. Digital and transvaginal ultrasound cervical assessment for prediction of successful labor induction. Int J Gynaecol Obstet. 2008 Jan;100(1):52-5. 
137. Tan PC, Vallikkannu N, Suguna S, Quek KF, Hassan J. Transvaginal sonographic measurement of cervical length vs. Bishop score in labor induction at term: tolerability and prediction of Cesarean delivery. Ultrasound Obstet Gynecol. 2007 May;29(5):56873.

138. Park KH, Hong J-S, Shin DM, Kang WS. Prediction of failed labor induction in parous women at term: role of previous obstetric history, digital examination and sonographic measurement of cervical length. J Obstet Gynaecol Res. 2009 Apr;35(2):301-6.

139. Gomes F, Ramalho C, Machado AP, Calado E, Cardoso F, Montenegro N. Transvaginal ultrasound assessment of the cervix and digital examination before labor induction. Acta Med Port. 2006 Apr;19(2):109-14.

140. Yanik A, Gülümser C, Tosun M. Ultrasonographic measurement of cervical length in predicting mode of delivery after oxytocin induction. Adv Ther. 2007 JulAug;24(4):748-56.

141. Rouse DJ, Owen J, Hauth JC. Criteria for failed labor induction: prospective evaluation of a standardized protocol. Obstet Gynecol. 2000 Nov;96(5 Pt 1):671-7.

142. Rouse DJ, Weiner SJ, Bloom SL, Varner MW, Spong CY, Ramin SM, et al. Failed labor induction: toward an objective diagnosis. Obstet Gynecol. 2011 Feb;117(2 Pt 1):26772.

143. Beckmann M. Predicting a failed induction. Aust N Z J Obstet Gynaecol. 2007 Oct;47(5):394-8.

144. Simon CE, Grobman WA. When has an induction failed? Obstet Gynecol. 2005 Apr;105(4):705-9. 
ANEXOS 


\section{ANEXOS}

\subsection{ANEXO 1. CHECKLIST ACOG}

The American College of
Obstetricians and Gynecologists

Women's Health Care Physicians

\section{Patient Safety Checklist}

Number 5 • December 2011

\section{SCHEDULING INDUCTION OF LABOR}

Date

Patient

Date of birth

MR \#

Physician or certified nurse-midwife

Last menstrual period

Gravidity/Parity

Estimated date of delivery Best estimated gestational age at delivery

Proposed induction date Proposed admission time

Gestational age of $390 / 7$ weeks or older confirmed by either of the following criteria (1):

- Ultrasound measurement at less than 20 weeks of gestation supports gestational age of 39 weeks or greater

Fetal heart tones have been documented as present for 30 weeks of gestation by

Doppler ultrasonography

Indication for induction: (choose one)

Medical complication or condition (1): Diagnosis:

Nonmedically indicated (1-3): Circumstances:

Patient counseled about risks, benefits, and alternatives to induction of labor (1)

• Consent form signed as required by institution

Bishop Score (see below) (1):

\begin{tabular}{c|c|c|c|c|c|}
\multicolumn{6}{c|}{ Bishop Scoring System } \\
\cline { 2 - 6 } \multicolumn{1}{c|}{ Score } & $\begin{array}{c}\text { Dilation } \\
(\mathbf{c m})\end{array}$ & $\begin{array}{c}\text { Position of } \\
\text { Cervix }\end{array}$ & $\begin{array}{c}\text { Effacement } \\
(\%)\end{array}$ & Station & $\begin{array}{c}\text { Cervical } \\
\text { Consistency }\end{array}$ \\
\hline 0 & Closed & Posterior & $0-30$ & -3 & Firm \\
\hline 1 & $1-2$ & Midposition & $40-50$ & -2 & Medium \\
\hline 2 & $3-4$ & Anterior & $60-70$ & $-1,0$ & Soft \\
\hline 3 & $5-6$ & - & 80 & $+1,+2$ & - \\
\hline
\end{tabular}

*Station reflects a -3 to +3 scale.

Modified from Bishop EH. Pelvic scoring for elective induction. Obstet Gynecol 1964;24:266-8.

- Pertinent prenatal laboratory test results (eg, group B streptococci or hematocrit) available $(4,5)$

- Special concerns (eg, allergies, medical problems, and special needs):

\section{To be completed by reviewer:}

Approved induction after $390 / 7$ weeks of gestation by aforementioned dating criteria

ב Approved induction before $390 / 7$ weeks of gestation (medical indication)

HARD STOP - gestational age, indication, consent, or other issues prevent initiating induction without further information or consultation with department chair 


\section{References}

1. Induction of Labor. ACOG Practice Bulletin No. 107. American College of Obstetricians and Gynecologists. Obstet Gynecol 2009;114:386-97.

2. Caughey AB, Sundaram V, Kaimal AJ, Cheng YW, Gienger A, Little SE, et al. Maternal and neonatal outcomes of elective induction of labor. Evidence Report/Technology Assessment No. 176. (Prepared by the Stanford University-UCSF Evidencebased Practice Center under contract No. 290-02-0017.) AHRQ Publication No. 09-E-5. Rockville (MD): Agency for Healthcare Research and Quality; 2009.

3. Clark SL, Frye DR, Meyers JA, Belfort MA, Dildy GA, Kofford S, et al. Reduction in elective delivery < 39 weeks of gestation: comparative effectiveness of 3 approaches to change and the impact on neonatal intensive care admission and stillbirth Am J Obstet Gynecol 2010;203:449.e1-449.e6.

4. American Academy of Pediatrics, American College of Obstetricians and Gynecologists. Antepartum care. In: Guidelines for perinatal care. 6th ed. Elk Grove Village (IL): AAP; Washington, DC: ACOG; 2007. p. 83-137.

5. American Academy of Pediatrics, American College of Obstetricians and Gynecologists. Perinatal infections. In: Guidelines for perinatal care. 6th ed. Elk Grove Village (IL): AAP; Washington, DC: ACOG; 2007. p. 303-48

Standardization of health care processes and reduced variation has been shown to improve outcomes and quality of care. The American College of Obstetricians and Gynecologists has developed a series of patient safety checklists to help facilitate the standardization process. This checklist reflects emerging clinical, scientific, and patient safety advances as of the date issued and is subject to change. The information should not be construed as dictating an exclusive course of treatment or procedure to be followed. Although the components of a particular checklist may be adapted to local resources, standardization of checklists within an institution is strongly encouraged.

\section{How to Use This Checklist}

The Patient Safety Checklist on Scheduling Induction of Labor should be completed by the health care provider and submitted to the respective hospital to schedule an induction of labor. The hospital should establish procedures to review the appropriateness of the scheduling based on the information contained in the checklist. A hard stop should be called if there are questions that arise that require further information or consultation with the department chair.

Copyright December 2011 by the American College of Obstetricians and Gynecologists, 409 12th Street, SW, PO Box 96920 , Washington, DC 20090-6920. All rights reserved. No part of this publication may be reproduced, stored in a retrieval system, posted on the Internet, or transmitted, in any form or by any means, electronic, mechanical, photocopying, recording, or otherwise, without prior written permission from the publisher. Requests for authorization to make photocopies should be directed to: Copyright Clearance Center, 222 Rosewood Drive, Danvers, MA 01923, (978) 750-8400.

Scheduling induction of labor. Patient Safety Checklist No. 5. American College of Obstetricians and Gynecologists. Obstet Gynecol 2011;118:1473-4. 


\subsection{ANEXO 2}

\section{DOCUMENTO DE CONSENTIMIENTO INFORMADO}

Por favor, lea atentamente este documento informativo en el cual le proponemos participar en un estudio sobre la inducción del parto.

\section{TITULO DEL ESTUDIO:}

Predicción del éxito de la inducción del parto mediante parámetros ecográficos

\section{OBJETIVO:}

El objetivo de este estudio en el que participarán aproximadamente 100 pacientes, es la valoración de un nuevo test predictor del éxito de la inducción del parto en nuestras gestantes.

\section{PARTICIPACION VOLUNTARIA.}

Su decisión de participar en el estudio es voluntaria y debe ser tomada libremente. Si decide aceptar, usted podrá retirar su consentimiento en cualquier momento del estudio. La decisión que tome no afectará a la relación con su médico, y seguirá recibiendo la mejor atención médica y tratamiento posible. Asimismo, su médico podrá retirarle del estudio en cualquier momento, si considera que ello es lo más apropiado para usted, o en caso de que no siga los procedimientos del estudio.

\section{PROCEDIMIENTOS A REALIZAR.}

Antes de iniciar el procedimiento de inducción del parto, será informada de la indicción del mismo, así como de las técnicas diagnosticas que se van a utilizar. Será sometida a una ecografía abdominal, una ecografía transperineal y otra ecografía vaginal, que no van a modificar ni la actitud ni el pronostico de la inducción del parto. Posteriormente se realizará una exploración ginecológica que no diferirá de la realizada a cualquier mujer que ingrese para atención del parto o para una inducción y que no desee participar en el estudio.

La participación en este estudio no modificará las decisiones clínicas a tomar, que será adoptadas según los criterios validados y ampliamente utilizados en la práctica clínica habitual en nuestro entrono, como son la selección del fármaco a utilizar para el inicio del parto, la analgesia o las técnicas de control fetal en las mujeres sometidas a inducción del parto.

\section{CONFIDENCIALIDAD.}

Los datos recogidos en el estudio se introducirán en una base de datos, para realizar el análisis estadístico. Su nombre no aparecerá en ningún documento del estudio, sólo se le asignará un número de paciente al inicio del mismo para garantizar la confidencialidad de la información. En ningún caso se le identificará en las publicaciones o comunicaciones en congresos que puedan realizarse con los resultados de este estudio. Al firmar este consentimiento, usted concede permiso al investigador principal para que pueda realizar su trabajo (tal como indica el artículo 15 del RD 561/1993), al personal de la Unidad de paritorio para controlar la calidad de los datos (realizar auditorías), y a las Autoridades Sanitarias en caso de inspección, para que tengan acceso a los documentos clínicos que identifican al paciente, así como al Consentimiento Informado firmado por usted. Todas las partes citadas guardarán la más estricta confidencialidad acerca de sus datos, de forma que no se violen sus derechos. 


\section{TITULO DEL ESTUDIO:}

Predicción del éxito de la inducción del parto mediante parámetros ecográficos

YO,

He leído esta hoja de información que se me ha entregado.

He podido hacer preguntas sobre el estudio.

He recibido suficiente información sobre el estudio.

He hablado con el doctor

Comprendo que mi participación es voluntaria.

Comprendo que puedo retirarme del estudio:

1. Cuando quiera.

2. Sin tener que dar explicaciones.

3. Sin que esto repercuta en mis cuidados médicos.

Presto libremente mi conformidad para participar en el estudio.

Firma del participante

Fecha:

. I ..........

Firma del investigador

Fecha:

.. / .......... 


\subsection{ANEXO 3}

HOJA DE RECOGIDA DE DATOS

ESTUDIO SOBRE LAS INDUCCIONES DEL PARTO EN NUESTRO SERVICIO. RELACION DEL INDICE DE BISHOP CON EL TIPO DE PARTO. BISHOP MODIFICADO POR ULTRASONIDOS.

\section{FILIACION:}

NOMBRE:

NUMERO DE HISTORIA.

EDAD.

AO: PARTO VAGINAL $\square$ CESAREA $\square$ INDICACION . INDUCIDO $\square$ INDICACION

PESO $\mathrm{kg}$.

TALLA m. IMC

ECOGRAFIA:

POSICION FETAL:

BIOMETRIA:

\begin{tabular}{|ll|l|}
\hline DBP: & $\mathrm{mm}$ & \\
\hline CA: & $\mathrm{mm}$ & \\
\hline LF: & $\mathrm{mm}$ & \\
\hline PFE: & $\mathrm{mm}$ & \\
\hline
\end{tabular}

DISTANCIA CABEZA-PERINE: $\mathrm{mm}$

LONGITUD CERVICAL:

$\mathrm{mm}$

ANGULO POSTERIOR:

ACUÑAMIENTO:

TIPO U:

o FUNNEL SI $\square \quad$ NO

DILATACIÓN ECOGRAFÍCA SI NO TEST DE BISHOP:

\begin{tabular}{|c|c|c|c|c|}
\hline & $\mathbf{0}$ & $\mathbf{1}$ & $\mathbf{2}$ & $\mathbf{3}$ \\
\hline Dilatación & 0 & $1-2$ & $3-4$ & $5-6$ \\
\hline Borramiento & $0-30 \%$ & $40-50 \%$ & $60-70 \%$ & $>80 \%$ \\
\hline Posición & Posterior & Media & Central & \\
\hline Consistencia & Dura & Media & Blanda & \\
\hline Presentación & SES & I & II & III \\
\hline
\end{tabular}

TOTAL: 
INDUCCIÓN:

FECHA:

HORA DE INICIO:

EG: SEMANAS

DIAS

INDICACION

RPM

GCP

OTRAS

METODO DE INDUCCION:

PG

DOSIS

RETIRADO

AMNIOREXIS $\square$

OXITOCINA

VALORACION SUBJETIVA DE LA PACIENTE (DE 0: NADA DE DOLOR A 10: DOLOR INSOPORTABLE):

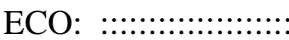

TACTO VAGINAL.

ANALGESIA:

$\begin{array}{lll}\text { FASE LATENTE: } & \text { SI } & \text { NO } \\ \text { FASE ACTIVA: } & \text { SI } & \text { NO }\end{array}$

\section{PARTO:}

INICIO DE FASE ACTIVA:

FECHA:

HORA:

ESTIMULACION: AMNIOREXIS:

OXITOCINA:

FECHA DEL PARTO:

HORA DEL PARTO:

VIA DEL PARTO:

VAGINAL

EUTOCICO $\square$ KIWI $\square \quad$ FORCEPS $\square$ ESPATULAS $\square$

CESAREA $\square$ INDICACION: RPBF:

FPP:

FI:

DPC:

OTRAS:

PESO RECIEN NACIDO:

OBSERVACIONES: 


\subsection{ANEXO 4}

\section{BASE DE DATOS (APLICACIÓN MICROSOFT OFFICE ACCESS)}

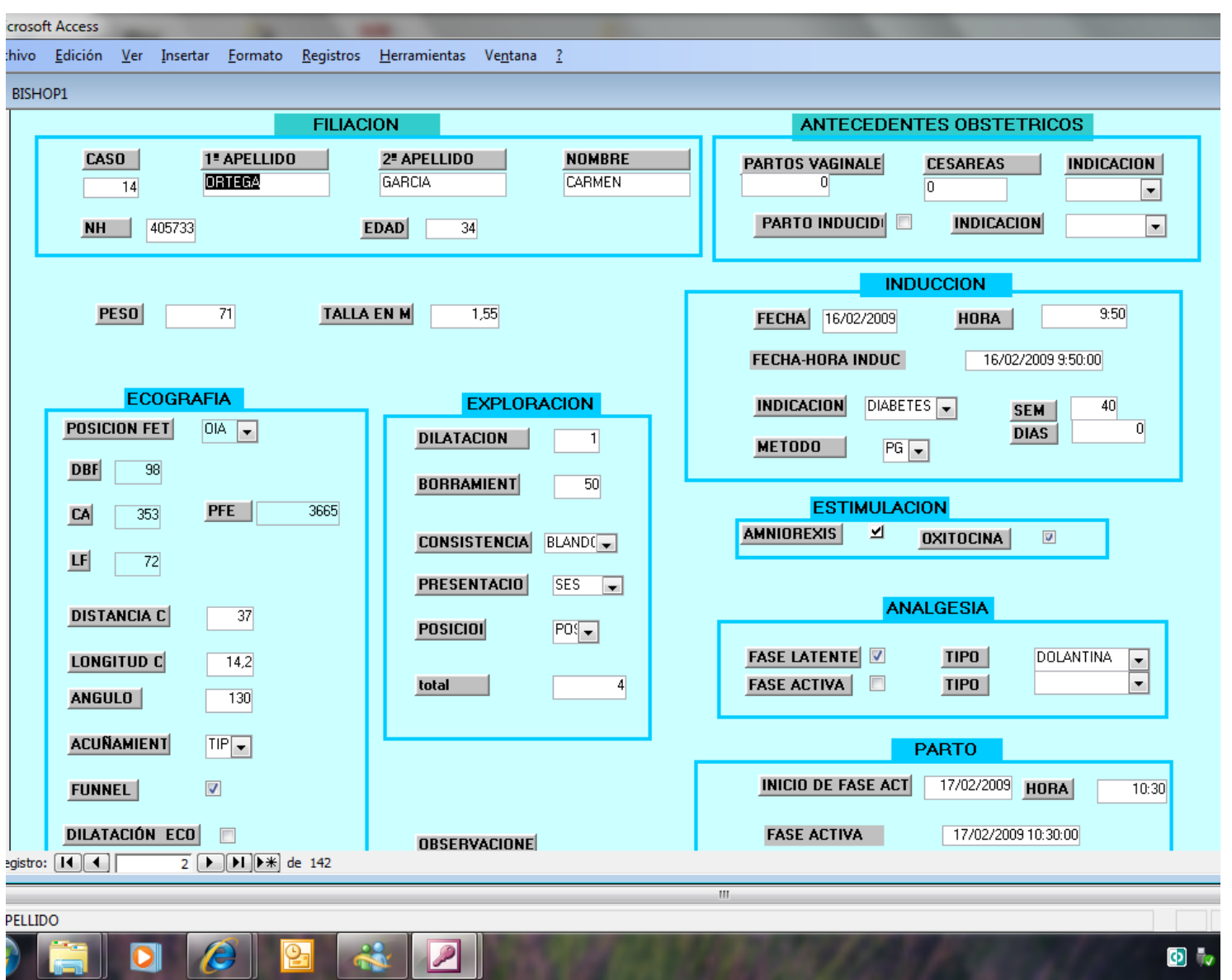




\subsection{ANEXO 5}

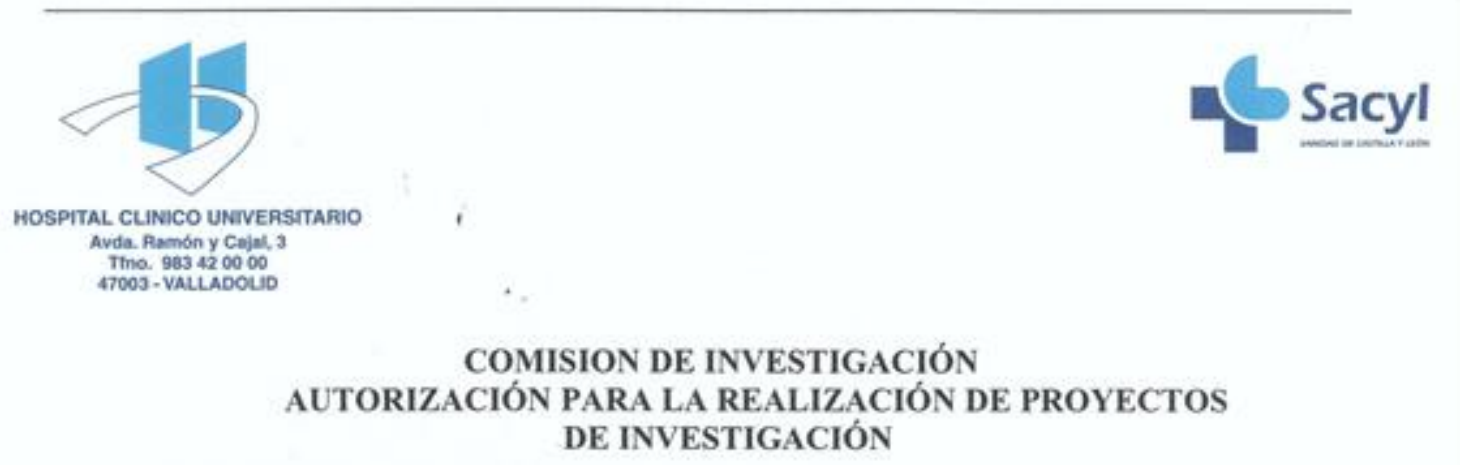

ANTONIO ORDUÑA DOMINGO, presidente de la Comisión de Investigación del Hospital Clinico Universitario de Valladolid, una vez revisado por la Comisión de Investigación el proyecto de investigación:

Titulo : "Predicción del éxito de la inducción del parto mediante parámetros ecográficos."

Investigador Principal: DRA CRISTINA ALVAREZ COLOMO

Equipo Investigador :

De. Julio Gobernado Tejedor.

Dr. Francisco J. Cortejoso Hernández.

Dra. Laura Barrero Real.

Dra. Henar Crespo Montaña.

Servicios implicados: OBSTETRICIA Y GINECOLOGIA.

Informa que la Comisión de Investigación ha decidido:

Autorizar la ejecución del proyecto en el Hospital Clinico Universitario de Valladolid

Observaciones: Ninguna

En Valladolid a 26 de FEBRERO de 2009

El Presidente de ja Cómisiónde Investigación

Fdo: Antonib Qretuña Domingo

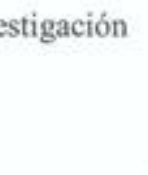




\title{
Ultrasound examination of the cervix for predicting labor induction success: failed validation in a routine clinical setting of a successful previous pilot study
}

\author{
S. De Miguel Manso ${ }^{1,2}$ (D) . C. Alvarez Colomo ${ }^{1,2} \cdot$ J. Gobernado Tejedor ${ }^{1,2} \cdot$ J. Schneider Fontan ${ }^{2} \cdot$ L. Barrero Real $^{1,2}$. \\ L. Martinez Ramos ${ }^{1}$
}

Received: 13 April 2019 / Accepted: 7 November 2019

(c) Springer-Verlag GmbH Germany, part of Springer Nature 2019

\begin{abstract}
Background Induction of labor (IL) involves an overload of work in hospitals, as well as increased intervention. Traditionally, the Bishop score (BS) has been used to predict the outcome of a IL, but there is a growing interest in studying the predictive capacity of ultrasound variables.

Objective Validate a pilot predictive model performed by a single observer (Alvarez-Colomo C), based on clinical parameters and ultrasound parameters, that showed a significant association with the IL result, obtaining a correct prediction of vaginal delivery in $82.8 \%$, with $15 \%$ false positive (FP). This validation was carried out under the usual conditions of clinical practice by four observers without distinction.

Methods A prospective, observational study was conducted between September 2010-July 2012, recruiting 231 single pregnancies (Group 2), who were to initiate the IL process, according to the methodology and inclusion criteria of the Alvarez-Colomo study (Group 1151 patients). The outcome variable was the method of delivery.

Results Only fetal head-perineal distance (FHPD), cervical length (CL) and BS showed significant association with the result of IL. After applying the logistic regression equation of the pilot study, the model developed by these four observers reached a predictive capacity of $70.74 \%(\mathrm{FP}=20 \%)$. Clinical characteristics were similar in both groups. Statistically significant differences were found between the two groups for: FHPD, posterior cervical angle (PCA) and funnel existence. Conclusion It has not been possible to validate the mathematical model of Alvarez's study in the daily conditions of clinical practice, probably due to differences in the ultrasound measurement of FHPD.
\end{abstract}

Keywords Validation pilot study $\cdot$ Bishop score $\cdot$ Cervical length $\cdot$ Fetal head-perineal distance $\cdot$ Prediction success induction of labor

\section{Introduction}

Induction of labor (IL) consists in the intended onset of labor through pharmacological or mechanical procedures prior to its spontaneous onset. It is one of the most frequent procedures in obstetrics; even in 2016, $24.5 \%$ of the births in the USA were induced [1]. IL involves an overload of work in hospitals, as well as an increased intervention rate in the

S. De Miguel Manso

soniademiguel@yahoo.com

1 Department of Obstetrics and Gynaecology, Universitary Clinic Hospital, Ramón y Cajal 3, 47003 Valladolid, Spain

2 University of Medicine, Valladolid, Spain form of operative deliveries, Cesarean sections and analgesic or anesthetic techniques. Traditionally, the Bishop score (BS) has been used to predict the outcome of an IL. However, the calculation of the BS is subjective, has a low predictive capacity $[2,3]$ and is fraught with discomfort for the patient [4]. Since the introduction of ultrasound examination as an aid in various obstetrical procedures, such as the evaluation of the progression of labor or the use of cervicometry for preventing preterm birth, several authors have studied a number of ultrasound variables for predicting IL success. Among them, the most promising ones have been cervical length (CL) [5-10], the posterior cervical angle (PCA) [5-8, 11], fetal head-perineal distance (FHPD) [5, 6, 12], dilatation [10], cervical wedge [7], the presence of a "funnel" image [8], the distance from the presentation edge to the 
external cervical os (EOC) $[9,10]$ and elasticity or cervical deformation (strain), obtained by a new Doppler-based tool called Doppler Imaging (TDI) [13]. These ultrasound parameters have compared favorably to the Bishop score in several studies and are less subjective than the latter, and an ultrasound examination, even a vaginal one, seems to be better tolerated by the patient than a classical vaginal examination [7-9, 14-16]. The objective of this study was to test under routine clinical conditions the validity of a previous pilot predictive model elaborated by a single observer of our team [17] which, based on clinical parameters (body mass index, maternal height, history of previous Cesarean section, previous vaginal delivery and $\mathrm{BS}$ ) and ultrasound parameters (CL and FHPD), resulted in a correct prediction of vaginal delivery in $82.8 \%$ of cases, with a $15 \%$ false-positive rate.

\section{Methods}

A prospective, observational study was conducted between September 2010 and July 2012, recruiting 231 singleton pregnancies (Group 2), who were to initiate the IL process, according to the methodology and inclusion criteria of our previous pilot study [18] (Group 1): Parturient above 18 years of age, informed consent (“Appendix 1") (approved by the Clinical Research Committee of the Center, "Appendix 2"), indication for IL, any parity, ruptured or intact membranes, reactive cardiotocographic pattern, no contraindication for vaginal delivery and no contraindication for drugs used in cervical maturation (according to our institutional protocol). Women with a history of previous Cesarean section were included into the study.

The evaluated clinical data were: maternal features (anthropometric and parity), BS, quantitative and qualitative ultrasound parameters at admission, indication of IL, method used for cervical maturation or IL and comfort assessment related to ultrasound and vaginal examination.

The CL (Fig. 1) or distance between the internal cervical os (ICO) and the external cervical os (ECO) was measured by means of transvaginal ultrasound, in a sagittal projection, following the same methodology used in preterm delivery [19], obtaining three measurements and considering the minimum value of all three.

The FHPD (Fig. 2) was measured as described by Eggebo et al. [6]: with the patient in lithotomy position and an empty bladder, by means of a transverse convex probe on the skin of the perineum, using firm pressure, without producing discomfort to the patient. Three measurements were obtained, and the arithmetic mean was used as the value of the variable. FHPD translates the degree of fit of the fetal cephalic presentation.

The PCA (Fig. 3) was measured by means of transvaginal ultrasound, obtaining an image similar to the CL by drawing

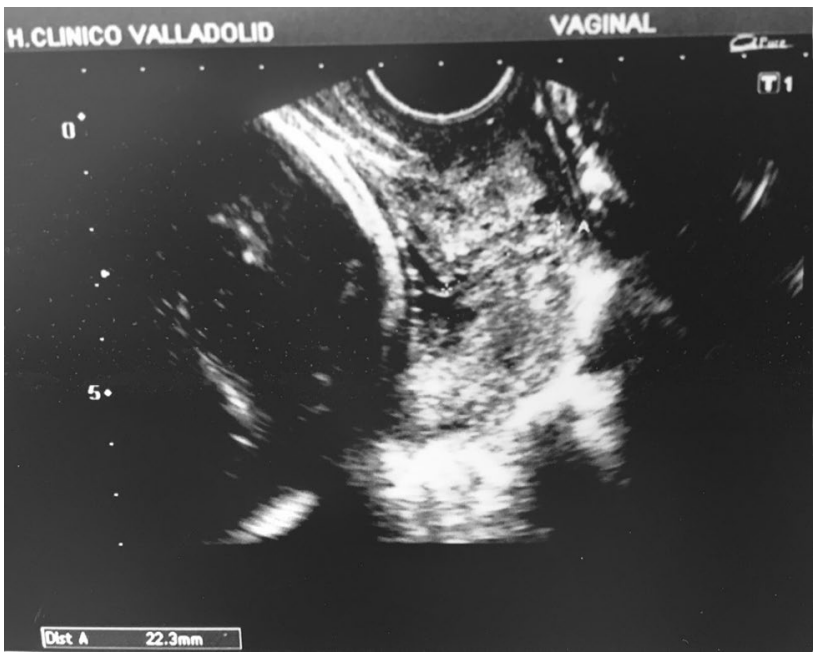

Fig. 1 Cervical length (CL): distance between the internal cervical os (ICO) and the external cervical os (ECO) in a sagittal projection of transvaginal ultrasound

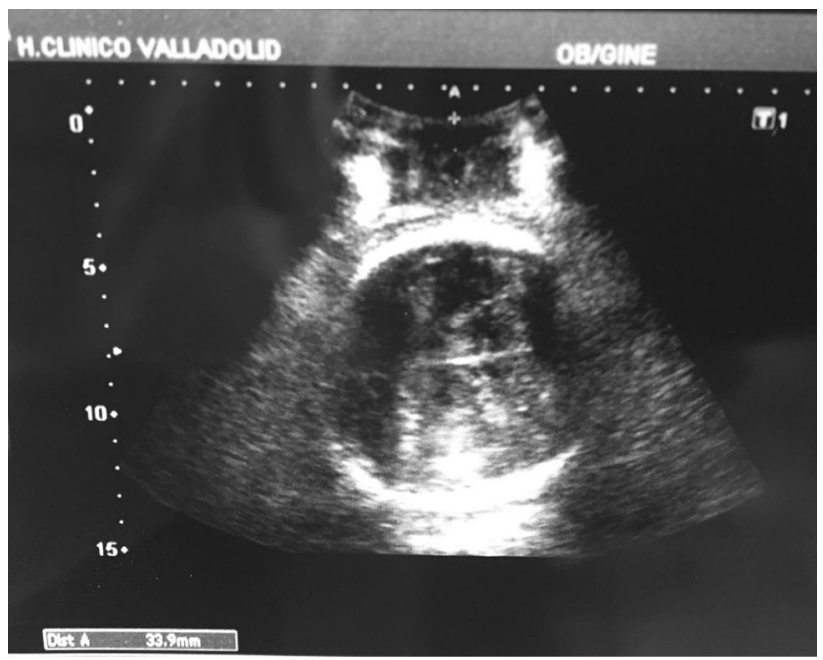

Fig. 2 Fetal head-perineal distance (FHPD): by means of a transverse convex probe on the skin of the perineum, using firm pressure, without producing discomfort to the patient. Three measurements were obtained using the media arithmetic of them

two lines that converged in the ICO, according to the methodology described by Rane et al. [20].

Transvaginal ultrasound also evaluates qualitative variables of the cervix: cervical wedge (OCI form, simulating the letter $T, U$, or $V$ ) [4] (Figs. 4, 5 and 6), cervical dilatation (thickness of the hypoechoic band that occupies the entire endocervical canal) [6] and funnel (incomplete dilatation of OCI with the apex toward the endocervical canal) [4].

Either one out of four experienced observers performed the ultrasound examinations, and the BS was calculated by a different obstetrician or midwife who did not know the ultrasound results. 


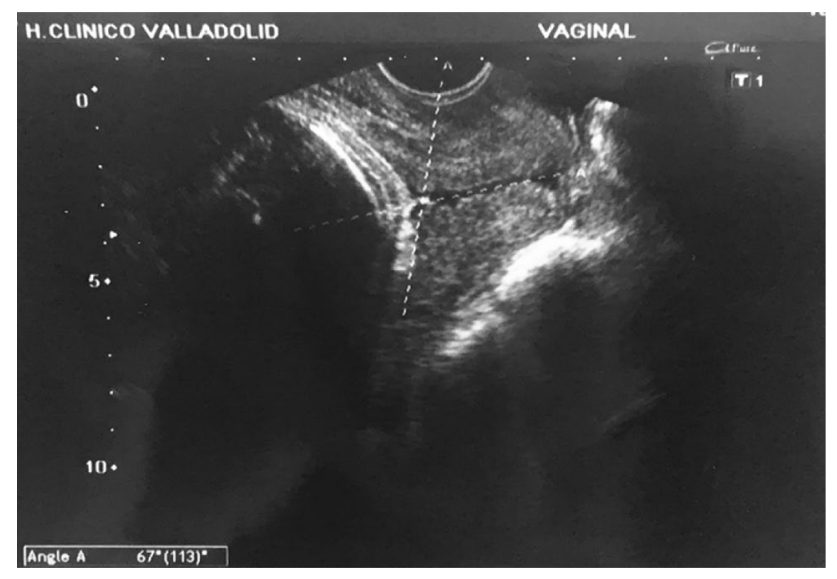

Fig. 3 Posterior cervical angle (PCA): in a sagittal projection similar to $\mathrm{CL}$, it draws two lines that converged into the ICO

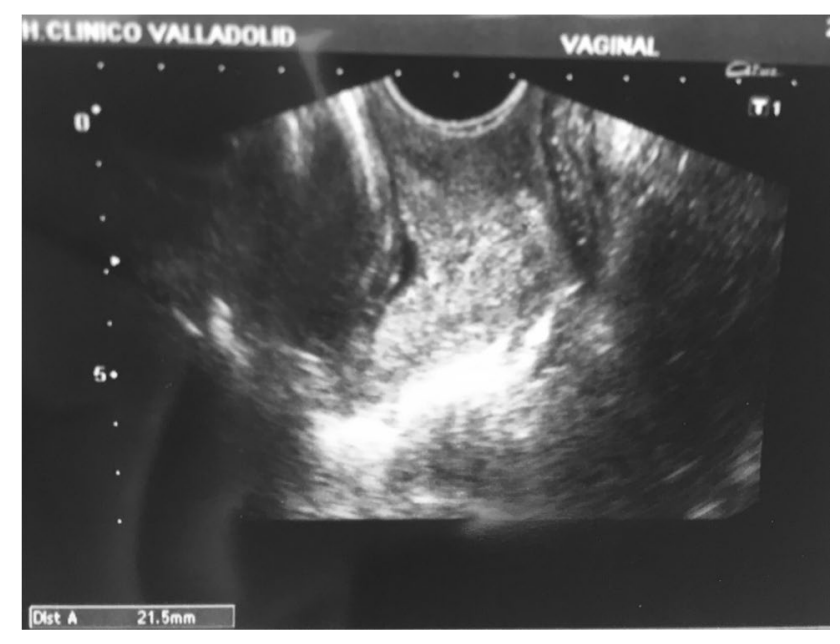

Fig. 4 Wedging pattern: OCI form, simulating the letter $T$

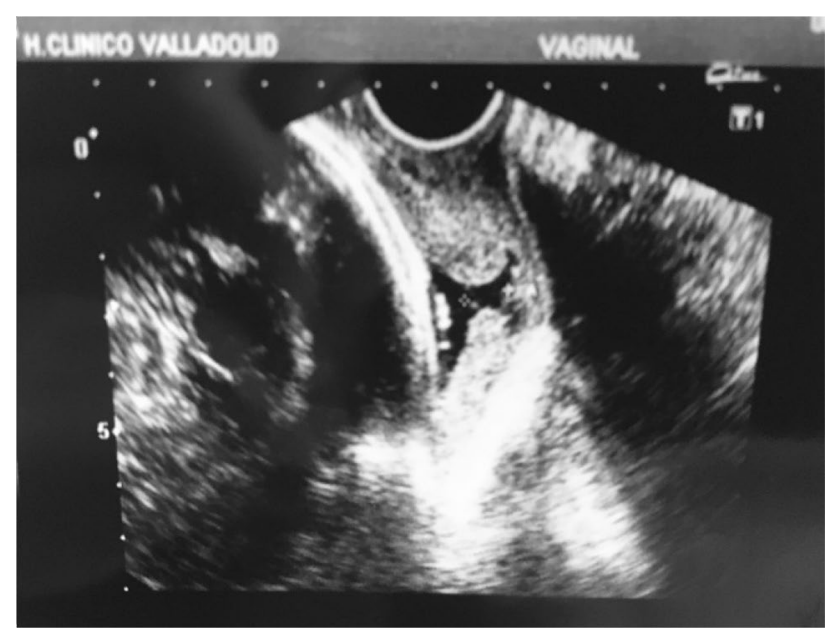

Fig. 5 Wedging pattern: OCI form, simulating the letter $U$

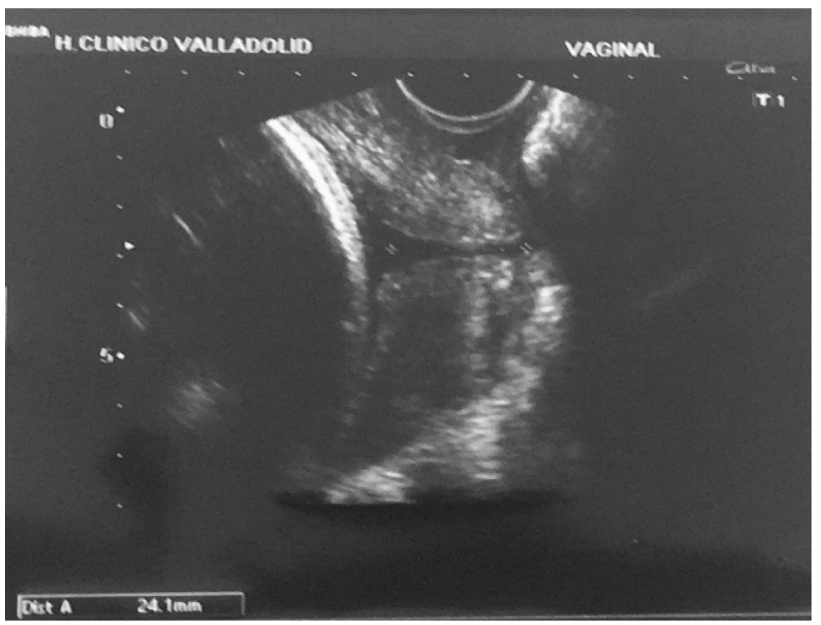

Fig. 6 Wedging pattern: OCI form, simulating the letter $V$

The maternal discomfort caused by both the ultrasound and pelvic examination was evaluated using an analog scale, where 0 is no discomfort and 9 is unbearable pain.

Cervical maturation was initiated with a controlled release device of dinoprostone (Propess ${ }^{\circledR}$, Ferring, Copenhagen) when the BS was equal to or lower than 7. If the BS was higher than 7 , induction was performed by amniotomy and oxytocin infusion as early as possible. If labor did not occur, the woman was reassessed after $24 \mathrm{~h}$, and repeated doses of dinoprostone were administered if necessary. If labor had not occurred after a second period of $24 \mathrm{~h}$, induction with oxytocin and amniotomy was indicated. If labor had not begun after $12 \mathrm{~h}$ of oxytocin infusion and amniotomy, a Cesarean section was indicated due to failure of induction.

The outcome variable was the method of delivery, independently of the time required or the indication for Cesarean section.

\section{Statistical analysis}

A descriptive statistical analysis was conducted by applying the Kolmogorov-Smirnov test to determine the normal distribution, expressing the data as mean values and standard deviations (SD) if the distribution was normal and as medians and interquartile ranges if it was not. Averages were compared by Student's $t$ test or the Mann-Whitney $U$ test and Fisher's exact test when the observed frequencies were less than 5 in $20 \%$ of the cells. The proportions were compared using the Chi-square test. Relative risk was calculated with confidence intervals of $95 \%$. $p$ values less than 0.05 were considered statistically significant. Statistical analysis was performed using IBM SPSS v23 licensed for University of Valladolid (Spain). 


\section{Results}

$231 \mathrm{IL}$ were analyzed (they account for $31.43 \%$ of all IL performed in the hospital during the study period). The median age was 33 years (IQR 30-36). The medians of anthropometric data were as follows: weight $74.2 \mathrm{~kg}$ (IQR 67-84), height $1.62 \mathrm{~m}$ (IQR 1.58-1.66) and BMI 27.97 (IQR 25.66-31.47). Regarding parity, 78.2\% were nulliparous and $15.2 \%$ had undergone a previous Cesarean section. The median gestational age (GA) was 280.5 days (IQR 271.25-289.25).

The most frequent indications for IL were: post-term pregnancy $24.7 \%$ and premature rupture of membranes (PROM) 20.8\%, followed by diabetes mellitus (DM) $16 \%$ and growth restriction (GR) $14.7 \%$.

The median values determined by ultrasound showed the following results: estimated fetal weight (EFW) 3139 grs (SD: 468.37), FHPD $49.03 \mathrm{~mm}$ (SD 9.30), CL $26.45 \mathrm{~mm}$ (SD 10.24), PCA $111.81^{\circ}$ (IQR 99-129). A funnel image was present in $8.2 \%$ of instances and ultrasound dilatation in $45.5 \%$. The most frequent form of cervical wedge was "T" (54.1\%), followed by "V" (31.6\%) and "U" (13.4\%). The Bishop score was lower than 6 in $86.15 \%$ of cases.

Regarding the method of cervical maturation, 176 women (75.9\%) needed only one dose of vaginal dinoprostone (Propess ${ }^{\circledR}$ ), whereas $21(9.1 \%)$ required a second dose $24 \mathrm{~h}$ following the previous one. In the rest of cases (34), oxytocin perfusion was used directly, and amniotomy was additionally performed, if necessary.

Regarding the mode of delivery, $30.3 \%$ of the IL ended in Cesarean section (all causes of Cesarean were included); almost one-third (24/71) were indicated due to risk of loss of fetal well-being. The overall Cesarean rate of the hospital during the study period was $23.4 \%$, whereas during that same period, the rate after IL amounted to $29.8 \%$. The median newborn weight (NW) was 3160 grs (IQR 2800-3540).

Ultrasound was better tolerated than pelvic examination, with a higher percentage of women who scored $0-1$ on the analog pain scale $(91.38 \%$ vs $37.07 \%)$ when examined by ultrasonography.

The relationship of the studied variables with the mode of delivery is presented in Table 1.

Low height and prior Cesarean increase the probability of Cesarean delivery, whereas having had a previous vaginal delivery increases the probability of a new vaginal delivery.

Only the ultrasound FHPD and CL parameters and the Bishop score showed a significant association with the result of IL. After applying the logistic regression parameter equation of the pilot study [18], the model reached a predictive capacity of $70.74 \%$ (Sensivity $78.3 \%$, Specificity $52.9 \%$,
Table 1 Relationship of variables with mode of delivery

\begin{tabular}{|c|c|c|c|}
\hline & $\begin{array}{l}\text { Vaginal } \\
N 159\end{array}$ & $\begin{array}{l}\text { C-section } \\
N 73\end{array}$ & $p$ \\
\hline Height $(\mathrm{m})$ mean & $1.63(\mathrm{SD} 0.60)$ & $1.61(\mathrm{SD} 0.64)$ & $0.028 *$ \\
\hline Bishop score mean & 3.62 (SD 1.76) & $2.96(\mathrm{SD} 1.74)$ & $0.009 *$ \\
\hline FHPD (mm) mean & 47.56 (SD 8.22) & 53.35 (SD 10.65) & $\mathbf{0 . 0 0 1}^{\times}$ \\
\hline $\mathrm{CL}(\mathrm{mm})$ mean & 25.18 (SD 9.79) & 29.07 (SD 10.78) & $0.010^{x}$ \\
\hline PCA $\left(^{\circ}\right)$ mean & $114.20($ SD 20.64) & $110.58(\mathrm{SD} 24.44)$ & $0.273^{*}$ \\
\hline \multicolumn{4}{|l|}{ Wedging pattern } \\
\hline$T$ & $86(68.3 \%)$ & $40(31.7 \%)$ & \multirow[t]{3}{*}{$0.904^{\dagger}$} \\
\hline$V$ & $50(67.6 \%)$ & $24(32.4 \%)$ & \\
\hline$U$ & $23(71.9 \%)$ & $9(28.1 \%)$ & \\
\hline \multicolumn{4}{|l|}{ Funnel } \\
\hline Yes & $12(60.0 \%)$ & $8(40 \%)$ & \multirow[t]{2}{*}{$0.390^{\dagger}$} \\
\hline No & $147(69.3 \%)$ & $65(30.7 \%)$ & \\
\hline \multicolumn{4}{|l|}{ Ultrasound dilatation } \\
\hline Yes & $72(67.9 \%)$ & $34(32.1 \%)$ & \multirow[t]{2}{*}{$0.854^{\dagger}$} \\
\hline No & $87(69.0 \%)$ & $39(31.0 \%)$ & \\
\hline \multicolumn{4}{|l|}{ Prior C-section } \\
\hline Yes & $18(51.4 \%)$ & $17(48.6 \%)$ & \multirow[t]{2}{*}{$\mathbf{0 . 0 1 8}^{\dagger}$} \\
\hline No & $141(71.6 \%)$ & $56(28.4 \%)$ & \\
\hline \multicolumn{4}{|l|}{ Prior vaginal delivery } \\
\hline Yes & $46(92.0 \%)$ & $4(8.0 \%)$ & \multirow[t]{2}{*}{$\mathbf{0 . 0 0 0}^{\ddagger}$} \\
\hline No & $113(62.1 \%)$ & $69(37.9 \%)$ & \\
\hline
\end{tabular}

$S D$ standard deviation, $F H P D$ fetal head-perineal distance, $C L$ cervical length, $P C A$ posterior cervical angle

*Mann-Whitney $U$ test

${ }^{x} t$ test

${ }^{\ddagger}$ Fisher test

†Pearson Chi-square

Table 2 Predictive model of validation study

\begin{tabular}{lclrl}
\hline & \multicolumn{2}{l}{ Observed } & Total & Success (\%) \\
\cline { 2 - 3 } & Vaginal & C-section & & \\
\hline Prediction & & & 158 & 63.29 \\
Vaginal & 126 & 32 & 71 & 50.70 \\
C-section & 35 & 36 & 229 & $\mathbf{7 0 . 7 4}$ \\
Total & 161 & 68 & & \\
\hline
\end{tabular}

positive predictive value $79.7 \%$, negative predictive value $50.7 \%$ ). It was able to predict better a vaginal delivery than a Cesarean section, with a $20 \%$ false-positive rate (Table 2). These results are worse than those published in the pilot study.

As can be seen from Table 3, the clinical features are similar in both study groups: Group 1 (previous pilot study): 151 women and a single observer [18], and Group 2 (present study): 231 women and four observers (Table 3). 
Table 3 Clinical characteristics

\begin{tabular}{llll}
\hline & Group 1 & Group 2 & $p$ \\
\hline Age, years mean (SD*) & $32.69(4.56)$ & $32.81(4.97)$ & $0.775^{\circ}$ \\
Weight, kg mean (SD) & $76.69(13.68)$ & $75.85(12.14)$ & $0.941^{\circ}$ \\
Height, m mean (SD) & $1.62(0.62)$ & $1.63(0.62)$ & $0.411^{\circ}$ \\
BMI, kg/m² mean (SD) & $29.15(4.61)$ & $28.72(4.29)$ & $0.346^{\circ}$ \\
Nulliparity & $75 \%$ & $78.2 \%$ & $0.535^{\dagger}$ \\
Prior C-section & $9.2 \%$ & $15.2 \%$ & $0.117^{\dagger}$ \\
Gestational age, days mean (SD) & $277.91(10.87)$ & $279.27(10.90)$ & $0.229^{\circ}$ \\
Bishop score interquartile range & Q1-Q3: 2-5 & $\mathrm{Q} 1-\mathrm{Q} 3: 2-5$ & $0.320^{\dagger}$ \\
$\leq 3$ & $52.3 \%$ & $56.28 \%$ & \\
$\leq 5$ & $82.8 \%$ & $86.15 \%$ & \\
C-section & $30.3 \%(46 / 152)$ & $30.3 \%(70 / 231)$ & $0.993^{\dagger}$ \\
Weight of newborn & $3160(2855-3500)$ & $3160(2800-3540)$ & $0.844^{\circ}$ \\
Grams mean (SD) & & & \\
\hline
\end{tabular}

* SD standard deviation

${ }^{\circ}$ Mann-Whitney $U$ test

${ }^{\dagger}$ Pearson Chi-square

However, there were significant differences between both groups when considering the ultrasound parameters evaluated. Statistically significant differences were found between the two groups for the variables: FHPD, PCA and funnel existence (Table 4).

No differences were found between both groups when analyzing the percentage of $\mathrm{C}$-section and the weight of the newborn (Table 3).

\section{Discussion}

We observed that both groups were comparable according to the clinical variables analyzed and especially for those appearing in the logistic regression model of the pilot study: body mass index, maternal size, antecedent of previous $\mathrm{C}$-section, previous vaginal delivery and $\mathrm{BS}$. These clinical variables were significant in relation to the outcome of IL in both groups.
The BS has been studied by many authors in order to predict the outcome of IL, with unsatisfactory results. Gabriel et al. [21] predicted the failure of IL in parturients with a BS lower than 5 with (Si 66\%, Sp 44\%, FP 21.7\%), Yanik et al. [22] determined a C-section probability of $80 \%$ for the combination of $\mathrm{BS} \leq 5$ and long CL, and Daskalakis et al. [23] related a BS $<5$ with a duration of birth longer than $12 \mathrm{~h}$. Kolkman et al., after a systematic review [3], concluded a low predictive capacity of BS for C-section after IL. Therefore, he did not recommend the use of BS to perform an IL. Ivars et al. [24] improved the predictive capacity of BS for vaginal delivery after IL by not assessing position and consistency and adding the parity of the woman. Finally, Elghorori et al. [17] found that cervical shortening was the best parameter of BS to predict vaginal delivery after IL, but ultrasound CL exceeds it.

For these reasons, ultrasound measurements are sought that independently, or associated with clinical parameters, obtain high predictive capacity in relation to the success

Table 4 Ultrasound values

\begin{tabular}{llll}
\hline & Group 1 & Group 2 & $p$ \\
\hline FHPD, mm mean (SD $\left.{ }^{2}\right)$ & $46.65(8.01)$ & $49.03(9.30)$ & $\mathbf{0 . 0 1 3}^{*}$ \\
PCA median (interquartile range Q1-Q3) & $110(91.25-124)$ & $113(99-129)$ & $\mathbf{0 . 0 4 8}^{*}$ \\
CL, mm mean (SD) & $27.61(10.21)$ & $26.45(10.24)$ & $0.276^{*}$ \\
Estimated fetal weight grams mean (SD) & $3091(464.44)$ & $3149(468.37)$ & $0.197^{*}$ \\
Funnel & $24.3 \%$ & $8.2 \%$ & $\mathbf{0 . 0 0 0}^{\dagger}$ \\
Ultrasound dilatation & $50 \%$ & $45.5 \%$ & $0.383^{\dagger}$ \\
\hline
\end{tabular}

$F H P D$ fetal head-perineal distance, $S D$ standard deviation, $P C A$ posterior cervical angle, $C L$ cervical length

*Mann-Whitney $U$ test

${ }^{\dagger}$ Pearson Chi-square 
or failure of IL. Several authors have developed their own mathematical models to predict the success of IL, some based on ultrasound and clinical variables such as Alvarez et al. [18] (prediction of vaginal delivery $82.3 \%$, through LC, FHPD, height, BMI, previous C-section and parity) and Pitarello et al. [11] (prediction of vaginal delivery $71.3 \%$ and vaginal delivery in $<24 \mathrm{~h} 73.6 \%$, by ultrasound cervical dilatation and ultrasound fetal station, previous parity and BS). Other authors, such as Hiersch et al. [25], predicted the success $(78.56 \%)$ or failure $(21.5 \%)$ of IL only by clinical variables (nulliparity, GA and digital cervical dilatation).

On the other hand, few predictive models have been validated internally or externally in an attempt to apply to the clinical practice.

In 2019, Meier et al. [26] review and compare clinical models that use accessible clinical and demographic factors (not sonographic or biochemical), which have been proposed and/or validated to predict the success of induction. They identified 16 studies and finally included 14 predictive models, between 1966 and 2018. Only a descriptive analysis could be carried out in view of the clinical and methodological heterogeneity between studies. Of these models, six were validated internally and three externally. In most, the performance of the model was measured with the area under the ROC curve, which varied between 0.68 and 0.79 in general, for the internal validation models was $0.67-0.77$ and for the externally validated was $0.61-0.73[27,28]$.

Levin et al. [27] create a prediction model of Cesarean section after IL $(n=364)$ that is validated externally with a large American cohort $(n=8466)$. They were significantly associated with C-section: Nulliparous, GA $\geq 40$ weeks, BMI, modified Bishop score and height. A normogram and a calculator were created and found to have a prediction of C-section of $73 \%$.

Alavifard et al. [28] perform an external validation of the Levine predictive model in a sample of 256 women with the same inclusion criteria as Levine, obtaining a modest predictive capacity (area under the ROC curve 0.61). Alavifard, unable to validate the Levine model in its population, concludes that a predictive model cannot be used as a isolated tool in the assessment of a labor induction.

In the present study, the only significant differences found between groups 1 and 2 were in the measurement of ultrasound parameters. Both PCA and the existence of funnel did not show influence on the outcome of induction in Group 1, whereas FHPD showed a high significance and OR.

The mid-point of the pelvic canal is the ischial spine, and this is located, according to the stages of descent of the fetal head of the World Health Organization, $5 \mathrm{~cm}$ from the perineum. Two prospective studies by Eggebo et al. in [6, 7] describe different cutoff points of the FHPD to predict the success of the IL, always below $5 \mathrm{~cm}$, since the fetal fit is established at the ischial spine level. Thus, in 2006 [6], they established a cutoff point of FHPD of $45 \mathrm{~mm}$ ( $\mathrm{Si} 83 \%$, FP 59\%, PPV 31\%, NPV 89\%). In their subsequent study in 2009 [7], FHPD $\leq 40 \mathrm{~mm}, \mathrm{CL} \leq 25 \mathrm{~mm}$ and PCA $>90^{\circ}$ were considered as cutoff points and they introduced the results of these ultrasound values and digital cervical dilatation assessment into a scoring model, predicting success or failure of IL in $71 \%$ of instances after the analysis of ROC curves. They concluded that the only significant element of BS in relation to the success of IL is dilatation, while cervical shortening, position and fit of BS could be replaced by previous ultrasound measurements.

Probably the discordance in FHPD is the cause of the lower predictive capacity of the model in group 2 of our study. The methodology, especially the degree of pressure of the ultrasound probe on the soft tissues of the perineum, determines the result of the measurement and therefore is subject to greater interobserver variability. In addition, transperineal measurements may be distorted if there is an abundance of gas in the rectum, which could be improved by raising the hip [29], if there is difficulty in locating the ICO or if there is an inadequate angulation of the convex probe, since the ultrasound must be directed perpendicular to the fetal skull, so that it is displayed as sharply as possible [30]. The measurement of the FHPD also depends on the experience of the examiners and the ultrasound device itself, depending on how different sizes of the convex probe are used and according to the calibration of the equipment [30]. In our study, the FHPD measure was acquired with a single ultrasound device and performed by four different observers, albeit with extensive ultrasound experience (at variance with the pilot study, in which a single observer performed all the measurements in all patients).

Possible interobserver variability of the ultrasound FHPD measurement is, admittedly, a limitation of our study. The variability or dispersion of the results is determined by repeatability and reproducibility, which indicate that some of the variation observed in the process is due to the measurement system used.

Repeatability is defined as the proximity of concordance between the results of successive measurements of the same variable under the same measurement conditions, which include: same procedure, same observer, same measuring instrument, same place and repetition in a short period of time.

Unfortunately, repeatability of FHPD measurement cannot be assessed for group 2 of our study, since a single observer measured FHPD in each patient.

\section{Conclusion}

After applying the mathematical model of our previous pilot study Alvarez et al. [18] by a second group of four observers, with a greater number of patients and without significant 
differences in their clinical features, the predictive capacity of vaginal delivery after IL of the initial study performed by a single observer was not reached. Therefore, it has not been possible to validate internally this model in the daily conditions of clinical practice, probably due to differences in the ultrasound measurement of FHPD.

Authors' contribution SMM contributed to protocol/project development, data collection or management, data analysis and manuscript writing/editing. CAC contributed to protocol/project development and data collection or management. JGT contributed to data analysis and manuscript writing/editing. JSF contributed to manuscript writing/editing. LBR contributed to data collection or management. LMR contributed to data collection or management.

\section{Compliance with ethical standards}

Conflict of interest The authors declare no conflicts of interest.

\section{Appendix 1: Documento de consentimiento informado}

Por favor, lea atentamente este documento informativo en el cual le proponemos participar en un estudio sobre la inducción del parto.

\section{Titulo del estudio}

Predicción del éxito de la inducción del parto mediante parámetros ecográficos.

\section{Objetivo}

El objetivo de este estudio en el que participarán aproximadamente 100 pacientes, es la valoración de un nuevo test predictor del éxito de la inducción del parto en nuestras gestantes.

\section{Participacion voluntaria}

Su decisión de participar en el estudio es voluntaria y debe ser tomada libremente. Si decide aceptar, usted podrá retirar su consentimiento en cualquier momento del estudio. La decisión que tome no afectará a la relación con su médico, y seguirá recibiendo la mejor atención médica y tratamiento posible. Asimismo, su médico podrá retirarle del estudio en cualquier momento, si considera que ello es lo más apropiado para usted, o en caso de que no siga los procedimientos del estudio.

\section{Procedimientos a realizar}

Antes de iniciar el procedimiento de inducción del parto, será informada de la indicción del mismo, así como de las técnicas diagnósticas que se van a utilizar. Será sometida a una ecografía abdominal, una ecografía transperineal y otra ecografía vaginal, que no van a modificar ni la actitud ni el pronóstico de la inducción del parto. Posteriormente se realizará una exploración ginecológica que no diferirá de la realizada a cualquier mujer que ingrese para atención del parto o para una inducción y que no desee participar en el estudio.

La participación en este estudio no modificará las decisiones clínicas a tomar, que será adoptadas según los criterios validados y ampliamente utilizados en la práctica clínica habitual en nuestro entorno, como son la selección del fármaco a utilizar para el inicio del parto, la analgesia o las técnicas de control fetal en las mujeres sometidas a inducción del parto.

\section{Confidencialidad}

Los datos recogidos en el estudio se introducirán en una base de datos, para realizar el análisis estadístico. Su nombre no aparecerá en ningún documento del estudio, sólo se le asignará un número de paciente al inicio del mismo para garantizar la confidencialidad de la información. En ningún caso se le identificará en las publicaciones o comunicaciones en congresos que puedan realizarse con los resultados de este estudio. Al firmar este consentimiento, usted concede permiso al investigador principal para que pueda realizar su trabajo (tal como indica el artículo 15 del RD 561/1993), al personal de la Unidad de paritorio para controlar la calidad de los datos (realizar auditorías), y a las Autoridades Sanitarias en caso de inspección, para que tengan acceso a los documentos clínicos que identifican al paciente, así como al Consentimiento Informado firmado por usted. Todas las partes citadas guardarán la más estricta confidencialidad acerca de sus datos, de forma que no se violen sus derechos.

\section{Titulo del estudio}

Predicción del éxito de la inducción del parto mediante parámetros ecográficos. 


\section{DOCUMENTO DE CONSENTIMIENTO INFORMADO}

$\mathrm{YO}$,

He leído esta hoja de información que se me ha entregado.

He podido hacer preguntas sobre el estudio.

He recibido suficiente información sobre el estudio.

He hablado con el doctor.

Comprendo que mi participación es voluntaria.

Comprendo que puedo retirarme del estudio:

1. Cuando quiera.

2. Sin tener que dar explicaciones.

3. Sin que esto repercuta en mis cuidados médicos.

Presto libremente mi conformidad para participar en el estudio.

Firma del participante

Fecha:

/ $\ldots \ldots . . . .$.

Firma del investigador

Fecha:

/ $\ldots . . . . .$. 


\section{Appendix 2}

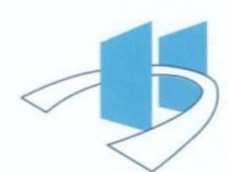

HOSPITAL CLINICO UNIVERSITARIO

Avda. Ramón y Cajal, 3

47003-VALLADOLID

\section{COMISION DE INVESTIGACIÓN \\ AUTORIZACIÓN PARA LA REALIZACIÓN DE PROYECTOS DE INVESTIGACIÓN}

ANTONIO ORDUÑa DOMINGO, presidente de la Comisión de Investigación del

Hospital Clínico Universitario de Valladolid, una vez revisado por la Comisión de Investigación el proyecto de investigación:

Titulo : "Predicción del éxito de la inducción del parto mediante parámetros ecográficos."

Investigador Principal: DRA CRISTINA ALVAREZ COLOMO

Equipo Investigador :

De. Julio Gobernado Tejedor.

Dr. Francisco J. Cortejoso Hernández.

Dra. Laura Barrero Real.

Dra. Henar Crespo Montaña.

Servicios implicados: OBSTETRICIA Y GINECOLOGIA.

Informa que la Comisión de Investigación ha decidido:

Autorizar la ejecución del proyecto en el Hospital Clinico Universitario de Valladolid

Observaciones: Ninguna

En Valladolid a 26 de FEBRERO de 2009

El Presidente de la Cómisiónde Investigación

Fdo: Antonio Qpduña Domingo

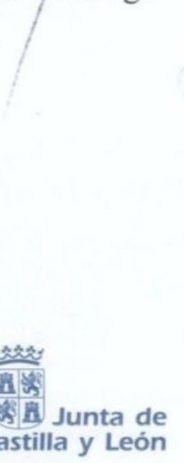




\section{References}

1. Martin JA, Hamilton BE, Osterman MJK, Driscoll AK, Drake P (2018) Births: final data for 2016. Natl Vital Stat Rep 67(1):1-55

2. National Collaborating Centre for Women'sand Children's Health (2008) Induction of labour. National Institute for Health and Clinical Excellence, London

3. Kolkman DG, Verhoeven CJ, Brinkhorst SJ, van der Post JA, Pajkrt E, Opmeer BC, Mol BW (2013) The Bishop score as a predictor of labor induction success: a systematic review. Am J Perinatol 30(8):625-630

4. Roman H, Verspyck E, Vercoustre L, Degre S, Col JY, Firmin JM, Caron P, Marpeau L (2004) Does ultrasound examination when the cervix is unfavorable improve the prediction of failed labor induction? Ultrasound Obstet Gynecol 23(4):357-362

5. Paterson-Brown S, Fisk NM, Edmonds DK, Rodeck CH (1991) Preinduction cervical assessment by Bishop's score and transvaginal ultrasound. Eur J Obstet Gynecol Reprod Biol 40(1):17-23

6. Eggebo TM, Gjessing LK, Heien C, Swedvig E, Okland I, Romundstad P et al (2006) Prediction of labor and delivery by transperineal ultrasound in pregnancies with prelabor rupture of membranes at term. Ultrasound Obstet Gynecol 27(4):387-391

7. Eggebo TM, Okland I, Heien C, Gjessing LK, Romunstand P, Salvesen KA (2009) Can ultrasound measurements replace digitally assessed elements of the Bishop score? Acta Obstet Gynecol Scand 88(3):325-331

8. Sieroszewski P, Banach R (2010) Comparison of the predictive value of digital examination (Bishop's score) and ultrasound evaluation for labor induction success. Ginekol Pol 81(2):105-110

9. Keepanasseril A, Suri V, Baga R, Aggarwal N (2007) Pre-induction sonographic assessment of the cervix in the prediction of successful induction of labour in nulliparous women. Aust N Z J Obstet Gynaecol 47(5):389-393

10. Bajpai N, Bhakta R, Kumar P, Rai L, Hebbar S (2015) Manipal cervical scoring system by transvaginal ultrasound in predicting successful labour induction. J Clin Diagn Res 9(5):QC04-9

11. Pitarello Pda R, Tadashi Yoshizaki C, Ruano R, Zugaib M (2013) Prediction of successful labor induction using transvaginal sonographic cervical measurements. J Clin Ultrasound 41(2):76-83

12. Prado CA, Araujo Junior E, Duarte G, Quintana SM, Tonni G, Cavalli Rde C, Marcolin AC (2016) Predicting success of labor induction in singleton term pregnancies by combining maternal and ultrasound variables. J Matern Fetal Neonatal Med 29(21):3511-3518

13. Fruscalzo A, Londero AP, Fröhlich C, Meyer-Wittkopf M, Schmitz R (2015) Quantitative elastography of the cervix for predicting labor induction success. Ultraschall Med 36(1):65-73

14. Torkildsen EA, Salvesen KA, Eggebo TM (2011) Prediction of delivery mode with transperineal ultrasound in women with prolonged first stage of labor. Ultrasound Obstet Gynecol 37(6):702-708

15. Kehila M, Bougmiza I, Ben Hmid R, Abdelfatteh W, Mahjoub S, Channoufi MB (2015) Bishop score vs. ultrasound cervical length in the prediction of cervical ripening success and vaginal delivery in nulliparous women. Minerva Ginecol 67(6):499-505

16. Gomez Laencina AM, Sanchez FG, Gimenez JH, Martinez MS, Valverde Martinez JA, Vizcaino VM (2007) Comparison of ultrasonographic cervical length and the Bishop score in predicting successful labor induction. Acta Obstet Gynecol Scand 86(7):799-804

17. Elghorori MRM, Hassan I, Dartey W, Abdel-Aziz E, Bradley M (2006) Comparison between subjective and objective assessments of the cervix before induction of labour. J Obstet Gynaecol 26(6):521-526

18. Álvarez-Colomo C, Gobernado-Tejedor JA (2016) The validity of ultrasonography in predicting the outcomes of labour induction. Arch Gynecol Obstet 293(2):311-316

19. Valentin L, Bergelin I (2002) Intra- and interobserver reproducibility of ultrasound measurements of cervical length and width in the second and third trimesters of pregnancy. Ultrasound Obstet Gynecol 20(3):256-262

20. Rane SM, Guirgis RR, Higgins B, Nicolaides KH (2004) The value of ultrasound in the prediction of successful induction of labor. Ultrasound Obstet Gynecol 24(5):538-549

21. Gabriel R, Darnaud T, Chalot F, Gonzalez N, Leymarie F, Quereux C (2002) Transvaginal sonography of the uterine cervix prior to labor induction. Ultrasound Obstet Gynecol 19(3):254-257

22. Yanik A, Gülümser C, Tosun M (2007) Ultrasonographic measurement of cervical length in predicting mode of delivery after oxytocin induction. Adv Ther 24(4):748-756

23. Daskalakis G, Thomakos N, Hatziioannou L, Mesogitis S, Papantoniou N, Antsaklis A (2006) Sonographic cervical length measurement before labor induction in term nulliparous. Fetal Diagn Ther 21(1):34-38

24. Ivars J, Garabedian C, Devos P, Therby D, Carlier S, Deruelle P, Subtil D (2016) Simplified Bishop score including parity predicts successful induction of labor. Eur J Obstet Gynecol Reprod Biol 203:309-314

25. Hiersch L, Borovich A, Gabbay-Benziv R, Maimon-Cohen M, Aviram A, Yogev Y, Ashwal E (2017) Can we predict successful cervical ripening with prostaglandin E2 vaginal inserts? Arch Gynecol Obstet 295(2):343-349

26. Meier K, Parrish J, D'Souza R (2019) Prediction models for determining the success of labor induction: a systematic review. Acta Obstet Gynecol Scand 22:1-13

27. Levine LD, Downes KL, Parry S, Elovitz MA, Sammel MD, Srinivas SK (2018) A validated calculator to estimate risk of cesarean after an induction of labor with an unfavorable cervix. Am J Obstet Gynecol 218(2):254.e1-254.e7

28. Alavifard S, Meier K, D'Souza R (2018) Prediction calculator for induction of labor: no Holy Grail yet! Am J Obstet Gynecol 219(4):419-420

29. Hertzberg BS, Kliewer MA, Baumeiser LA, McNally PB, Fazekas CK (1994) Optimizing transperineal sonographic imaging of the cervix: the hip elevation technique. J Ultrasound Med 13(12):933-936

30. Benediktsdottir S, Salvesen KÅ, Hjartardottir H, Eggeb $\varnothing$ TM (2018) Reproducibility and acceptability of ultrasound measurements of head-perineum distance. Acta Obstet Gynecol Scand 97(1):97-103

Publisher's Note Springer Nature remains neutral with regard to jurisdictional claims in published maps and institutional affiliations. 